\title{
Safety Analysis Report-Building 3544 Process Waste Treatment Plant
}

\author{
R. J. Braatz \\ R. A. Robinson
}

LNITE

-MASTER

PORTIONS QF THIS REPORT ARE ILIEGIBLE. It has been reproduced from the best available copy to permit the broadest possible ava11ability.

\section{OAK RIDGE NATIONAL LABORATORY}

OPERATED BY UNION CARBIDE CORPORATION FOR THE ENERGY RESEARCH AND DFYFIOPMFNI AIMINISTRATION 


\section{DISCLAIMER}

This report was prepared as an account of work sponsored by an agency of the United States Government. Neither the United States Government nor any agency Thereof, nor any of their employees, makes any warranty, express or implied, or assumes any legal liability or responsibility for the accuracy, completeness, or usefulness of any information, apparatus, product, or process disclosed, or represents that its use would not infringe privately owned rights. Reference herein to any specific commercial product, process, or service by trade name, trademark, manufacturer, or otherwise does not necessarily constitute or imply its endorsement, recommendation, or favoring by the United States Government or any agency thereof. The views and opinions of authors expressed herein do not necessarily state or reflect those of the United States Government or any agency thereof. 


\section{DISCLAIMER}

Portions of this document may be illegible in electronic image products. Images are produced from the best available original document. 
Printed in the United States of America. Available from

Natıonal Technlcal InIunıatiun Servicc

U.S. Department of Commerce

5285 Port Royal Road, Springfield, Virginia 22161

Price: Printed Copy \$5.00; Microfiche \$2.25

This report was prepared as an account of work sponsored by the United States Government. Neither the United States nor the Energy Research and Development Administration/United States Nuclear Regulatory Commission, nor any of their employees, nor any of their contractors, subcontractors, or their employees, makes any warranty, express or implied, or assumes any legal liability or responsibility for the accuracy, completeness or usefulness of any information, apparatus, product or process disclosed, or represents that its use would not infringe privately owned rights. 
Contract No. W-7405-eng-26

OPERATIONS DIVISION

\section{SAFETY ANALYSIS REPORT - BUILDING 3544}

PROCESS WASTE TREATMENT PLANT

R. J. Braatz and R. A. Robinson

\section{JUNE 1976}

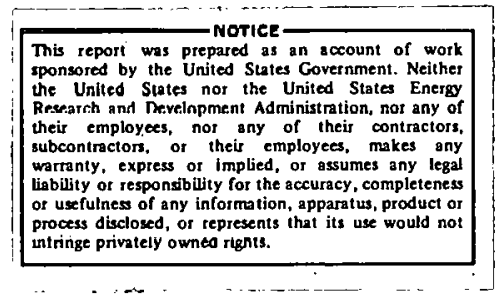

OAK RIDGE NATIONAL LABORATORY

Oak RIdge, Tennessee 37830

operated by

UNION CARBIDE CORPORATION

for the

ENERGY RESEARCH AND DEVELOPMENT ADMINISTRATION 
THIS PAGE

WAS INTENTIONALLY

LEFT BLANK 


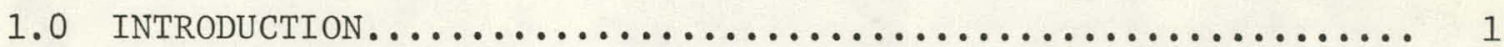

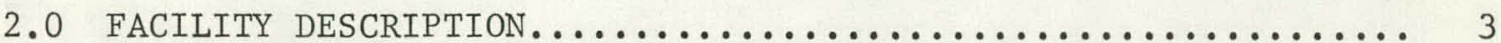

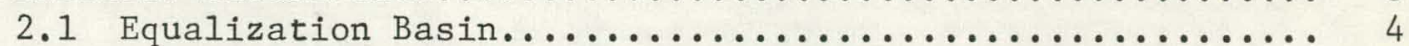

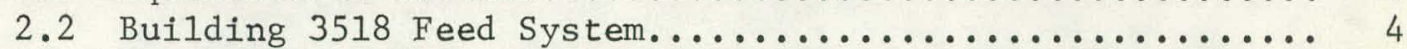

2.3 Building 3544 - Process Equipment Building........... 4

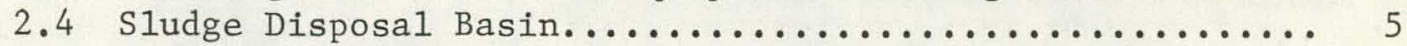

2.5 Radioactive Waste Transf er Piping................ 5

3.0 PROCESS DESCRIPTION.............................. 6

4.0 MAJOR PROCESS EQUIPMENT............................ 8

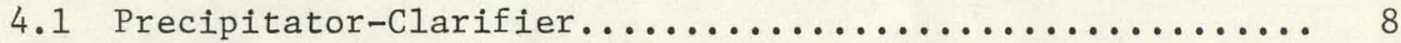

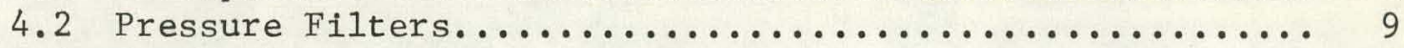

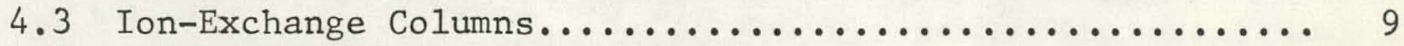

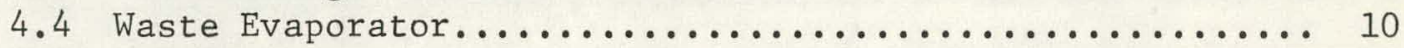

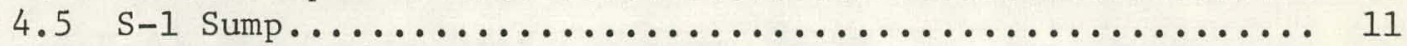

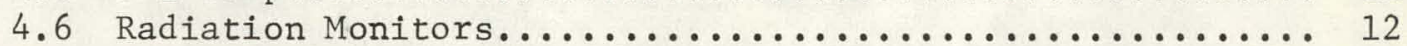

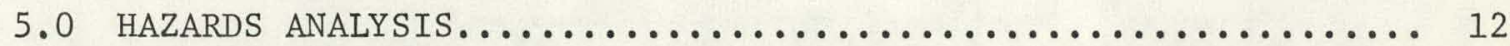

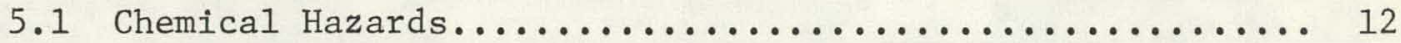

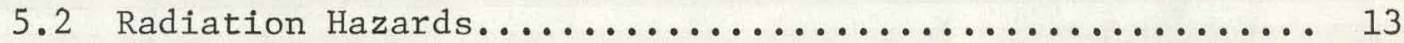

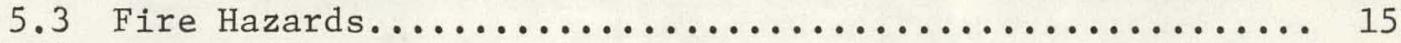

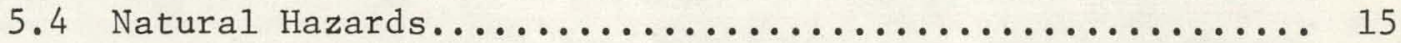

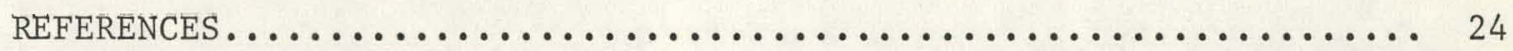

APPENDIX - Operating Procedures for Process Waste Treatment Plant 


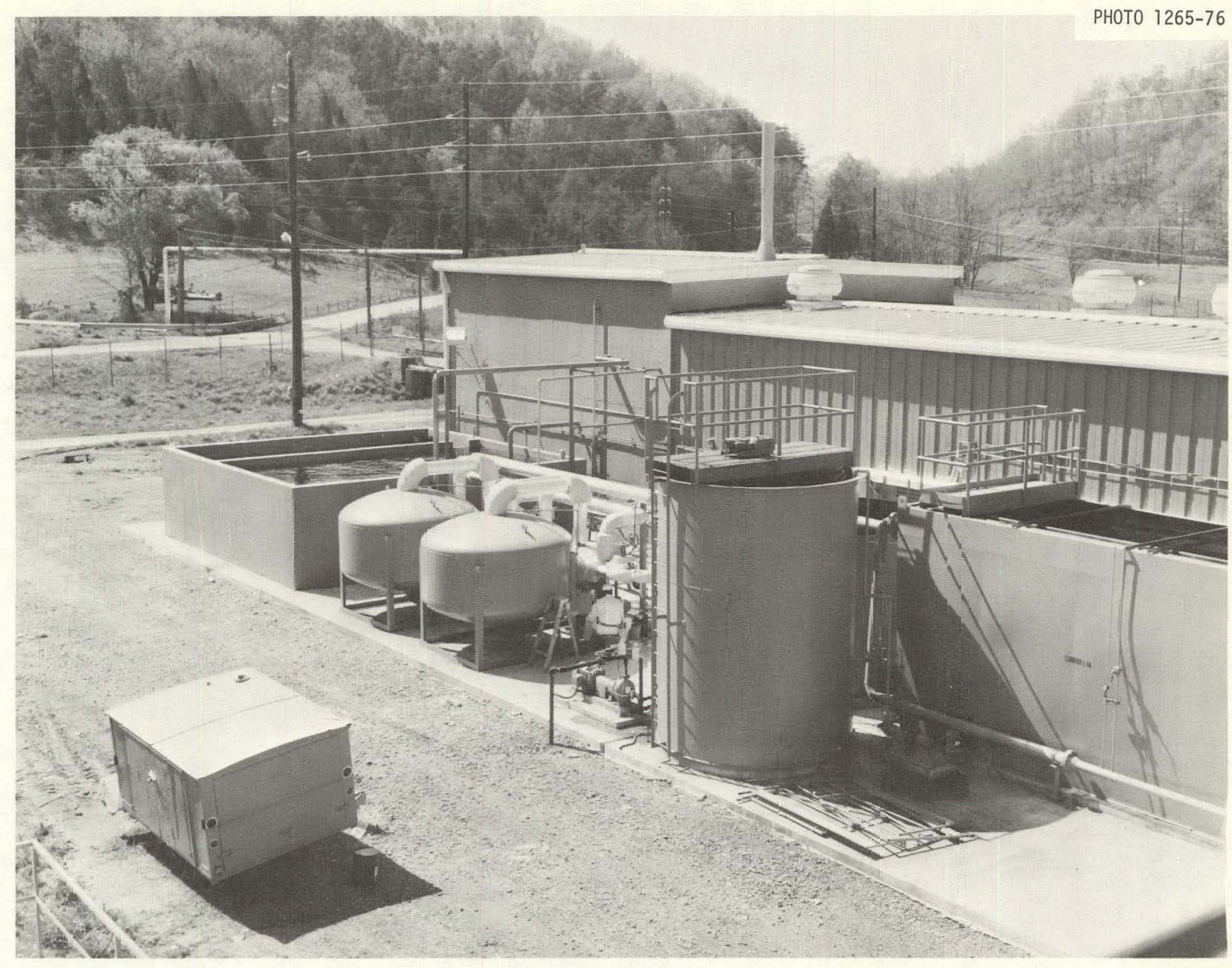

PWTP BUILDING \& EQUIPNENT FAD 
SAFETY ANALYSIS REPORT - BUILDING 3544

PROCESS WASTE TREATMENT PLANT

R. J. Braatz and R. A. Robinson

ABSTRACT

A new Process Waste Treatment Plant has been constructed at ORNL. The wastes are processed through a precipitation-clarification step and then through an ion exchange step to remove the low-level activity in the waste before discharge into White Oak Creek. There are no unusual hazards associated with the operation of the plant.

\subsection{INTRODUCTION}

Low contamination level liquid wastes at ORNL are called process waste and are primarily streams which, under normal operating conditions, would contain no radioactivity but which, in the event of an equipment failure or human error, could become contaminated. It includes such things as steam condensate from heating coils in vessels containing radioactive solutions, vessel cooling water, rainwater run-off from potentially contaminated areas, condensate from the intermediate level waste (ILW) evaporator, some building sink and floor drains, etc. The only routine discharge of radioactivity into the process waste system comes from the overheads from the ILW evaporator and run-off from certain contaminated areas such as the ILW waste storage tank farm.

For the past several years, the average annual flowrate of process waste has been in the vicinity of $80 \mathrm{gpm}$; but during short periods of heavy rainfall, flows in excess of $200 \mathrm{gpm}$ sometimes occur. The composition varies depending on Laboratory activities, but a typical representative analysis is given in Table 1 . The principal radioactive contaminants are ${ }^{137} \mathrm{Cs}$ and ${ }^{90} \mathrm{Sr}$. The waste streams from various areas of the Laboratory flow into a small pond called the Equalization Basin which acts as a surge volume to equalize the fluw to the treatment plant. The previous method of treatment of this waste employed a "Soda-Lime" process which is similar to a municipal water softening process. The decontamination factor for ${ }^{137} \mathrm{Cs}$ and ${ }^{90} \mathrm{Sr}$ achieved by the "Soda-Lime" process ranges from 5 to 10 . 
ORNL-DWG 75-12203

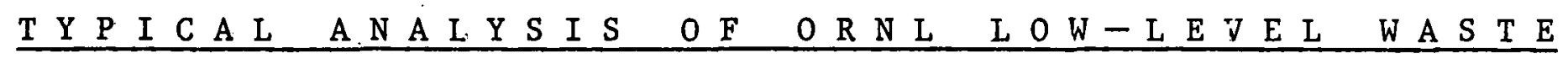

\begin{tabular}{|c|c|c|c|}
\hline CONSTITUENT & PPM & CONSTITUENT & PPM \\
\hline Total Hardness & $100-120$ & Dissolved $\mathrm{CO}_{2}$ & 10 \\
\hline Calcium Hardness & $60-85$ & Bicarbonate & $50-80$ \\
\hline Total Alkalinity & $80-95$ & Carbonate & $<1$ \\
\hline Calcium & $20-30$ & Phosphate & $0.39-3.3$ \\
\hline Magnesiun & $2-10$ & Sulfate & 12 \\
\hline Sodium & $25-30$ & Fluoride & 7 \\
\hline Uranium & $<0.01$ & Nitrate & 26 \\
\hline Copper & 0.05 & Chlorine & 5 \\
\hline Aluminum & 0.01 & Total Solids & 180 \\
\hline Silicon & 2.6 & & \\
\hline Iron & 0.1 & & \\
\hline Nicke1 & 0.03 & $\mathrm{pH} \quad 7-8$ & \\
\hline Chromium & 0.05 & Gross $B$ & $1.8 \times 10^{-4} \mu \mathrm{Ci} / \mathrm{m} 1$ \\
\hline
\end{tabular}


In 1963, ORNL developed a process for the treatment of large volumes of low activity waste called the Scavenging Precipitation-Ion Exchange Process. $^{1,2}$ Based on a pilot plant study of this process, it appears that decontamination factors for the trace quantities of radionuclides in ORNL process waste could be improved over one-hundred-fold above that possible with the soda-lime process. Accordingly, when it was decided in 1972 that the existing Soda-Lime Process Plant would need to be replaced, a conceptual design was prepared for a new facility utilizing the Scavenging PrecipitationIon Exchange Process. ${ }^{3}$ The project was authorized for FY-74, and design was carried out by the ORNL Engineering Division. Site preparation for the new facility was started in February 1974, by the Rust Engineering Company, and construction of the facility was started in August 1974, by the Cousins Construction Company. Procurement of all major process equipment such as pumps, 'tanks, precipitator-clarifier, ion exchange columns, valves, etc., was carried out by UCCND. Construction was completed in October 1975, at a total project cost of $\$ 1.3 \times 10^{6}$.

\subsection{FACILITY DESCRIPTION}

The Process Waste Treatment Plant consists of the following integrated components :

(1) The Equalization Basin

(2) Building 3518 Feed System

(3) Building 3544 - Process Equipment Building

(4) Sludge Disposal Basin

(5) Radioactive Waste Transfer Piping

The first three components are located in the main Oak Ridge National Laboratory area generally southeast of the steam plant. The Sludge Disposal Basin is located in Burial Ground 5 in Melton Valley about $3300 \mathrm{ft}$ south of the Building 3544 Treatment Plant. The waste transfer piping connects the treatment facility with the disposal basin and the ORNL Intermediate Level Waste (ILW) system. Drawing EA-001 shows the locale of the entire facility with respect to the main Laboratory area and Melton Valley. 


\subsection{Equalization Basin}

The Equalization Basin is a previously existing one million gallon basin for storing low-radioactive level (< $3.5 \mu \mathrm{Ci} / \mathrm{gal}$ ) aqueous process wastes. Process waste is essentially process water used in Laboratory operations and contaminated with small quantities of radionuclides, principally the isotopes of Strontium $\left(\mathrm{Sr}^{90}\right)$ and Cesium $\left(\mathrm{Cs}^{137}\right)$. Some of these wastes are collected and routed through a continuous monitoring station that automatically diverts them either to discharge without further treatment, or (if the wastes contain more than $40 \mathrm{~B}$ counts $\mathrm{min}^{-1} \mathrm{ml}^{-1}$ ) to the basin for storage and subsequent treatment for fission product removal before discharge. Other waste streams go directly to the basin for treatment regardless of the activity concentration.

\subsection{Building 3518 Feed System}

The feed system in Building 3518 is the previously exlstiug hetwork of piping, pumps, and valves on the discharge side of the Equalization Basin and the feed side of the Lime-Soda Treatment Plant. The lime-soda precipitation process has been utilized for many years as the method of treatment for the removal of fission products from process waste. The existing feed system, with minor piping and control modifications, was utilized to link the Equalization Basin with the new Process Waste Treatment Plant.

\subsection{Building 3544 - Process Equipment Building}

The new treatment process for removal of flsslum products from proccoo waste is housed in a new building (3544) and on an adjacent reinforced concrete pad. The building plan and sectlums and the process equipment layout are shown in Drawings EE-028, EE-029, and EE-030. The bu1lding is a prefabricated rigid frame metal structure, with insulated walls and roof, attached to a containment and radiation shielded area of $1 \mathrm{ft}$ thick reinforced concrete walls. The roof of the contained area is unshielded and matches that of the attached structure. The prefabricated structure is $60 \mathrm{ft}$ by $30 \mathrm{ft}$ by $16 \mathrm{ft}$ high; the shielded area is $34 \mathrm{ft}$ by $30 \mathrm{ft}$ by $20 \mathrm{ft}$ high, giving overall dimensions of $94 \mathrm{ft}$ by $30 \mathrm{ft}$ with approximately 2820 sq $f t$ of gross floor area. The prefabricated building area is partitioned into an Office and Control Room and a Chemical Make-Up Area. 
The process instrument control panel, motor control center, laboratory facilities, and restroom facilities are located in the Control Room. Tankage for 1iquid chemical storage and solution make-up, process pumps, a water softener, instrument transmitter rack, and dry chemical storage are located in the Chemical Make-Up Area. A 1-ton monorail hoist for handling chemicals and equipment services the area. The building shielded area houses ion-exchange columns and regeneration solution tanks, an evaporator system, concentrated waste tank, an acid off-gas scrubber, and process pumps.

The adjacent concrete pad, just east of the building, is also $94 \mathrm{ft}$ by $30 \mathrm{ft}$. The head-end treatment equipment (precipitator-clarifier, surge tank, and pressure filters); the sludge holdup and transfer system; and a concrete compartmented clearwell approximately $23 \mathrm{ft}$ sq by $6-2 / 3 \mathrm{ft}$ deep are located on this pad.

\subsection{Sludge Disposal Basin}

A 115,000 gal basin located in Burial Ground 5 in Melton Valley provides a means for disposing of radioactive sludge from the new treatment plant. The sludge, generated as a 2 to 4 percent by weight slurry in the head-end treatment, will be accumulated in an agitated tank and periodically pumped to the basin. The basin is lined with a 30 mil thick plasticized polyvinyl chloride (PVC) liner to positively contain the solids and liquid. The sludge will settle and accumulate in the basin; the supernate liquid will be pumped back to the Equalization Basin by a decant system installed at the sludge disposal site. The estimated life of the sludge basin is ten years; after which time it will be completely dewatered, filled and protected from surface water. Space is available at the same site for additional future disposal basins.

\subsection{Radioactive Waste Transfer Piping}

Two low-level radioactive liquid waste streams are generated by the waste treatment process; a slurry or sludge waste from head-end treatment containing 2 to 4 percent by weight solids, and a concentrated waste from ion-exchange regeneration, evaporation, and neutralization. An underground pipeline constructed from 2-in., Schedule 80, unplasticized polyvinyl chloride (PVC) pipe is provided to transfer sludge waste from the holding 
tank at the treatment plant to the Sludge Disposal Basin in Melton Valley. The line is also used for the return of decant water from the disposal basin back to the Equalization Basin. The concentrated waste is transferred in an underground pipeline constructed from 1-1/2 in., Schedule 40, Type 304L stainless steel pipe. This line connects the concentrated waste tank in the treatment plant to the previously existing ILW collection system.

\subsection{PROCESS DESCRIPTION}

Design of the Process Waste Treatment Plant is based on a process developed at the Oak Ridge National Laboratory and pilot plant demonstrated several years ago using Laboratory generated low-level waste; it is called the Scavenging-Precipitation Ion-Exchange Process (SP-IX). The chemical. and engineering flowsheets based on the SP-IX process are shown in Drawings EE-001, EE-002, and-EE-003. Sizing of the process equipment and piping is based on a design flow rate of 200 gal per minute of process water. This incorporates an over capacity of about 50 percent to provide desired flexibility for handling of emergency situations and possible future sources of low-level waste.

The process consists of three basic operations: precipitation, filtration, and ion exchange. The first two of these, together called head-end treatment, utilize conventional water-treatment equipment; namely, a static in-line pipe mixer, a sludge-blanket type precipitator-clarifier, and pressure f1lters. The 1on-exchange equipment is tailored to the process and based on criteria developed during the pilot plant operations.

In the head-end treatment, a flocculant precipitate of calcium carbonate and magnesium hydroxide is formed by adjusting the $\mathrm{pH}$ of the waste stream to 11.8 ( $\sim 0.01 \mathrm{~N}$ in $\mathrm{NaOH}$ ) with a concentrated $\mathrm{NaOH}$ solution. At the same time, copperas oolution $\left(\mathrm{FeEO}_{4} \cdot 7 \mathrm{H}_{2} \mathrm{O}\right)$ is added to an $\mathrm{Fe}^{2+}$ concentratun of $5 \mathrm{ppm}$ as a coagulant and flocculating agent. These chemical additions take place immediately ahead of the static pipe-mixer and are regulated by a $\mathrm{pH}$ control loop and as a function of waste stream feed rate. Coagulation of the precipitates into larger particles occurs in the flocculator section of the precipitator-clarifier where the mixture is gently agitated as it. downflows to the bottom. The floc enters the bottom of the clarifier section 
where solids separation is achieved by upflowing the mixture through a sludge-blanket. The sludge-blanket consists of fluidized particles that trap the floc and furnish additional nuclei to continue the precipitation reaction by crystal growth. As particles in the sludge-blanket agglomerate, they settle and form a slurry in the bottom of the vessel. It is this chemical and physical action that scavenges radionuclides, dirt particles, and algae from the waste stream and retains them in the slurry.

The slurry is periodically pumped from the bottom, controlled by an automatic adjustable timed cycle, to an agitated 6000 gal sludge holding tank. The slurry, which will average 2 percent to 4 percent by weight solids and contain approximately 50 percent of the radioactivity present in normal process waste, will be accumulated to a determined level in the holding tank and then transferred by pumping through the sludge waste transfer pipeline to the lined disposal basin in Melton Valley.

The effluent from the clarifier section overflows to a 6500 gal surge vessel and then is pumped through pressure-type polishing filters containing a fixed bed of uniformly-sized $(0.6 \mathrm{~mm}$ to $0.8 \mathrm{~mm})$ anthracite.

After filtration, the waste stream, now less than $10 \mathrm{ppm}$ in hardness, downflows through an Ion exchange column containing sodium-form Duolite CS-100 resin. This is a phenolic-carboxylic cation exchange resin, a weakacid type selected because of its high preference for sorbing cesium ion in the presence of sodium. The resin is nearly 100 percent efficient in removing strontium and cesium with a capacity in excess of 2000 bed volumes of nornal low-level waste. To regenerate the resin, the loaded column is removed from service; then, without fluidizing the bed, the resin is upflow eluted with two batches (five bed volumes each) of $0.5 \mathrm{~N}$ nitric acid. The first elution removes most of the radionuclides and hardness ions the resin sorbed; the second elution completes the acid regeneration and is stored for use in the first half of the next acid regeneration cycle. After rinsing, the resin is converted to the sodium form by upflow eluting with 20 bed-volume of $0.1 \mathrm{~N}$ sodium hydroxide. The $\mathrm{NaOH}$ regenerant and the rinse water is sent to the Equalization Basin for recycle.

After ion-exchange, the process waste stream, now completely stripped of radioactivity and hardness but still about $0.01 \mathrm{~N}$ in sodium hydroxide, flows to. the first compartment of the clearwell. The clearwell is 
partitioned into two compartments connected by an overflow weir. The first compartment provides 13,500 gal of plant-treated process waste water for filter backwashing. In normal operation, this source of treated waste is also utilized for makeup of the $\mathrm{NaOH}$ regenerant by line mixing with concentrated $\mathrm{NaOH}$ solution to the required concentration of $0.1 \mathrm{~N}$. The second compartment provides a means of neutralizing the plant effluent with sulfuric actd at the weir and a final holdup volume of 7500 gal prior to discharge to White Oak Creek.

The firot acid olution from lon-exchange column rogeneration is evourated to reduce the volume. The overhead condensate, which is dilute nitric acid, is used for acid regenerant solution make-up. The acid concentrate from the evaporator constitutes the other waste stream from the process. It is neutralized with sodium hydroxide and transferred by pumping through the concentrated waste pipeline to the Intermediate Level Waste (ILW) system for subsequent disposal.

\subsection{MAJOR PROCESS EQUIPMENT}

\subsection{Precipitator-Clarifier}

The precipitator-clarifier is a horizontal design package unit, Model 4. manufactured by the Permutit Company for a treating capacity in excess of $200 \mathrm{gpm}$ input flow. The unit operates on the suspended sludge-blanket principle of filtering and is constructed to include a downflow mixing compartment with mechanical agitation and an upflow sludge filter compartment. The two compartments are separated by a sloping partition wall. Total detention time in the treating tank, which is $20 \mathrm{ft}$ long by $8 \mathrm{ft}$ wide by $10-1 / 2 \mathrm{ft}$ high, is 60 minutes at the design rate of flow.

The upper level of the oludge blanket 1o controlled by intennttently withdrawing sludge. The blowdown cycle is initiated and controlled by an automatic blowdown system comprising an automated valve and pump which is operated by an adjustable control system. Intervals between blowdown cycles and the duration of the blowdown are regulated by a timer. The timer is independently adjustable to provide a wide range of sludge blowdown adjustment. The blowdown system includes backflushing which automatically introduces fresh water into the blowdown piping. The flushing water 
flows into the sludge filter compartment in the reverse direction to normal blowdown flow to clear blowdown piping and nozzles of sludge.

Sampling taps are provided to allow taking samples from the following places in the precipitator: top and bottom of the mixing compartment; three different levels in the filter compartment; and the effluent collector. The unit is also fitted with Permutit chevron tube settlers at the top of the filtering or clarification compartment. These polystyrene devices increase both the throughput and clarification efficiency of the equipment.

The outer tank and inner structure is of all welded construction from carbon steel;'all piping is also of carbon steel, Schedule 40 .

\subsection{Pressure Filters}

The two pressure filters are also package units, Custom Type "G", manufactured by the Permutit Company. Each unit is capable of filtering a flow rate of $170 \mathrm{gpm}$ based on $3 \mathrm{gpm}$ flow per square feet of filtering area. The filter vessel is a cylindrical shell $8-1 / 2 \mathrm{ft}$ in diameter with dished heads; overall height is about $8 \mathrm{ft}$. Construction is all welded from carbon steel plate.

The filter is designed for normal downflow through the filter bed and vertical upflow for backwashing. The inlet to the filter provides uniform distribution of the unfiltered stream over the filter media. The filter media is No. 1 anthracite screened to an effective size range of $0.6 \mathrm{~mm}$ to $0.8 \mathrm{mu}$ and having a depth of over $24 \mathrm{in}$. on the vesse1 straight section. The underdrain system provides uniform collection of the filtered stream; it also supports and retains the filter media and distributes backwash water flow across the media surface.

A 6-in. manually operated multi-port valve of the rotary disk type is provided to control the direction of flow during filtering, backwashing, and rinsing operations. Valves for regulating flow during backwash and rinsing are also provided. All the piping is carbon steel, Schedule 40 .

\subsection{Ion-Exchange Columns}

The ion-exchange column was designed by UCC-ND Engineering at Oak Ridge Nätional Laboratory and fabricated by WSF Industries, Tonawanda, New York. Design, fabrication; and inspection was in accordance with the 
ASME Code and the vessel is ASME Code stamped. Three columns are provided by the process design, each capable of treating a waste flow rate of about $100 \mathrm{gpm}$.

The column, designed to a working pressure of $75 \mathrm{psig}$, is a cylindrical shell $3 \mathrm{ft}$ in diameter and $12 \mathrm{ft} 8 \mathrm{in}$. in height with a dished head top and flanged bottom. Construction is all welded from Type 304L stainless steel throughout: externals, vessel, and internals. Besides inlet and outlet nozzles at top and bottom, a manhole is provided in the top head and four sight glasses are located around the midpoint of column height for monitoring resin level and flow action. The column is mounted on legs.

The column is designed for counterflow operation; that is, 1 nading or exhaustion in vertical downflow and regeneration in vertical upflow. An internal pipe distribution system is provided in the top of the column to disperse the waste stream uniformly. A pipe-tree underdrain system provides for uniform collection of the treated stream and even distribution of the regenerant solutions. The underdrain system is integral with the bottom flange on which the resin bed is supported.

Each column is charged with 44 cubic feet of resin on top of about 1 foot of depth of sand. This gives a resin bed depth of over $6 \mathrm{ft}$ not including the sand base and results in an $\mathrm{H} / \mathrm{D}$ ratio of $>2.0$. Over $3 \mathrm{ft}$ of freeboard is provided above the bed when the resin is in the expanded or sodium form.

Three ion-exchange columns, each rated at $100 \mathrm{gpm}$ capacity, affords economical and flexible operation. At the design rate of $200 \mathrm{gpm}$, two columns are operated in parallel with one in standby; at low flows up to 100 gpm, unly une culumn is in service.

\subsection{Waste Evaporator}

The waste evaporator was designed by UCC-ND Engineering at ORNL and fabricated by WSF Industries, Tonawanda, New York. Design, fabrication, and inspection was in accordance with the ASME Code, and vessel is ASME Code stamped.

The evaporator is a cylindrical vessel $4 \mathrm{ft}$ in diameter with a dished bottom head and removable flanged top head, also dished. The height is $5 \mathrm{ft}$ not including the supporting legs. Flanged nozzles are provided in 
the top head for feed inlet, vapor outlet, and for instrumentation monitoring liquid-level, density, and.temperature; in the shell for steam and condensate; and in the bottom for concentrate outlet. Two internal submerged pipe colls, helically wound from 1-1/2 in. pipe, provide $84 \mathrm{sq} \mathrm{ft}$ of heat transfer surface. Heat is supplied by low pressure ( 35 psig) steam. A woven mesh-type entrainment separator is incorporated in the vapor outlet. The vessel, piping, and internals are of all welded construction from Type 304L stainless steel; all piping is Schedule 40.

The evaporator is designed for a maximum feed rate of $83 \mathrm{gph}$ at boilup rate of $77.5 \mathrm{gph}$ using saturated steam at 50 psia. Operation is semicontinuous at a constant liquid level by automatically controlling the feed rate at a manually set steam rate. The operating volume is 220 gallons. An overhead condensing system, vertically mounted and cooled by process water, is designed for total vapor condensation and condensate subcooling.

\subsection{S-1 Sump}

The sump located on the north end of the equipment pad and the network of underground piping draining to it perform an important function in the waste treatment process. The sump is lined to operating depth with chemical resistant Amercoat lorporation plastic liner. 'l'wo centrifugal pumps, a $\perp$ stainless steel, level controlled, and each rated at $200 \mathrm{gpm}$ are mounted in the sump. The pumps discharge to the Equalization Basin.

The building floor drains and curbed area drains under tanks are connected to the sump with an all PVC piping system. Any chemical spill, acid or base, can be flushed to the sump and pumped to the basin.

The equipment pad drains connect to the sump through cast iron pipe. The precipitator-clarifier can also be drained to this system through an open standpipe if maintenance requires it.

Drains from the clearwell are connected to the sump through another cast iron pipe. The surge tank overflow pipe and the ion-exchange column $\mathrm{NaOH}$ regenerant are also connected to this drain. Thus, in case of ion exchange activity breakthrough and contamination of the clearwell, the waste can be recycled to the basin until the upset is corrected. In case of upset in the head-end, the precipitator-clarifier can be recycled to the basin via the surge tank overflow. 


\subsection{Radiation Monitors}

Drawing QE-009 shows the location and type of radiation monitors in the Process Waste Treatment Plant building. For process control, Geiger tube-type radiation sensors are externally mounted on the ion-exchange columns. These are designed to operate both in a fixed position and to vertically scan the resin bed. In use, the instrument monitors the accumulation of radioactive contaminants on the resin bed. The condition of the column in service can thus be determined, and regeneration can be initiated before breakthrough occurs. A low-range gamma detector is used to monitor the effluent stream from the ion-exchange columns to the clearwell. This is a backup device for the column detectors and indicates by alarm that radioactivity breakthrough has occurred.

For personnel, a beta-gamma monitor and an alpha monitor are located at the exit door from the ion exchange room. These devices are for checking shoes, hands, and clothing for possible radioactive contamination.

A beta-gamma constant alr monitor and a monitron are located inside the fon-exchange room.

\subsection{HAZARDS ANALYSIS}

\section{S.1 Chemical Hazards}

The chemicals used in the operation of the Process Waste Treatment Plant are common to many operations at the Laboratory and do not present any new or unusual hazard. Operators are required to wear full face shields, rubber gloves, and coveralls during the make-up of all solutions and the unloading of bulk liquid chemicals. 'lhe area in which chemical make-up and receiving operations are carried out contains two eye-wash fountains and two overhead safety ehowers. Combined operating procedures and data shecta are used for all make-up operations.

Sodium Hydroxide ( $\mathrm{NaOH})$. $\mathrm{NaOH}$ is received as a 50 percent solution by tank truck and is unloaded by means of a pipe connection outside the building into a 2000 gal carbon steel hold-tank inside the bullding. It is used as a $5 \mathrm{~N}$ solution in an off-gas scrubber; as a $3 \underline{\mathrm{N}}$ solution for $\mathrm{pH}$ adjustment of incoming process waste; and as a 1 N solution for regeneration of the ion 
exchange columns. The various strength solutions are made up in a $400 \mathrm{gal}$ and a 200 gal carbon steel make-up tank. Transfers from the hold tank to the make-up tanks and from the make-up tanks to the point of use are made by pumps.

Nitric Actd $\left(\mathrm{HNO}_{3}\right)$. Nitric acid is received as a $13.6 \mathrm{~N}$ solution by tank truck and is unloaded by means of an outside pipe connection into a 500 gal stainless steel hold tank inside the building. It is used as a $0.5 \mathrm{~N}$ solution for stripping activity off the ion exchange columns during the resin regeneration operation. The solution is made up in a $2000 \mathrm{gal}$ stainless steel make-up tank. All transfers are by pump.

Sulfuric Acld $\left(\mathrm{H}_{2} \mathrm{SO}_{4}\right)$. Sulfuric acid is received as a $62^{\circ}$ Bé solution by tank truck. It is unloaded into a 100 gal Carpenter 20 stainless stee1. tank inside the building through a rigid Schedule 40 PVC pipeline with an unloading connection outside the building. The acid is used undiluted to neutralize the effluent from the plant before discharge to White Oak Creek.

Ferrous Sulfate $\left(\mathrm{FeSO}_{4} \cdot 7 \mathrm{H}_{2} \mathrm{O}\right)$. Ferrous sulfate is received as a granular solid in $50 \mathrm{1b}$ bags. It is made up as a $86 \mathrm{~g} / \mathrm{l}$ solution in a $200 \mathrm{gal}$ stainless steel make-up tank and is used as a flocculating agent in the precipitator-clarifier unit.

In addition to the above, small quantities of other reagents are used for titrations, $\mathrm{pH}$ and hardness tests. Concentrated brine solution is used for regenerating the water softener unit. The floor area under all of the chemical hold and make-up tanks is enclosed by $4 \mathrm{in}$. high concrete curbs so that any leakage will be contained and flow through floor drains to process waste.

\subsection{Radiation Hazards}

During normal operation, the radioactive content of the waste being processed is a tiny fraction of a $\mu \mathrm{Ci} / \mathrm{gal}$ (Table 1 ); and there is no significant direct radiation or accidental ingestion hazard.

- Any radiation hazard that might occur at the Process Waste Treatment Plant would be because of an accident somewhere else within the Laboratory that releases radioactive materials into the process waste system. The incoming waste lines to the process waste treatment system all-terminate 
in the Equalization Basin, and any accidental discharge of radioactive material into the system would be diluted by the water in the basin and water coming from other sources. If the radioactivity concentration of the combined streams is low enough to permit processing through the plant, the waste can be recycled as many times as necessary to reduce the activity in the effluent to a level suitable for discharge into White Oak Creek. If the radiation level is such that there is excessive operator exposure, the waste in the Equalization Basin can be pumped to a 4 million gallon emergency basin located on the northwest side of SWSA-6. After the source of the radioactivity leak inco the process waste system is found and corrected, the waste in the emergency basin can be brought back at a rate that will permit sate processing when $1 \mathrm{t}$ is blended wILl luw contamination level waste. The activity will concentrate on the ion exchange columns and can be stripped from the columns and sent to the intermediate level waste system as frequently as necessary to provide operator protection. The ion exchange columns, waste evaporator, and waste concentrate hold tank are located within a one-foot thick concrete cell structure and can be operated entirely remotely from the Control Room. In actual practice, the frequency of stripping the activity from the columns is more likely to be dictated by activity breakthrough because the resin becomes loaded with non-radioactive constituents in the waste ( $\mathrm{Ca}, \mathrm{Mg}$, erc.) rather than by radiation considerations.

Within the shielded area there is a beta-gamma monttron and a constant air monitor that alarm in the Control Room. Each ion exchange column has a gamma monitor that can traverse the length of the resin bed to determine when the column needs regeneration to prevent breakthrough. In addition, a portion of the effluent from the columns is continuously pumped through a beta-gamma ion chamber; and the countrate is recorded; and an alarm sounds if it exceeds pre-set levels.

The activity stripped off the columns is fed to an evaporator where it is concentrated to recover nitric acid for re-use, and the bottoms are neutralized with $\mathrm{NaOH}$ and transferred to the intermediate level waste system. The condensate from the evaporator steam coils is continuously monitored by a beta-gamma ion chamber before discharge to White Oak Creek. In the event of a coil leak, the condensate can be directed back to the 
process waste system. The strip solution is concentrated to a total salt content of $\sim 4 M$ and, in practice, the concentrate from 4-5 regeneration cycles is accumulated before a transfer is made to the ILW system. On an average, approximately $0.5 \mathrm{Ci}$ of activity in 200-300 gal of liquid is involved in each transfer.

The off-gas from all the process vessels passes through a $\mathrm{NaOH}$ scrubber and is discharged at roof top. Ventilation air in the shielded ion exchange room is filtered through an absolute filter and discharged at roof top. Air from other portions of the building is discharged unfiltered through roof vents. The scrubber solution is periodically combined with the process waste concentrate and sent to the ILW system.

\subsection{Fire Hazards}

The entire building structure is protected by a sprinkler system. When activated, the sprinkler system alarms locally and at Fire Headquarters. There are no flammable type chemicals used in the process. All pump motors are protected by thermal overload switches. The building is constructed of metal and concrete, and all tanks and equipment are of metal construction.

\subsection{Natural Hazards}

The building housing the equipment is constructed and installed in accordance with the Southern Standard Building Code and the 1973 Uniform Building Code for Seismic Loading in a Zone 2 area. Under these codes, horizontal wind loads up to 20 psf will not cause failure of wall panels; and forces up to 25 psf, acting outward on the roof, will not cause separation between the roof and walls. Seismic forces corresponding to horizontal and vertical ground accelerations of $0.1 \mathrm{~g}$ and $0.15 \mathrm{~g}$ will not cause failure of the structure. The floor elevation of the structure is at an elevation of $781.8 \mathrm{ft}$ which is $13.8 \mathrm{ft}$ above the maximum probable flood level estimated by TVA for the Clinch River at the White Oak Creek watershed. 


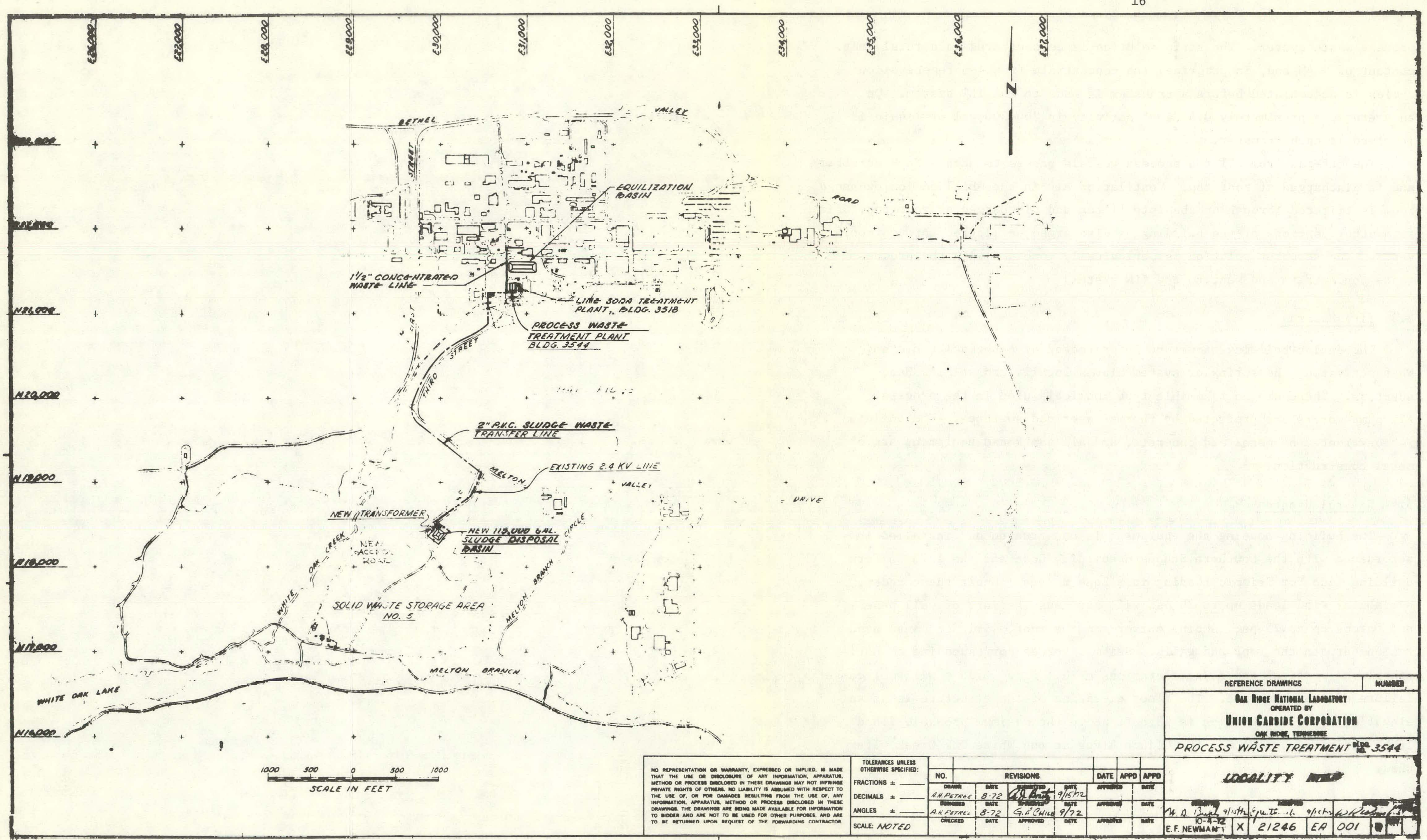




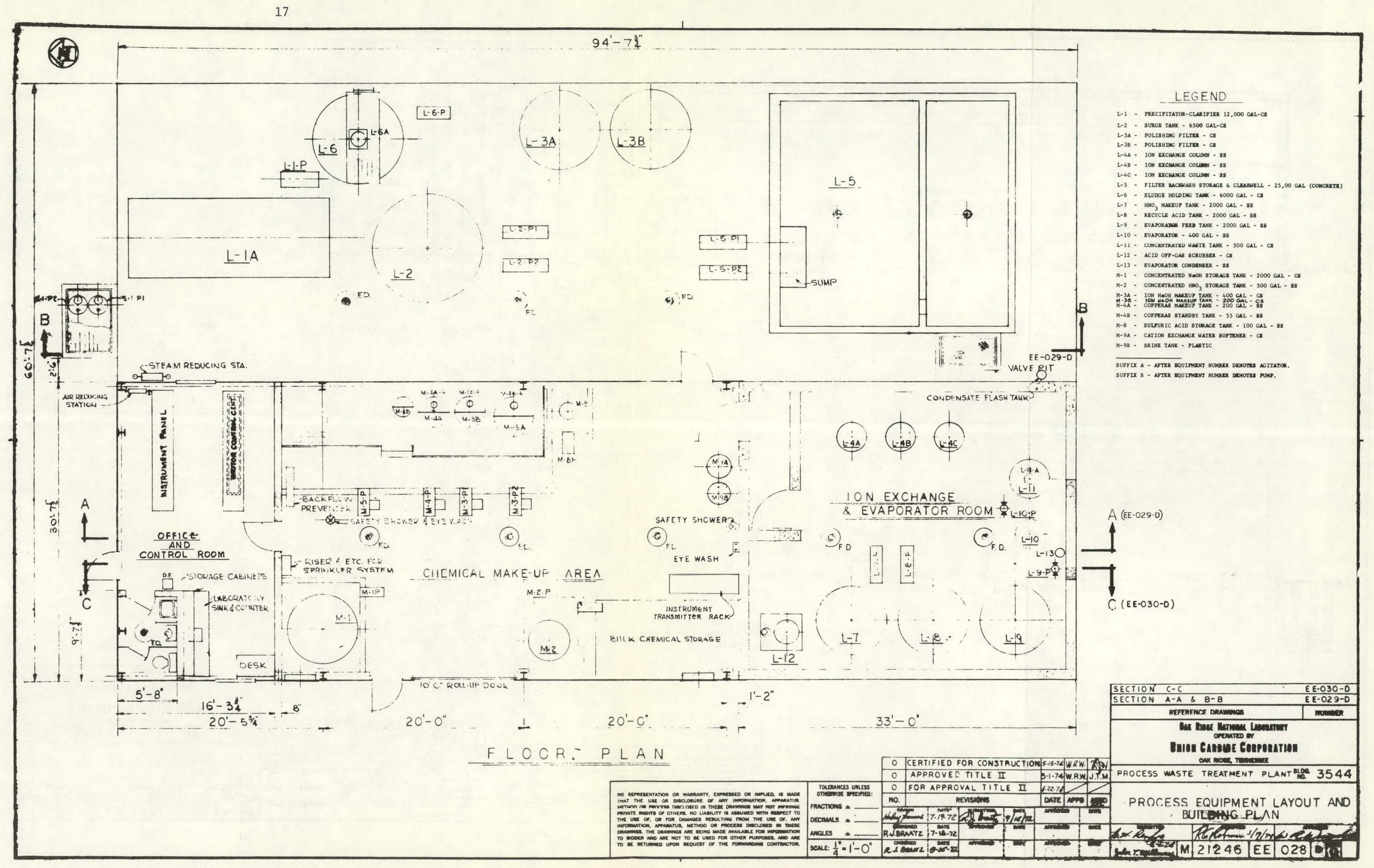

Process Equipment Layout and Building Plan 

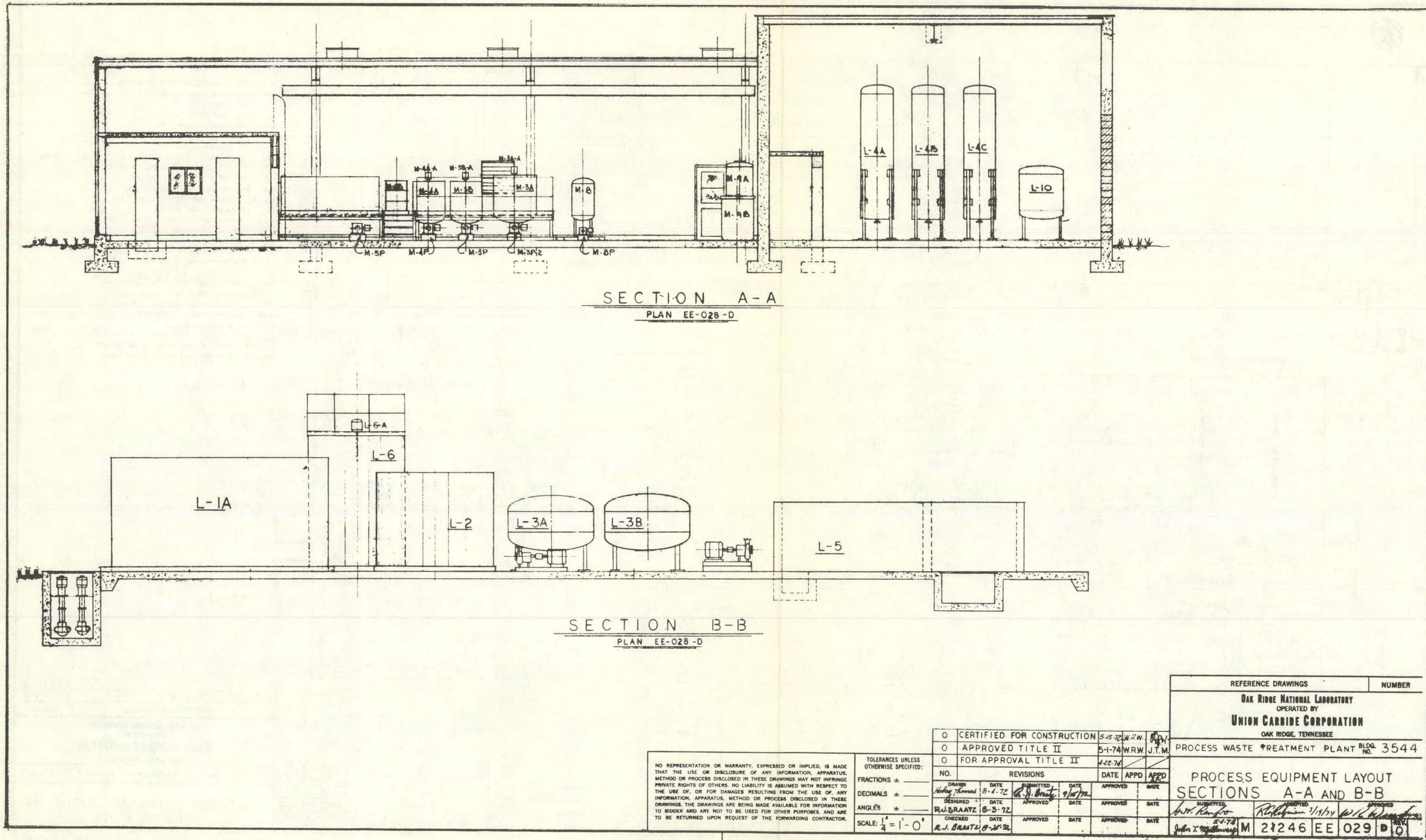

Process Equipment Layout, Sections $A-A$ and $B-B$ 

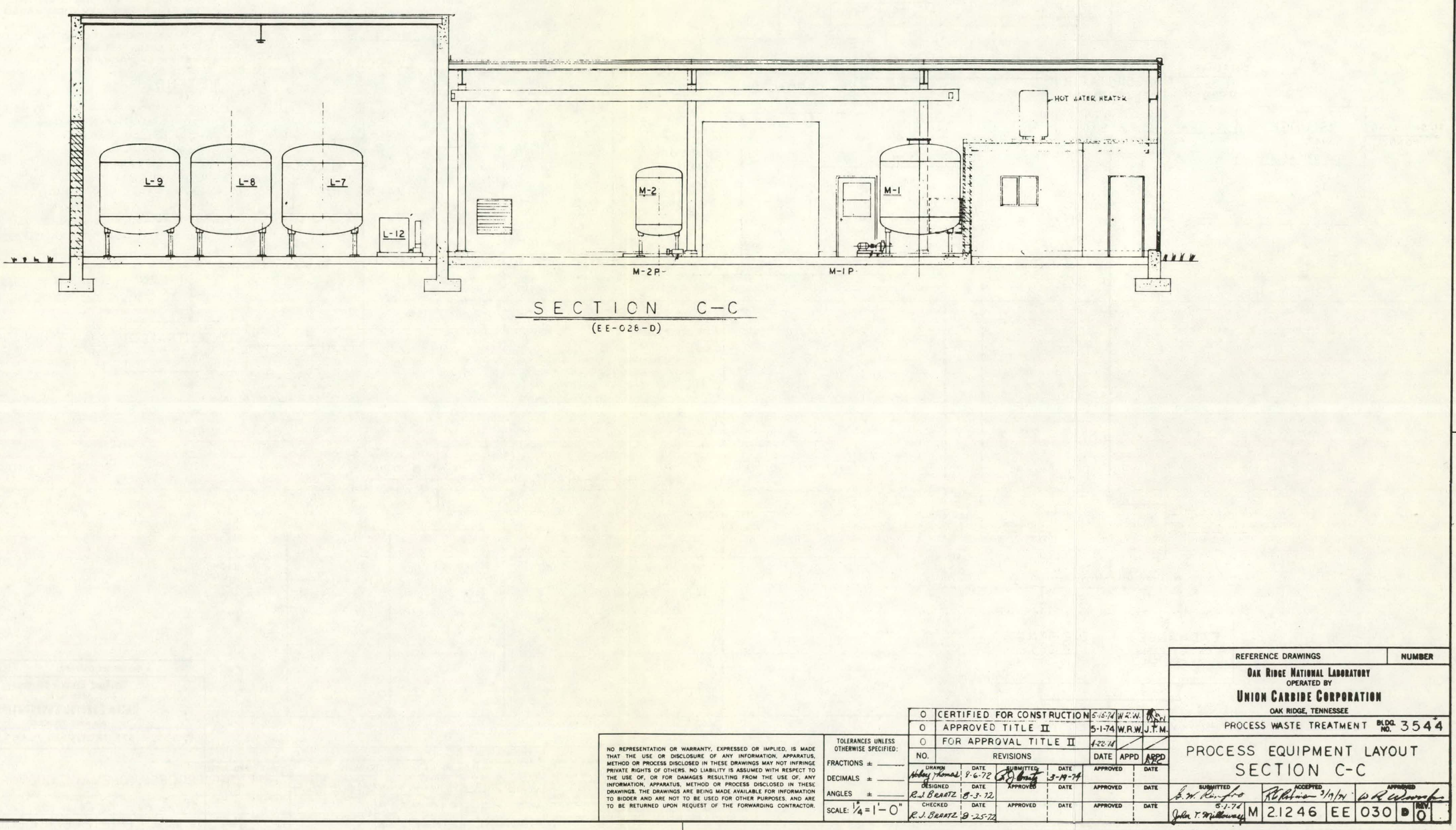
20

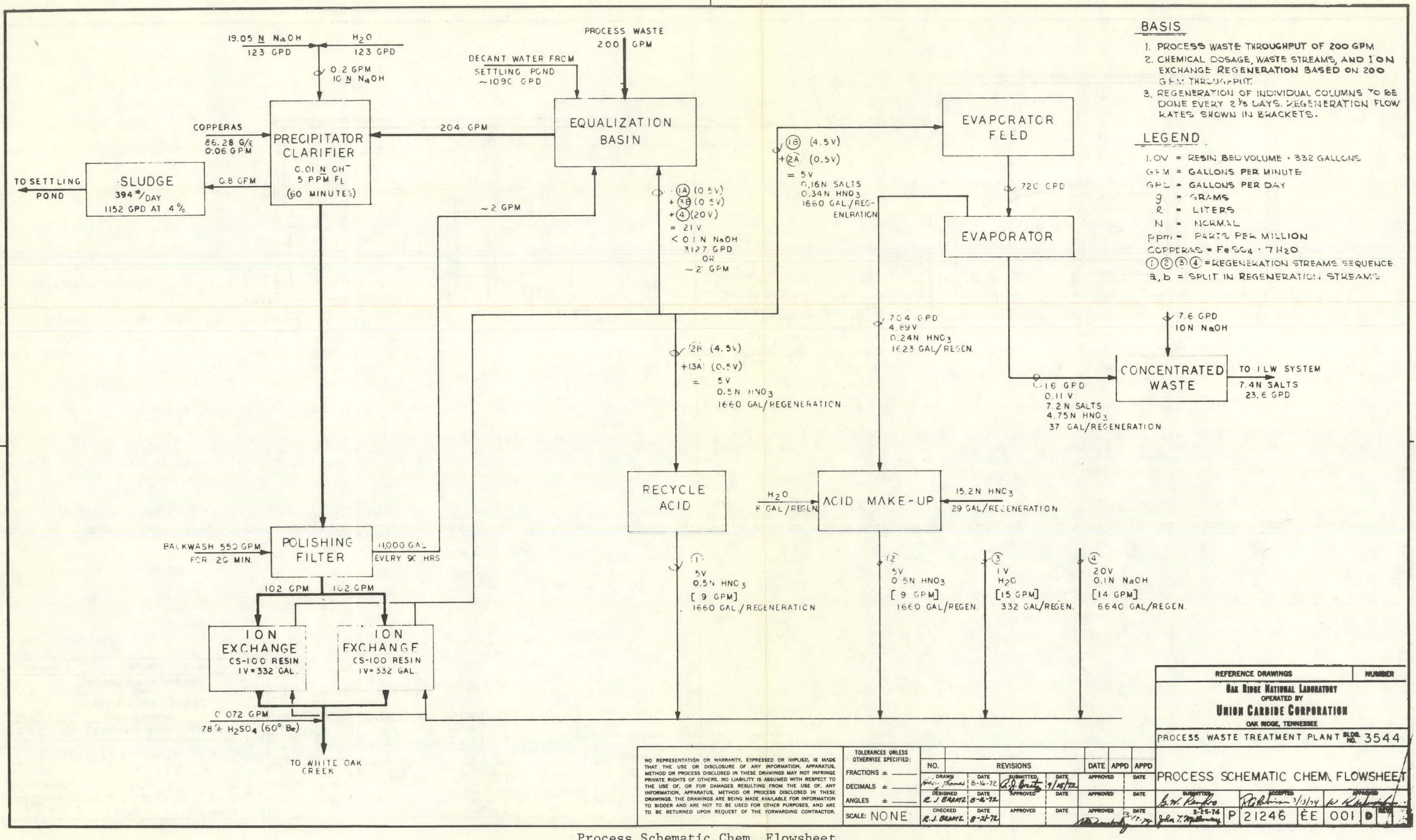

Process Schematic Chem. Flowsheet 


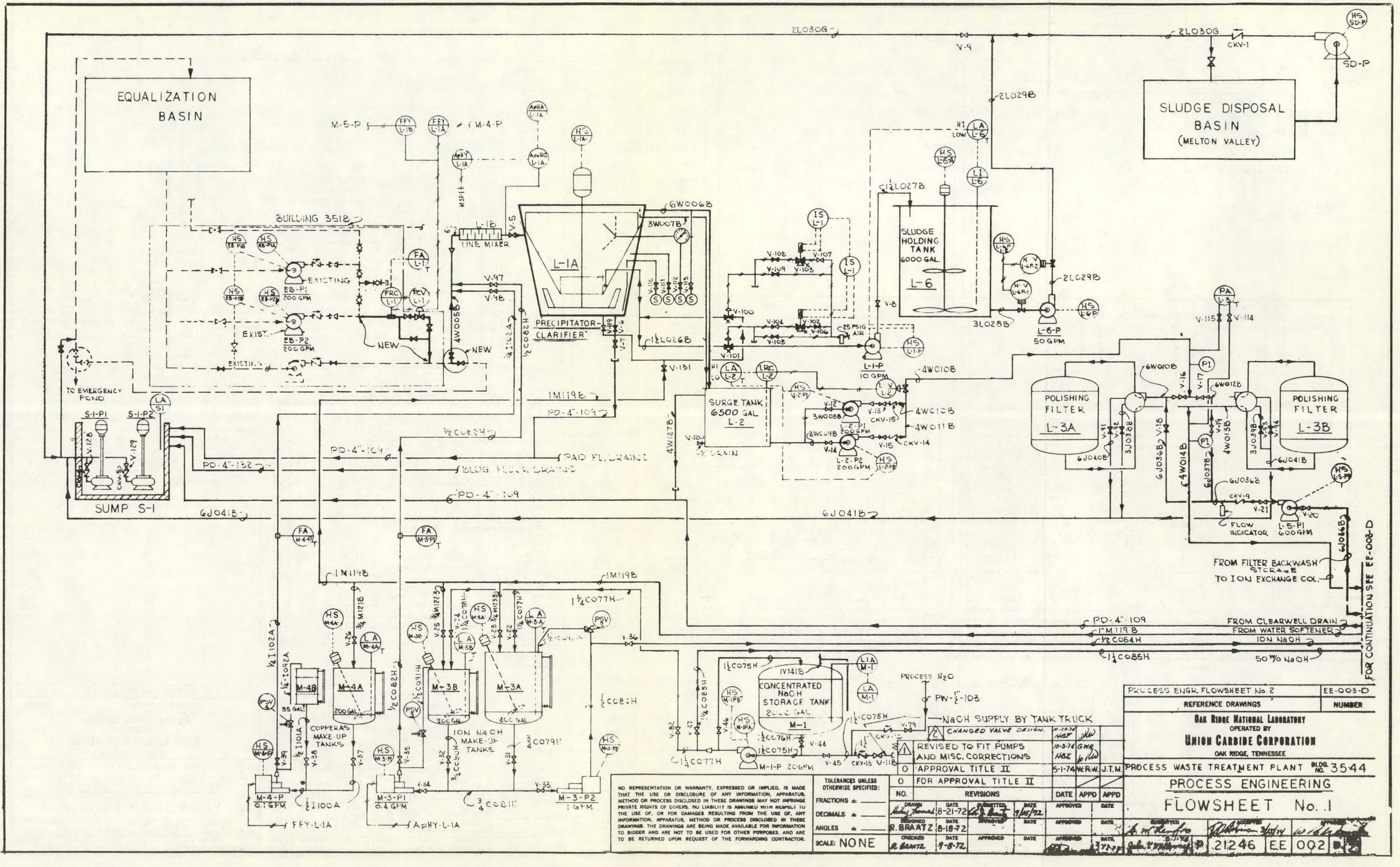

Process Engineering, Flowsheet No. 1 


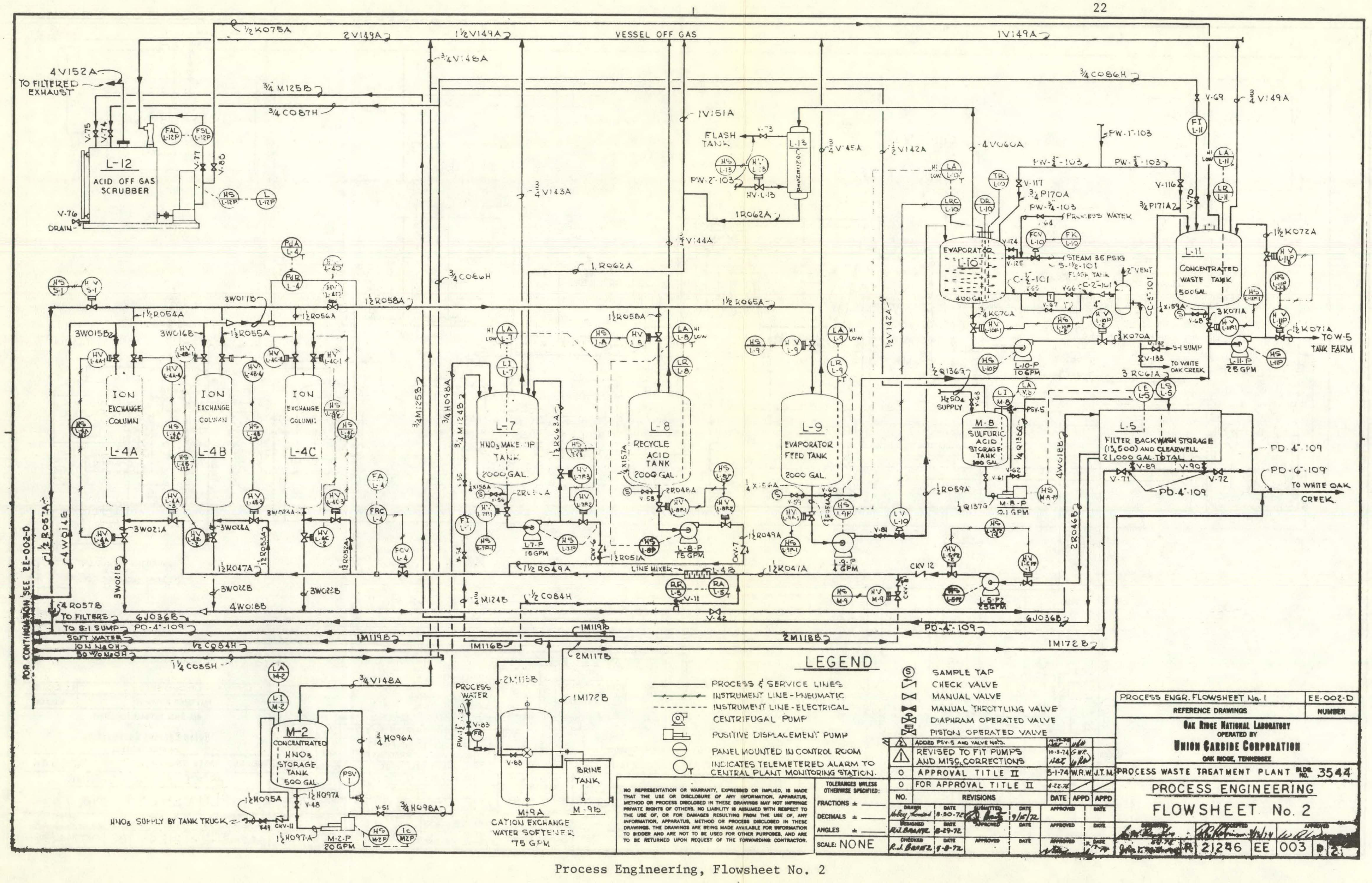




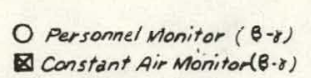

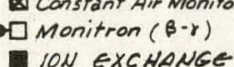

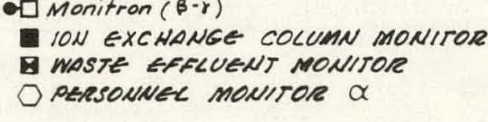

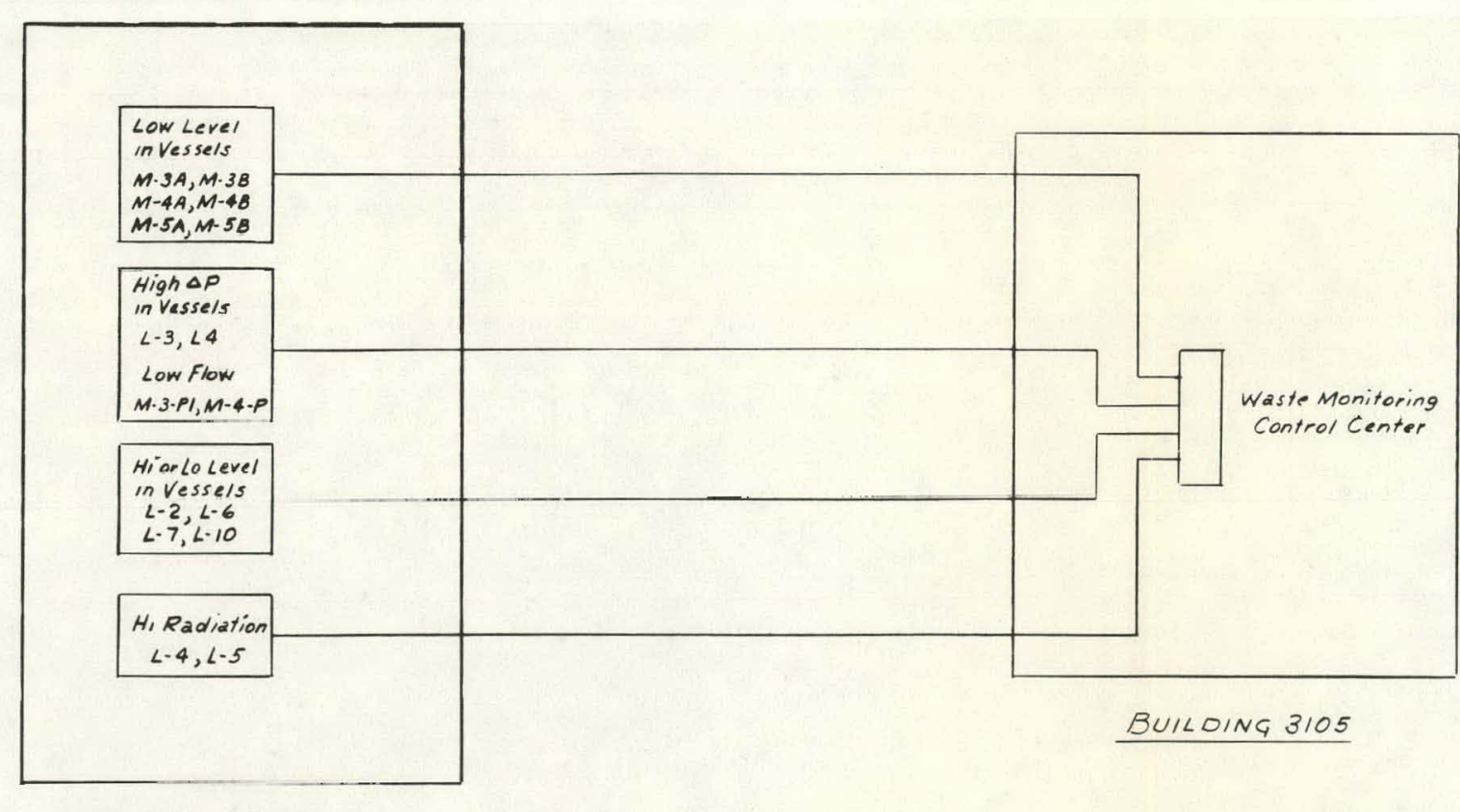

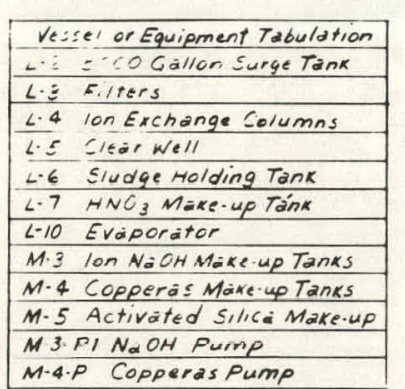

NOTE:

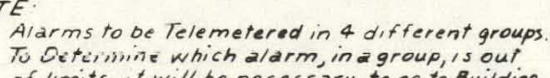

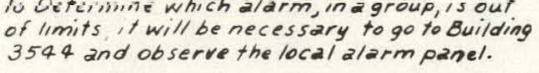

$\frac{\text { BULLING. } 3544}{\text { Telemertry }}$ 


\section{REFERENCES}

1. R. R. Holcomb, Low Radioactivity Level Waste Treatment. Part I, Laboratory Development of a Scavenging Precipitation Ion-Exchange Process for Decontamination of Process Water Wastes, ORNL-3322 (June 1963).

2. R. E. Brooksbank, et a1., Low Radioactivity Level Waste Treatment. Part II, Pilot Plant Demonstration of the Removal of Activity from Low-Level Process Waste by a Scavenging-Precipitation Ion-Exchange Process, ORNL-3349 (May 1963).

3. R. J. Braatz, J. P. Jarvis, Conceptual Design Report for the Proposed ORNL Process Waste Treatment P1ant, ORNL-TM-4004 (Nov, 1972). 
A P P ENDIX

OPERATING PROCEDURES

FOR

PROCESS WASTE TREATMENT PLANT 


\section{THIS PAGE \\ WAS INTENTIONALLY \\ LEFT BLANK}


CONTENTS

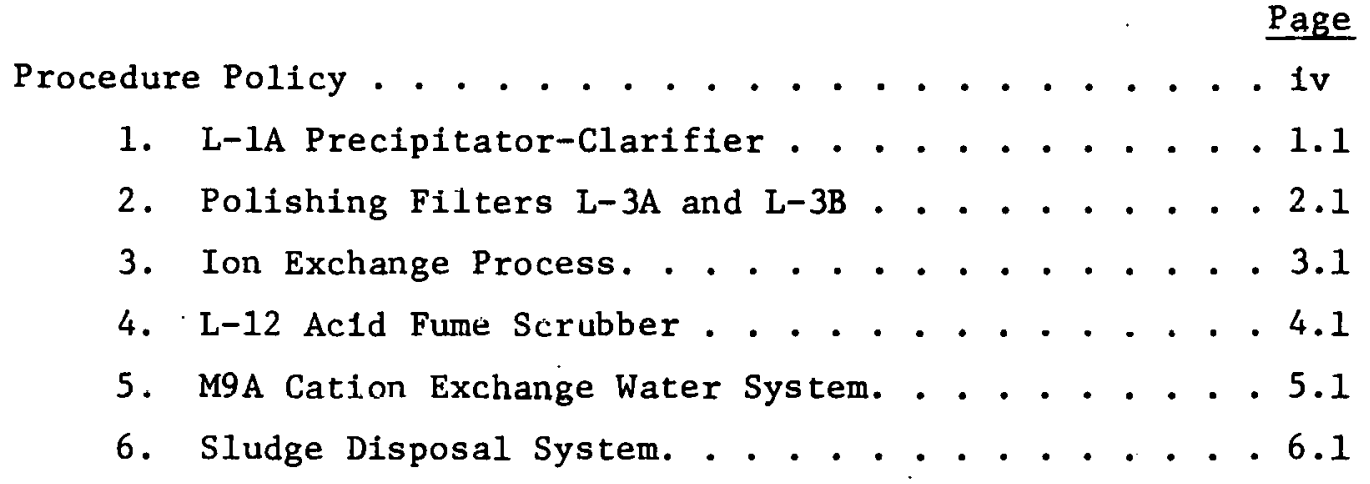




\section{THIS PAGE \\ WAS INTENTIONALLY \\ LEFT BLANK}


PROCEDURE POLICY

In an effort to ensure safe and efficient operation of the Process Waste Treatment Plant, procedures have been prepared for the various operations associated with this facility. These procedures present the approved manner for carrying out these operations and will be modified and updated as changes are warranted.

Operating procedures are maintained current by formal issuance as conditions change. These procedures are categorized and issued accordingly:

1. Procedures of a temporary nature (those which may or may not become permanent but are of indefinite duration) are issued by the waste disposal supervisor and addressed to the Procedure Memorandum Book. Procedure memoranda books are located at the Waste Disposal Monitoring Center, Building 3105, the Process Waste Treatment Plant, and at the waste disposal supervisor's office.

The waste disposal supervisor is responsible for maintaining a current copy in his office and should periodically compare his copy against the Building 3105 and Process Waste Treatment Plant copies to assure that the books are up to date. As a procedure memorandum is outdated, it will be removed from the book and the procedure marked "void" on the table of contents.

2. New procedures of a permanent nature (those which describe permanent changes in operating conditions) are issued as required by the waste disposal supervisor, subject to approval of the department and division superintendents, and incorporated as permanent additions to the operating procedures. Such an addition will be located in the manual based on subject category.

If an existing portion of the procedures manual has become obsolete, that particular portion will be rewritten in its entirety. The obsolete section will be removed from the manual and the current procedure inserted. It is the responsibility of the waste disposal supervisor to maintain a current procedures manual. 
3. Instructions to shift personnel are issued by the waste disposal supervisor or assistant as the need arises and are. maintained current in the "Supervisor's Logbook". These instructions are of a temporary nature, are for a specified time, and will be removed and discarded after they have become obsolete. 


\subsection{L-IA PRECIPITATOR-CLARIFIER}

\subsection{References}

Permutit Operating Instructions

Permutit Dwg. No. 185-17073, Precipitator Layout and Assembly

Permutit Dwg. No. 129-22630, Agitator Drive Assembly

Permutit Dwg. No. 157-37831, Agitator Assembly

Permutit Dwg. No. 101-35875, Blowoff Flushback Schematic

Permutit Dwg. No. 102-31725, Blowoff Flushback Wiring

Permutit Dwg. No. 184-16379, Chevron Module Assembly

ORNL Dwg. P-21246-EC-002-DO, Process Engineering Flowsheet No. I

ORNL Dwg. P-21246-EC-003-DO, Process Engineering Flowsheet No. 2

ORNL Dwg. P-21246-EE-041-DO, Precipitator-Clarifier Process Piping,

Plan and Elevation JJ

ORNL Dwg. P-21246-EE-042-DO, Precipitator-Clarifier Process Piping, Elevations and Details Sheet

ORNL Dwg. I-21246-EI-015-D2, Instrumentation System Diagram, sheet 1

ORNL Dwg. E-21246-ED-011-DO, Electrical Power Plant, sheet 1

ORNL Dwg. D-37887, Pump Suction and Discharge Lines

\subsection{Introduction}

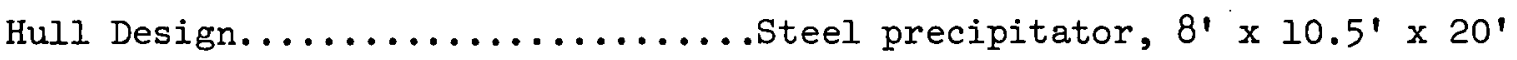

Capacity...................240 gpm (with tube settler module)

$175 \mathrm{gpm}$ (without tube settlers)

Purpose....................Treatment Radioactive Waste

Flow Measurement........................... plate with $D / P$ type flow indicator

Flow Control................. Diaphragm actuated, spring opposed control valve

Chemical Feeds....................... Copperas

Sludge Removal System:

Timer control,

Initial blowoff setting $20 \%$ or 4 mimutes,

Initial flushback setting $2 \%$ or 24 seconds.

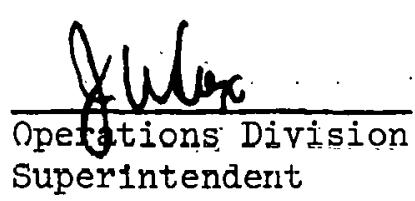

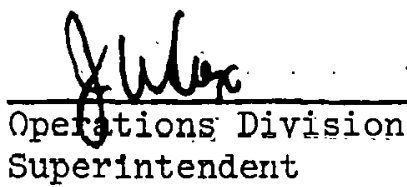

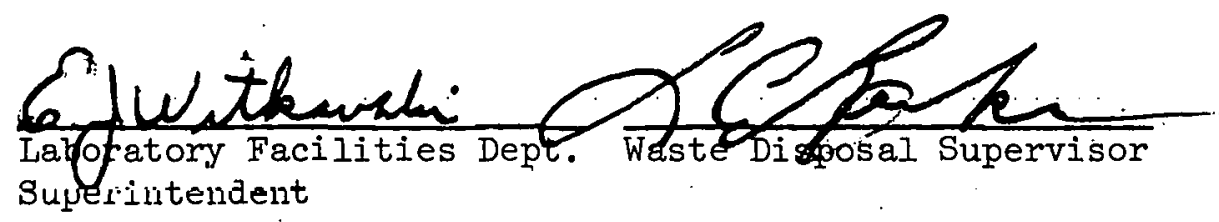


$2-25-76$

General Description

The Permutit Package Precipitator is designed for the removal of turbidity, color, organic matter, and the reduction and control of alkalinity.

The Permutit Package Precipitator is a sludge blanket clarifier. It consists of a mixing-coagulation zone, a sludge filter zone, and a clear zone. Raw water and chemicals enter at the top of the Precipitator's mixing coagulation compartment. Flow is downward under a dividing partition into the bottom of the sludge filter zone. The water flows up through the sludge blanket to a collector at the top which carries the clarified effluent into the outlet pocket and then overflows into surge tank L-2.

The normal sludge that is formed is blown off under automatic control. Heavy sludge in the port area is blown off under manual control.

\subsection{Personnel Requirements}

A. A waste disposal supervisor, available on a 24 hour call-in basis, who is responsible for the treatment operations.

B. A chemical operator who performs the mechanical, sampling, and analytical functions required to operate the plant.

1.4. Prccautions

A. The clarification area is a goggle area.

B. Do not stand on the settler modules.

C. Do not start Milroyal pumps against a closed valve.

\subsection{Procedures}

A. Feed pimps located in Bldg. 3518 tranjfer waste waler frum lhe equalization basin into clarifier L-IA for treatment with copperas and $\mathrm{NaOH}$. The soft, clear effluent from the clarifier overflown into surge tank L-2; it is pumped through a polishing filter and then an ion exchange column which removes the bulk of the radio-
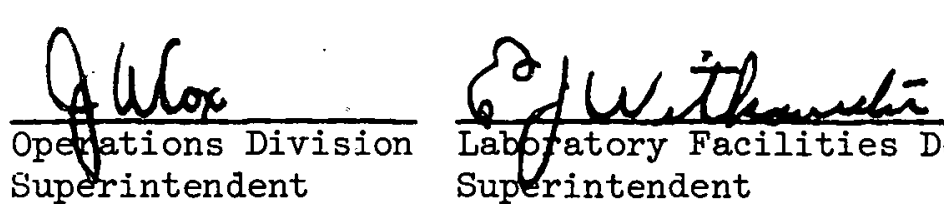
Suptrintendent 


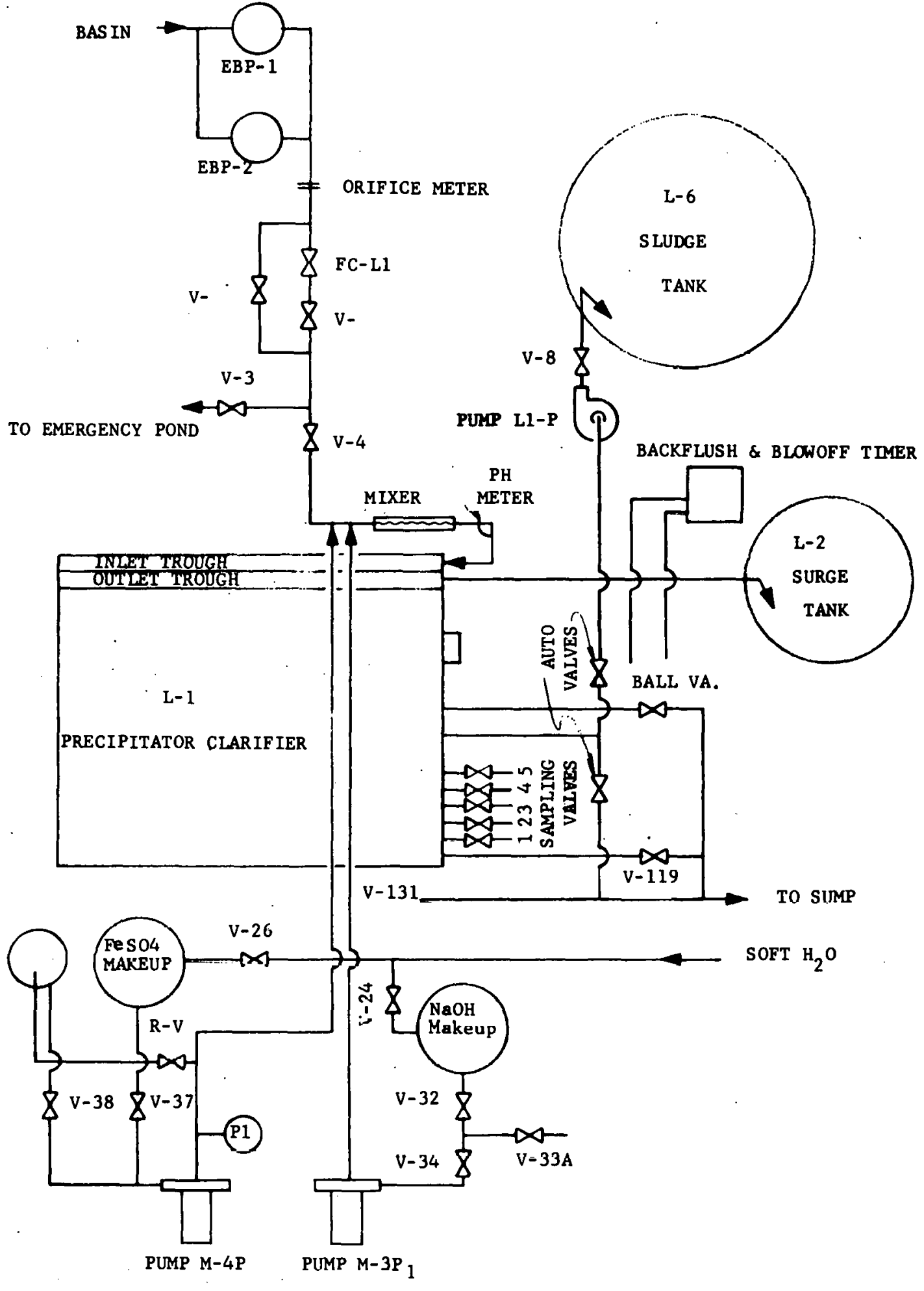

PRECIPITATOR CLARIFIER SYSTEM 
activity. The column discharges into a holdup tank where the water is neutralized with $\mathrm{H}_{2} \mathrm{SO}_{4}$ and allowed to overflow into White Oak Creek.

The following steps prepare the plant for startup:

1. Make up chemical feed solutions.

a. Copperas $\left(\mathrm{Fe}_{2} \mathrm{SO}_{4} \cdot 7 \mathrm{H}_{2} \mathrm{O}\right)$

1. Close V-37 at bottom of tank M4A.

2. Open V-26 and add 140 gallons of soft water to tank M-4A. Turn on agitator $\mathrm{M}-4 \mathrm{~A}$ and add $100 \#$ of $\mathrm{Fe}_{2} \mathrm{SO}_{4}-\mathrm{H}_{2} \mathrm{O}$. Continue agitation until dissolution is complete.

b. $3 \mathrm{~N} \mathrm{NaOH}$

1. Cluse valves $V-31$ and $V-33 A$ at bottom of tank $M-3 A$.

2. Open $V-23$ and add 282 gallons of water into $M-3 A$.

Then turn on Mm-3A mixer.

3. Open V-44 and V-82 at tank M-1. Then turn on pump M-1 P (check seal water on).

4. Open $V-22$ (at $M-3 A$ ) and adjust the $M-3 A$ volume to 335 gallons with $\mathrm{NaOH}$.

5. 'l'urn M-1 P off (stop seal water flow). Then close V-44 and $\mathrm{V}-82$.

6. Allow M-3A mixer to operate for 10 minutes after caustic addition is complete. Then stop mixer.

7. Record $M-3 A$ volume: gallons.

2. Align valves at the following stations ( $O=$ open, $X=$ closed $)$ :

a. Fead pumpe EB...P-I and P-2.

\begin{tabular}{|c|c|c|c|}
\hline EBP-1 & 0 & $\mathrm{FBP}-3$ & $\cap$ \\
\hline EBP-2 & 0 & $\angle B P-4$ & 0 \\
\hline
\end{tabular}

b. Control valve PCV-Ll.

$v-1 \cdots \frac{0}{\mathrm{X}}$

$\mathrm{V}-2 \cdot \underline{0}$

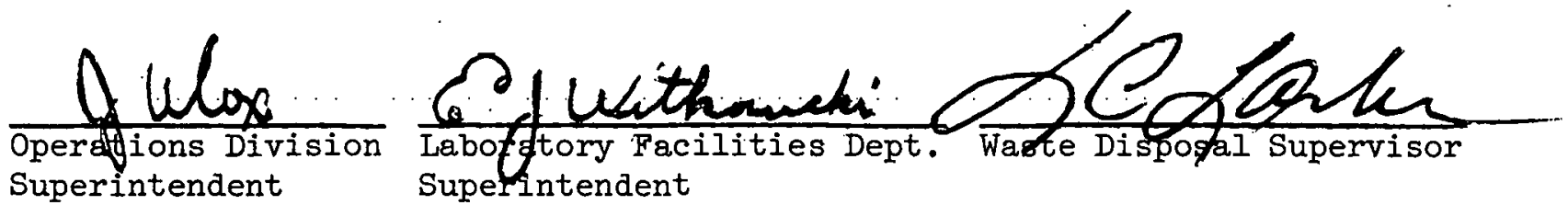


$2-25-76$

c. Valve pit \#I.

$\mathrm{V}-3 \frac{\mathrm{X}}{\mathrm{V}-4} \mathrm{O}$

d. Sludge blowdown system.

Soft water, $\mathrm{V}-13 \mathrm{I}$

Pump L-IP, V-8 0

Air supply to control valves $\mathrm{V}-100$ and $\mathrm{V}-101$ :

\begin{tabular}{llll}
$V-104$ & 0 & $V-107$ & 0 \\
$V-105$ & 0 & $v-108$ & 0 \\
$V-100$ & 0 & $v-109$ & 0 \\
\hline
\end{tabular}

e. Copperas feed pump M-4P.

$\begin{array}{llll}V-37 & 0 & V-39 & 0 \\ V-38 & 0 & v-97 & 0\end{array}$

f. $3 \mathrm{~N} \mathrm{NaOH}$ feed pump M-3Pl.

\begin{tabular}{llll}
$V-31$ & $\frac{0}{\mathrm{X}}$ & $V-34$ & 0 \\
$V-32$ & $\frac{\mathrm{X}}{\mathrm{V}}$ & $\mathrm{V}-35$ & $\frac{0}{\mathrm{~V}}$ \\
$\mathrm{~V}-33$ & $\mathrm{~V}-98$ & 0 \\
\hline
\end{tabular}

$\mathrm{V}-33 \mathrm{~A}$

g. Column feed pumps L-2P1 and L2P2.

$\begin{array}{lllll}V-12 & 0 & V-14 & 0 \\ V-13 & 0 & V-15 & 0\end{array}$

h. Polishing filters $\mathrm{L}-3 \mathrm{~A}$ and $\mathrm{L}-3 \mathrm{~B}$.

1. To use I-3A:

$\mathrm{V}-16 \frac{\mathrm{O}}{\mathrm{X}} \quad \mathrm{V}-18 \frac{\mathrm{X}}{\mathrm{V}-19}$
3A multiport valve - FILTER
3B multiport valve - REWASH

Alulax Operatipns Division Superimdendent
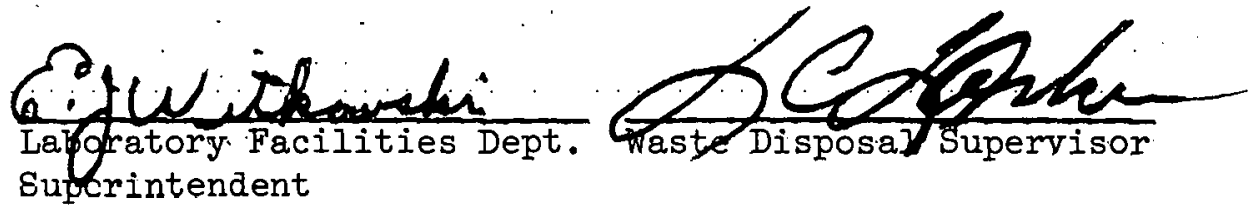
2. To use $\mathrm{L}-3 \mathrm{~B}$ :

$$
\begin{aligned}
& \begin{array}{llll}
V-16 & \frac{X}{X} & V-18 & \frac{X}{X} \\
V-17 & 0
\end{array} \\
& 3 A \text { multiport valve - REWASH } \\
& \text { 3B multiport valve - FILTER }
\end{aligned}
$$

B. Start up the plant by performing the following steps at the control panel.

1. Set FC-Ll to manual control and close FCV-LI.

2. Set FFY-LIB at 0.5 . Start $\mathrm{M}-\mathrm{P} 4$.

3. Jel $A C=I=I A$ to ivintiol at $\Gamma I I$ il.8. Dtart M-3F.

4. Start feed pump EBP-1.

5. By manually adjusting $\mathrm{FC}-\mathrm{LI}$, increase the f'low to $\mathrm{L}-1 \mathrm{~A}$ by increments of 10\% until the desired flow rate is reached. Allow a lapse of 5 minutes between flow adjustments.

6. Start agitator motor I-IP when the clarifier is about $1 / 3$ full.

7. Set IC-12 to manual control and close valve LV-L2.

8. Start $\mathrm{L}-2 \mathrm{PI}$ when the $\mathrm{L}-2$ level reaches $40 \%$.

9. Put $\mathrm{L}-4 \mathrm{~A}$ on line by opening $\mathrm{HVL}-4 \mathrm{~A}-1$ and HVL-4A-2.

10. Slowly open valve LV-L2 by gradually increasing the output pressure on LC-L2. This will start a slow, controlled flow to the polishing filter. When the build up in tank L-2 stops, set the control point at this level and switch LC-L2 to auto control.

11. Start M-8P. Ad,just stroke so that the $\mathrm{pH}$ of $\mathrm{H}_{2} \mathrm{O}$ from $\mathrm{L}-5$ is $7.0_{-0.5}^{+}$.

12. When the sludge blanket in the clarifier reaches sample point $\# 4$, start pump L-IP. This pump operates on a time cycle - see Sludge Removal System, Procedure E.

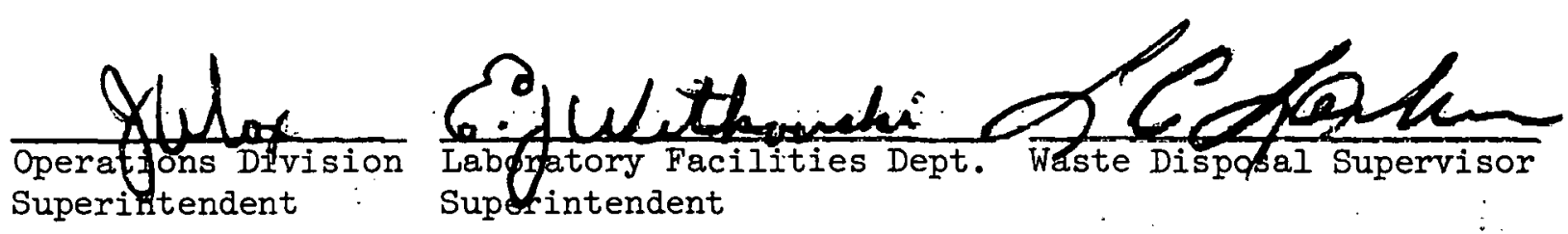


$2-25-76$

C. Chemical Control

The optimum chemical concentrations needed for proper operation have been determined by pilot plant operation: $0.01 \mathrm{~N}$ in $\mathrm{OH}^{-}$and 5 ppm $\mathrm{Fe}^{2}$. The resultant $\mathrm{pH}$ of 11.8 enhances cesium retention on the exchange resin and the copperas is oxidized to ferric hydroxide which precipitates as a large floc that adsorbs the smaller precipitated particles. Most of the dissolved calcium and magnesium precipitate as carbonate and hydroxide, combine with the ferric hydroxide floc, and carry down dirt and some radionuclides. The dose rates for a waste water feed rate of $200 \mathrm{gpm}$ are:

1. Copperas: $0.06 \mathrm{gpm}$ of a $86.28 \mathrm{gm} /$ liter solution.

2. $\mathrm{NaOH}$ : $0.20 \mathrm{gpm}$ of a $10 \mathrm{~N}$ solution.

This should produce water of less than $10 \mathrm{ppm}$ hardness $\left(\mathrm{CaCO}_{3}\right)$ and 5 ppm Jackson Turbidity units.

The chemical solutions are fed into the clarifier line mixer by 2 each Milroyal pumps equipped with Pneumatic Capacity Control. $\mathrm{PH}$ controller AC-L-1A automatically controls the $\mathrm{NaOH}$ feed rate by pneumatically changing the stroke of M-3P. The ferrous sulfate feed is controlled in a similar manner; however, the controlling variable is the flow rate into the clarifier; controller FFY-LIB adjusts the stroke of $M-4 P$ at a rate proportional to the FC-II output.

D. Control of Sludge Blanket

Proper control of the density and level of the sludge blanket is important for gnon nperating results. With the correct chemical dosages, the sludge blanket can be controlled by adjusting the blowoff rate.

Five sample lines are provided for checking the condition of the sludge blanket and the effluent.

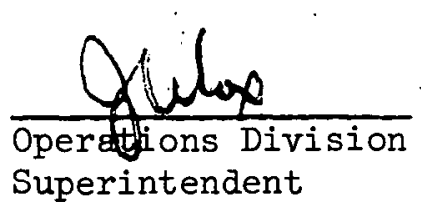

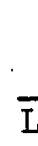
Superintendent 
Sample \#l - Upper Mixing Zone

Sample \#2 - Lower Mixing Zone

Sample \#3 - Upflow Zone

Sample $\# 4$ - Upflow Zone

Sample \#5 - Effluent Pocket

Collect samples from sample points \#l and \#2. Collect $100 \mathrm{ml}$. from each point in a graduated cylinder. Then allow the cylinders to stand undisturbed. After 10 minutes, observe the upper level of the sludge layer. Read this graduation as the sludge density in this sample (per cent by volume). 'lhe intormation on sliudge density from these samples is used to control operation in the following way:

\section{l.. Agitator Speed}

The agitator drive motor and worm gear speed reducer are provided with step-cone sheaves so that four speed adjustments are possible.

During normal operation the agitator speed reducer should be run at as high a speed as possible without causing disturbance of the sludge blanket.

Collect samples from sample lines \#l and \#2, and read the SLUDGE DENSITY AFTER 10 minutes quiet settling. The sludge density in the upper mixing zone (SAMPLE \#1) should be within 25\% to $75 \%$ of the sludge density in the lower mixing zone (SAMPTE \#?). EXAMPLE: If Sample \#2 reads 16\% (upper level of sludge layer is at the $16 \mathrm{ml}$. mark) Sample \#l should be somewhere between $\left(16 \times \frac{25}{100}\right)=4 \%$ density and $\left(16 \times \frac{75}{100}\right)=12 \%$ density for best operation.

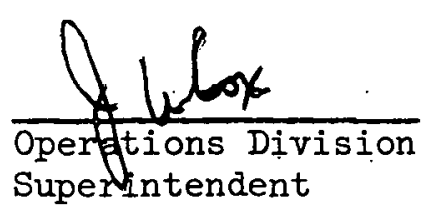

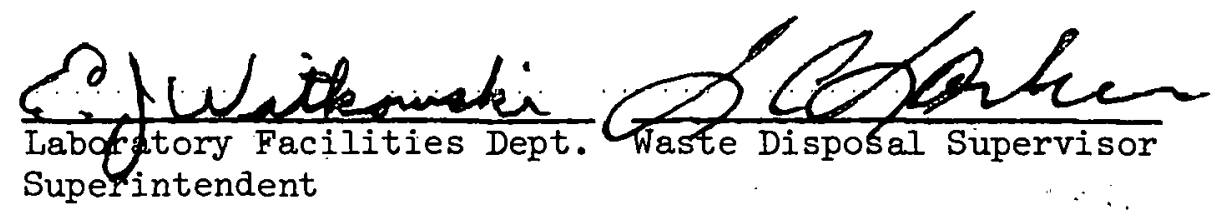


If the sludge density in SAMPIE \#i is too low, compared with \#2, then INCREASE the speed of the agitator. If SAMPLE \#I density is too close to being the same density as SAMPLE \#2, DECREASE the agitator speed.

If the sludge density in SAMPIE \#I is too low, compared with \#2, then INCREASE the speed of the agitator. If SAMPLE \#I density is too close to being the same density as SAMPLE \#2, DECREASE the agitator speed.

After each adjustment in agitator speed, wait at least 30 minutes before making the next test.

Note: This is a general rule which applies for most--but not for all type waters. In some cases it may not be possible to operate within the limits described above. If so, set the agitator at the highest speed which will not disturb the sludge blanket in the upflow zone.

\section{Sludge Blowoff}

The sludge blowoff discharges to waste intermittently on a timed cycle. See system description. This bleedoff of sludge, and the rate at which the Precipitator is treating water, are the main factors which determine the height of the SLUDGE BLANKET. Adjust the flowoff flow rate and timer duration so that during operation the top of the sludge blanket is maintained between sample points \#3 and \#4. Increasing the rate and/or time of hlowhown will lower the level of the blanket. Cutting back on this will raise the blanket level. During operation, check the blanket level frequently enough to maintain the top of the blanket between sample points \#3 and \#4. To locate the top of the sludge blanket, draw a sample from the various points. When sludge appears in any sample, the top of the blanket lies between that point and the next higher point.

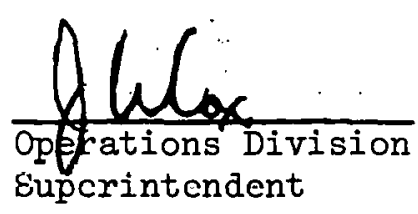

Eupcrintendent
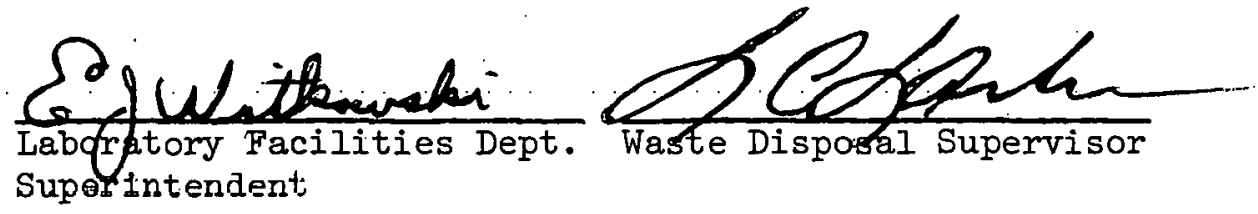
If the flow rate through the unit is increased, the blanket level will immediately rise. Therefore, whenever an increase in rate is expected, such as backwashing of filters and purifiers, the blanket level should be lowered beforehand. This depends to a great degree on the nature of the water being treated and is best determined by experience. Under conditions where the flow rate fluctuates frequently, set the blanket between points $\# 3$ and $\# 4$ at the maximum rate. Whenever a change is made in the dosage of any chemical, aliow several hours to elapse before taking any samples for tests. This will give sufficient time for new conditions to become stabilized throughout the system.

\section{E. Sludge Removal System}

The sludge zone is intermittently blown off, and the piping reverse flushes, under automatic control.

A sludge header in the sludge zone connects to waste through a diaphragm valve in the discharge line. Pressure to the diaphragm of the sludge valve is controlled by a solenoid valve through a manually set 4-way valve. When the solenoid is energized, pressure is relieved from the valve diaphragm. This causes the Aquamatic valve V-I0I to open, assisted by the valve spring. Precipitator desluages, $I-I F$ pums to $I=G$, until the blówot't timer vimes vul. When the timer times out, the solenoid is de-energized, closing the vent port and applying pressure to the blowoff valve V-i0l diaphragm. This closes the blowoff valve. Every 20 minutes the cycle is repeated.

Olulas Opeptions Division Superintendent

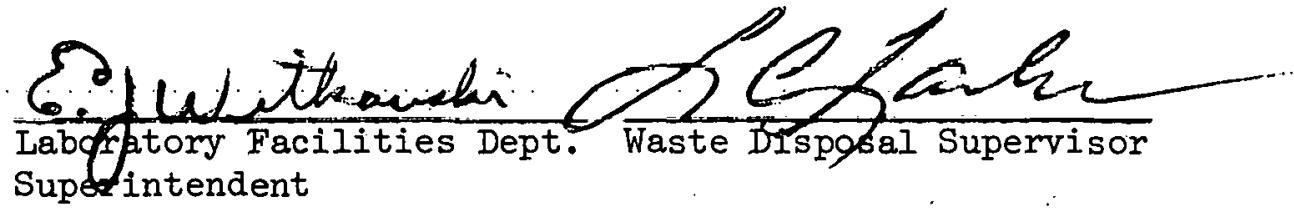


The flushback also is controlled by a separate time and diaphragm valve and operates in exactly the same manner. When the times are synchronized (see pages $\mathrm{C}-2$ and $\mathrm{C}-3$ Permutit Operating Instructions), the flushback will occur one (I) minute before blowoff every time around.

The manual 4-way valve has 3 operating positions. For normal operation, place handle in "AUTO" position. To open the blowoff valve at any time, move handle so that it points to "OPEN" which vents the line and opens the blowoff (of flushback) valve. In like manner, automatic valves may be closed by rotating handle to "CLOSE" position.

A port header blowdown system also is supplied in addition to the normal sludge blowoff system. The port header is located at the bottom of the mixing zone and provides for the removal of grit and sludge particles too heavy to be lifted to the concentrator section. The port header blowoff system is operated manually at periodic intervals. Suggested blowoff is for 20 or 30 seconds, once or twice a day. Flush out the header just before blowoff.
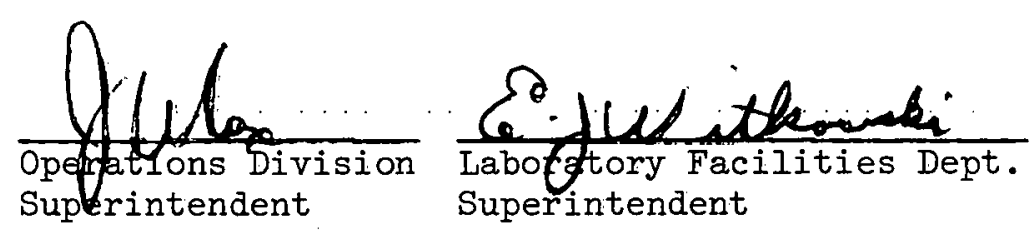

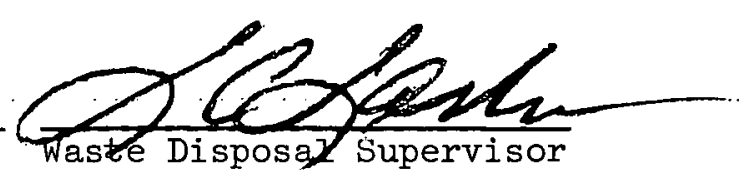




\subsection{POLISHING FILTERS L-3A AND L-3B}

\subsection{References}

Permutit Operating Instructions for Filters and Carbon Purifiers with Multiport Valves

Permutit Dwg. 184-6536, Filter Layout

Permutit Dwg. 102-33600, Strainer Assembly

Permutit Dwg. 101-36157, Internal Assembly

ORNL Dwg. P-21246-EE-002, Process Engineering Flowsheet No. 1 ORNL Dwg. P-21246-EE-041, Precipitator Clarifier Process Piping

\subsection{Introduction}

\section{DATA}

1. Number of Units

2. Size - diameter

$$
\text { - height }
$$

3. Maximum Operating Pressure

4. Maximum Operating Temperatures

5. Under Drain (type)

6. Valve (type)

7. Operation

8. Filter Bed (type)

9. Filter Bed

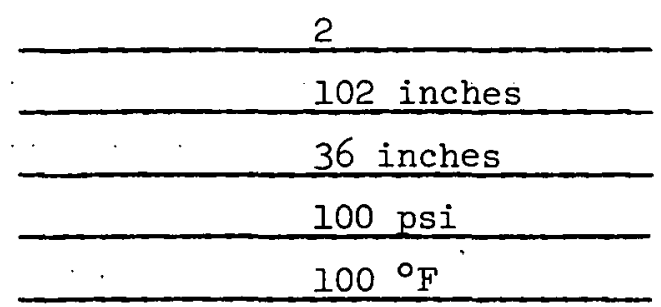

Double drain with strainers

$\frac{\frac{6 \text { in. Multiport }}{\text { Manual }}}{\frac{\text { Anthracite }}{155 \mathrm{ft}}}$

10. Operating Rates
a. Filter, maximum
b. Backwash
Duration
c. Rewash
Duration

\begin{tabular}{l}
\hline $.170 \mathrm{gpm}$ \\
\hline$\ldots 10 \mathrm{gom}$ \\
\hline $170 \mathrm{gpm}$ \\
\hline
\end{tabular}

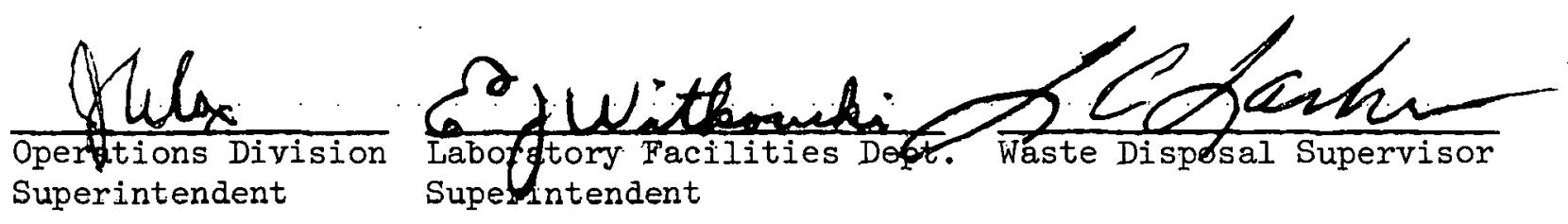



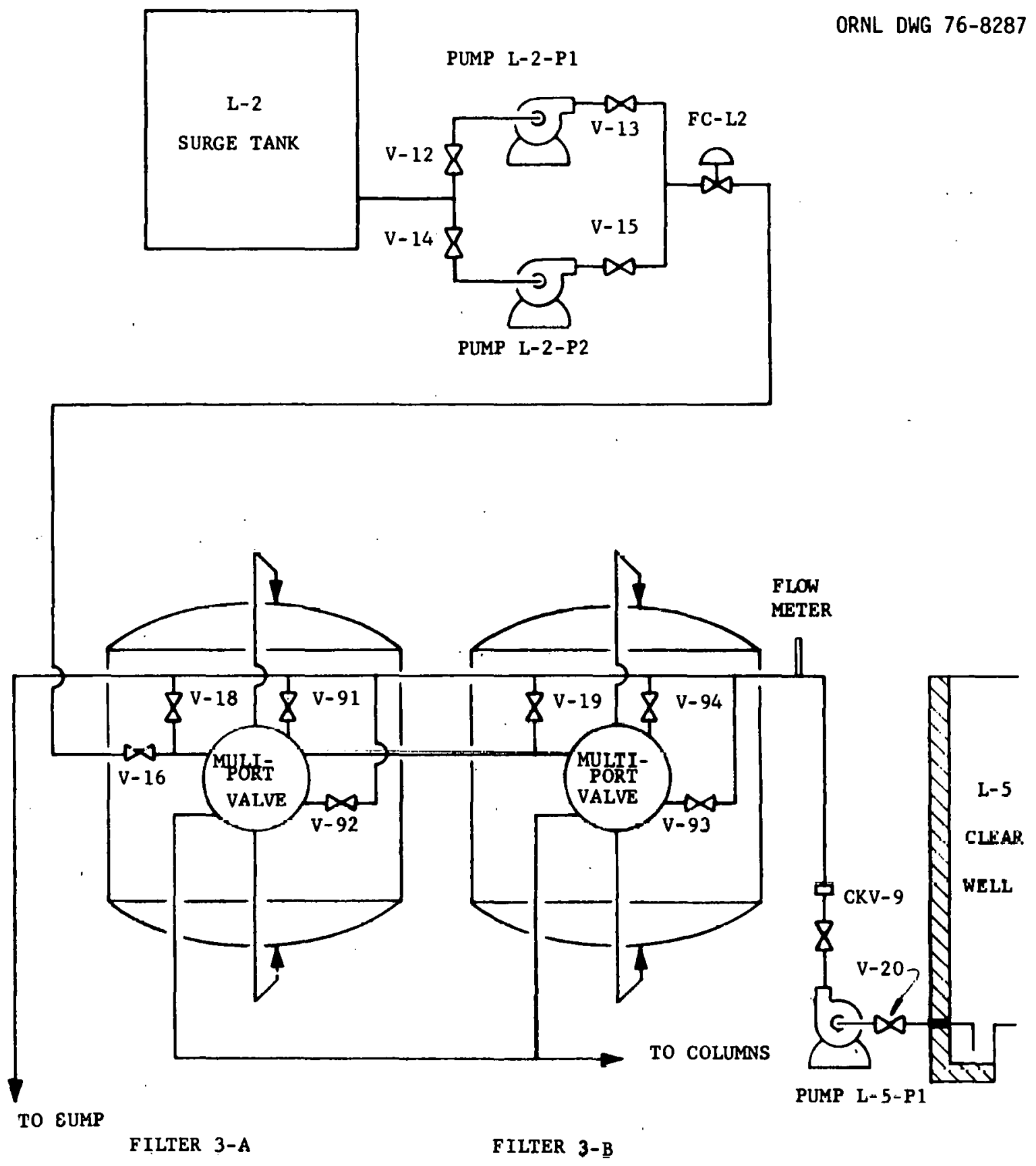
$2-25-76$

\subsection{Personnel Requirements}

A. A waste disposal supervisor, available on a 24 hour call-in basis, who is responsible for the treatment operations.

B. A chemical operator who performs the mechanical, sampling, and analytical functions required to operate the plant.

\subsection{Precautions}

A. The clarification area is a goggle area.

B. Always rotate multiport valve in direction indicated by arrow.

C. Open valves admitting flow to filter units slowly. This prevents surges which might upset filter media or damage strainers.

\subsection{Procedures}

A. To filter: Set valve positions as follows $(0=$ open, $X=$ closed $)$ :

1. $\mathrm{L}-3 A$ on istream, $3 B$ standby.

\begin{tabular}{llll}
$\mathrm{V}-16$ & $\mathrm{O}$ & $\mathrm{V}-18$ & $\mathrm{X}$ \\
$\mathrm{V}-17$ & $\mathrm{X}$ & $\mathrm{V}-19$ & $\mathrm{X}$ \\
\hline
\end{tabular}

Multiport valve $3 \mathrm{~A}$ is in Filter position.

Multiport valve $3 B$ is in Rewash position.

2. $L-3 B$ is on stream, $3 A$ standby .

\begin{tabular}{|c|c|c|c|}
\hline$v-16$ & $X$ & $V-18$ & $\mathrm{X}$ \\
\hline$V-17$ & 0 & V-19 & $X$ \\
\hline
\end{tabular}

Multiport valve $3 \mathrm{~A}$ is in Rewash position.

Multiport valve $3 B$ is in Filter position.

B. Backwash: When the pressure drop across a filter increases 5-6 psi over normal pressure drop with a clean bed, or the quality of the effluent has deteriorated, the filter should be backwashed to clean it.

Set valves as follows $(0=$ open, $X=$ closed $)$ :
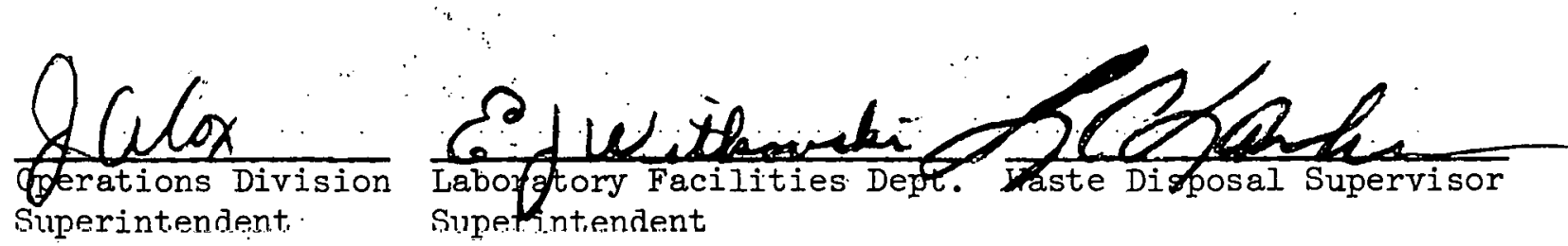
1. Backwash L-3A, L-3B on stream.

\begin{tabular}{|c|c|c|c|c|c|}
\hline$v-16$ & 0 & $V-19$ & $\mathrm{X}$ & $V-91$ & $1 / 4$ \\
\hline$V-17$ & 0 & $\mathrm{~V}-20$ & 0 & V-92 & $X$ \\
\hline V-18 & $x$ & $V-2 I$ & 0 & & \\
\hline
\end{tabular}

a. Rotate multiport $3 \mathrm{~A}$ to wash position:

b. Start pump L-5Pl. Slowly open V-18 to full open and adjust flow to $570 \mathrm{gpm}$ by throttling V-91. Backwash unit 10 minutes.

c. Rotate multiport $3 A$ to Rewash position. Adjust flow to 170 gpm by throttling valve 92. Rinse unit for 3 minutes. Shut down $\mathrm{L}-5 \mathrm{P} I$ and close valve $\mathrm{V}-18$.

2. Backwash $\mathrm{L}-3 \mathrm{~B}, \mathrm{~L}-3 \mathrm{~A}$ on stream

\begin{tabular}{|c|c|c|c|c|c|}
\hline$v-16$ & 0 & $V-19$ & $\mathrm{X}$ & $V-94$ & $1 / 4$ \\
\hline V-17 & $x$ & $V-20$ & 0 & V-93 & $\mathrm{X}$ \\
\hline V...18 & $\mathrm{X}$ & $V-2 I$ & 0 & & \\
\hline
\end{tabular}

a. Rotate multiport $3 \mathrm{~B}$ to Wash position.

b. Start pump L-5PI. Slowly open V-19 to full open and adjust flow to $570 \mathrm{gpm}$ by throttling V-94. Backwash unit 10 minutes.

c. Rotate multiport $3 B$ to Rewash position. Adjust flow to 170 gpm by throttling valve V-93. Rinse unit t'or 3 minutes. Shut down L-5PI and close valve V-I9.
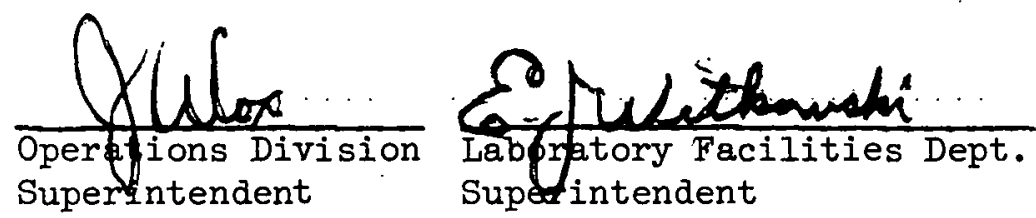

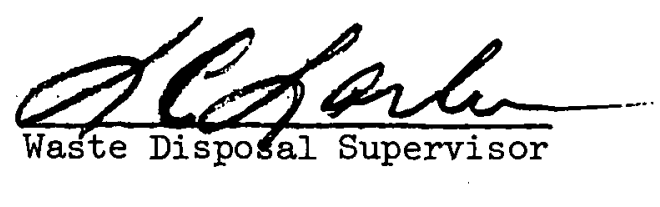




\subsection{ION EXCHANGE PROCESS}

\subsection{References}

ORNL Dwg. M-21246-EE-026, Ion Exchange Column L4A, B \& C Details Sheet No. 1

ORNL Dwg. M-21246-EE-027, Ion Exchange Column L4A, B \& C Details Sheet No. 2

ORNL Dwg. P-21246-EE-031, Ion Exchange Room - Process Piping Plan \& Elevation F-F

ORNL Dwg. P-21246-EE-032, Ion Exchange Room - Process Piping Elevation G-G \& H-H

Diamond Shamrock Tech Sheet 100: Duolite C5-100

\subsection{Introduction}

The ion exchange phase of the treatment process consists of 3 each, $12^{\prime}$ ht. $x 3^{\prime}$ OD, 304L SS resin columns with a rated throughput of 100 gpm. The columns are loaded with $45 \mathrm{ft}^{3}$ of Duolite CS-100, a weak acid cation exchange resin. The rated capacity of each column is 2000 bed volumes of approximately 660,000 gallons. The columns are designed for counterflow with upflow in the regeneration phase. The maximum upflow velocity in regeneration is $4-5 \mathrm{~cm} / \mathrm{minute}$ for nitric acid and $6-8 \mathrm{~cm} /$ minute for caustic solution. Column design provides a $50 \%$ free board for resin expansion during regeneration.

After filtration, the clarified effluent having less than $10 \mathrm{ppm}$ of hardness is fed to a cation exchange column containing sodium-form Duolite CS-100 resin. This is a phenolic-carboxylic cation exchange resin (a weak-acid type resin), which was selected because of its high preference for sorbing cesium over sodium present in the liquid phase. Breakthrough of cesium does not occur until 2000 bed volumes of waste have been fed to the column. To regenerate the resin, the column is

Mulox Opentions Division Superintendent

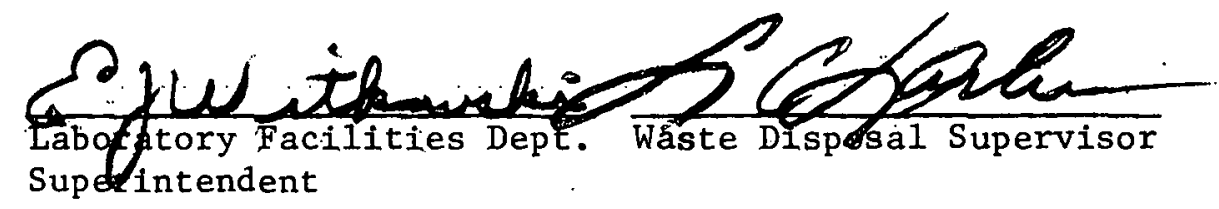


removed from service, back washed with one-half bed volume of water, and upflow eluted with five bed volumes of $0.5 \underline{N}$ HNO remaining from a prior regeneration. This volume of acid effectively removes almost all the sorbed hardness and radioactivity. It is pumped into storage tank L-9 and eventually evaporated: the distillate is adjusted to $0.5 \mathrm{~N}$ and recycled, while the bottoms are transferred to the ILW system. Another five volumes of $0.5 \mathrm{~N} \mathrm{HNO}_{3}$ are then fed to complete the elution; this acid is routed to storage tank $L-8$ for use during the first half of the next regeneration. The bed is then rinsed with one bed volume of water and converted to the sodium form by feeding 20 volumes of $0.1 \underline{\mathrm{N}}$ $\mathrm{NaOH}$ in an upflow mode through the resin.

\section{3 Personnel Requirements}

1. A waste disposal supervisor, available on a 24 hour call-in basis, who is responsible for the treatment operations.

2. A chemical operator who performs the mechanical, sampling, and analytical functions required to operate the plant.

\subsection{Precautions}

1. The chemical makeup and the ion exchange rooms are goggle areas.

2. The makeup of nitric acid solution for the elution of the resin in the columns is one of the most important operations in the plant because the acid concentration is very critical. If the nitric concentration is too low the resin will not be effectively eluted and the quality of the product water will be lowered. More importantly, if the nitric concentration is too high, the resin will be destroyed.

\subsection{Procedures}

A. Exhaustion Phase

1. Align valves as follows $(X=$ closed, $0=$ open) to route flow from filter $\mathrm{L}-3 \mathrm{~A}$ or $\mathrm{B}$ through column $\mathrm{L}-4 \mathrm{~A}$ to clearwell.

\begin{tabular}{|c|c|c|}
\hline 0 & $\mathrm{HVL}-4 \mathrm{Al}$ & $\mathrm{X}$ \\
\hline$n$ & HVT $-4 \mathrm{~A} 2$. & $\mathrm{X}$ \\
\hline
\end{tabular}

2. Align valves as follows $(X=$ closed, $O=$ open) to route flow from filter $L-3 A$ to $B$ tinrough column L-4B to clearwell L-5.

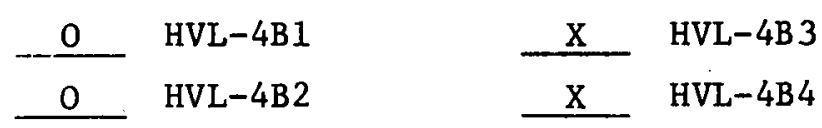




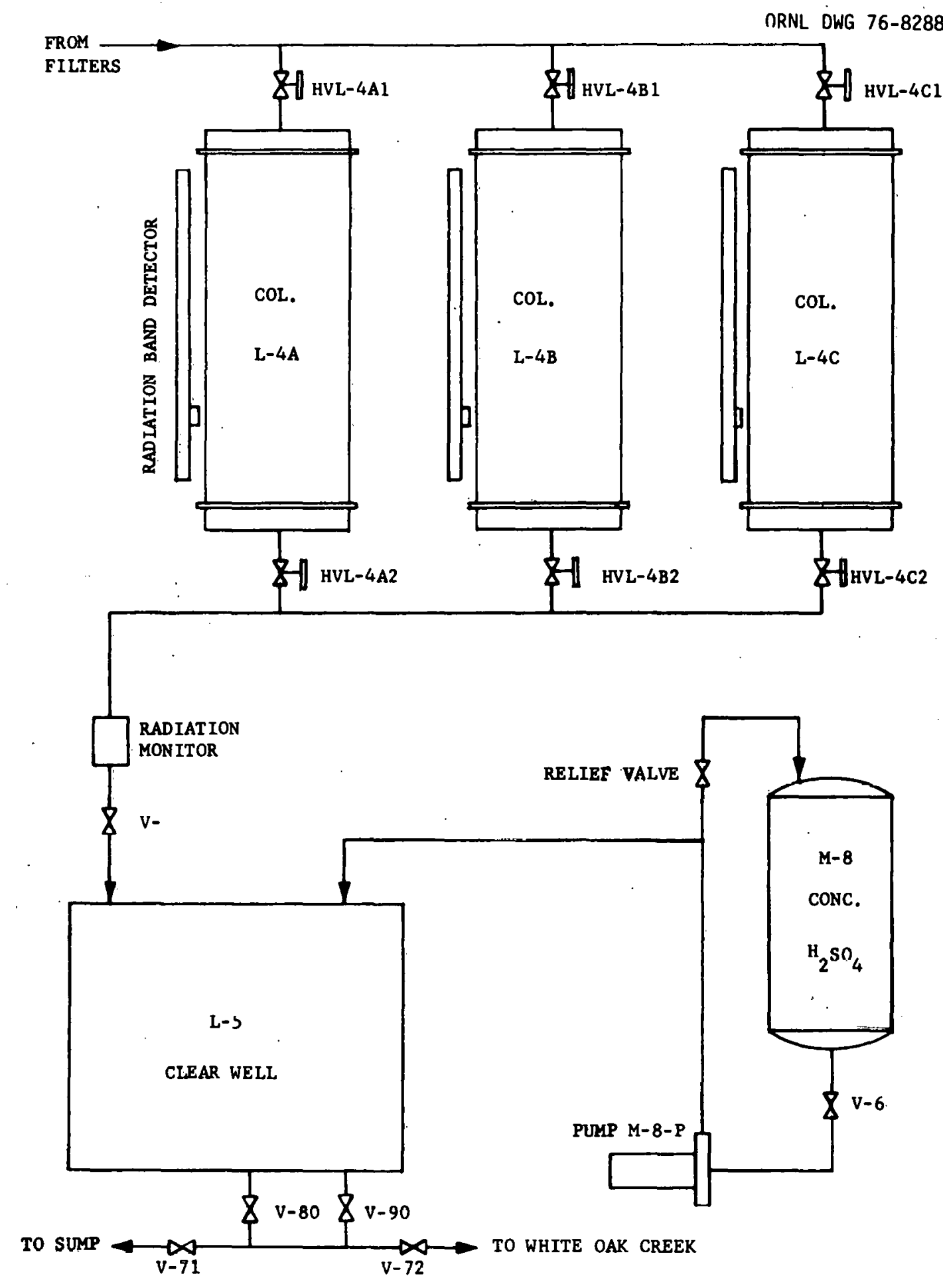

OPERATION OF ION EXCHANGE COLUMNS 
3. Align valves as follows $(X=$ closed, $0=$ open) to route flow from filter L-3A or B through column L-4C to clearwell L-5.

\begin{tabular}{llll}
0 & HVL-4C1 & $\mathrm{X}$ & HVL-4C3 \\
\hline 0 & HVL-4C2 & $\mathrm{X}$ & HVL-4C4 \\
\hline
\end{tabular}

B. Resin Regeneration Phase

The normal regeneration procedure consists of the following steps:

1. Makeup of $0.5 \underline{\mathrm{N}} \mathrm{HNO}_{3}$ in $\mathrm{L}-7$.

2. Acid Elution of Column.

3. Water Wash and Caustic Treatment of Column

4. Eluate Concentration and $\mathrm{HNO}_{3}$ Recovery.

1. Procedure for Makeup of $0.50 \pm 0.05 \mathrm{~N}$ Nitric Acid Solution in L-]

The makeup of nitric acid solution for elution of the ion exchange resin in the columns is one of the most important operations in the plant because the acid concentration is very critical. If the $\mathrm{HNO}_{3}$ concentration is too low the resin will not be effectively eluted and the quality of future pronirt water will be lowered. More importantly, if the $\mathrm{HNO}_{3}$ concentration is too high, the resin will be destroyed. (Note that the resin in each column cost $\$ 3300$. ) In addition, the makeup procedure gets very complicated if too much $\mathrm{HNO}_{3}$ is put into tank L-7 because there is no conventent means for disposal of the excess amount.

At the beginning of this makeup, L-7 will contain approximately 1600 gallons of $<0.1 \mathrm{~N} \mathrm{HNO}_{3}$ from previous operations. Adjust this solution to 1700 gallons ( $86.0 \%$ on LR-L7) of $0.50 \pm 0.05 \mathrm{HNO}_{3}$ by means of the following procedure: Record date this makeup procedure started:

Time Initials

1. Close HV-L7P-2 and open HV-L7P-3. Then open HV-L7P-1 and turn on pump L-J-P (check seal water on prior to starting pump) to circulate solution from $\mathrm{L}-7$ for mixing. Circulate $\mathrm{L}-7$ for 30 minutes.

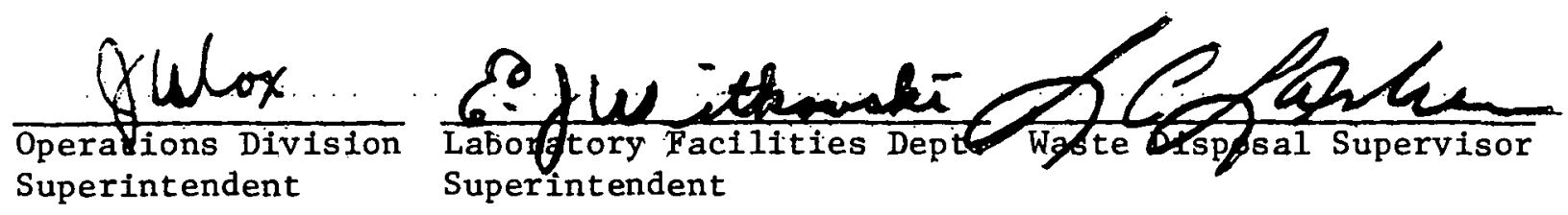




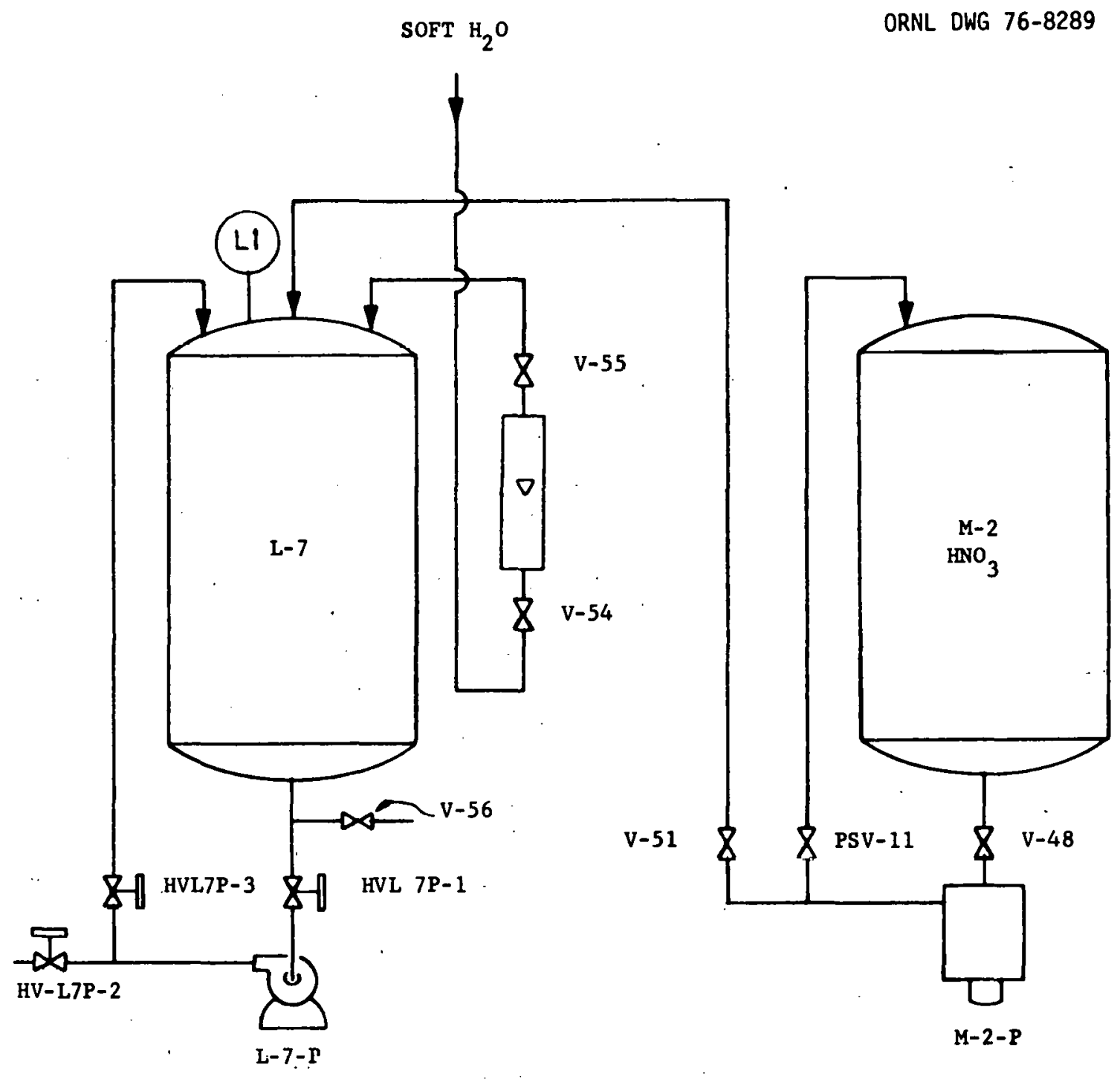

PREPARATION OF . 5N $\mathrm{HNO}_{3}$ SOLUTION 
2. Drain about $250 \mathrm{~m} 1$ from $\mathrm{L}-7$ sample valve $\mathrm{V}-56$. Then obtain a sample of approximately $250 \mathrm{ml}$ in a new, clean poly bottle. Log sample in Sample Book --code "MUE-... . Label sample bottle with this number. Titrate for " $\mathrm{H}^{+}$analysis." Record $\mathrm{H}^{+}$Result: $\underline{\mathrm{N}}$

3. If $\mathrm{H}^{+}$result from Step 2 was less than $0.45 \mathrm{~N}$, proceed as follows:

(a) Calculate:

$\mathrm{L}=$ present $\mathrm{L}-7$ volume (from chart) $=$ gallons.

(b) Calculate:

$$
\begin{aligned}
& T=\frac{L \times\left(0.50-H^{+}\right)}{13.0} \\
& T=\ldots
\end{aligned}
$$

(c) Transfer … stock $\mathrm{HNO}_{3}$ from M-2 to L-7 as follows:

(1) Set M-2-P micrometer stroke adjustment on $50 \%(1.0 \mathrm{gal} / \mathrm{min})$.

(2) Open $V-48$ and $V-51$.

(3) Se.t $M-2-P$ timer on " $T$ " minutes. Then $\varepsilon$ tart $M-2-P$.

(4) When transfer is complete, check that M-2-P is off. Then rinse $V_{r} 48$ and $V-51$. Finally, record LR-L7 reading: $\%$.

(5) Continue circulating the $0.5 \underline{\mathrm{N}} \mathrm{HNO}_{3}$ solution with L-7-P for at least 30 minutes.

(6) Drain about $250 \mathrm{ml}$ from L-7 sample valve $\mathrm{V}-56$. Then obtain a sample of approximately $250 \mathrm{~m} 1$ in a new, elean poly bottle. Log sample in

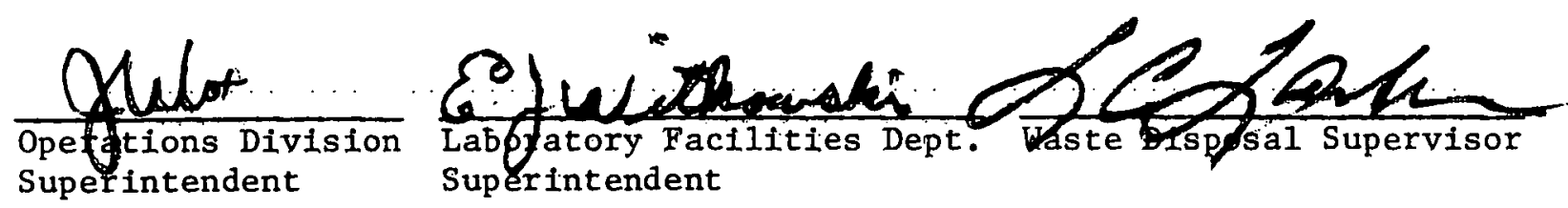


Time Initials

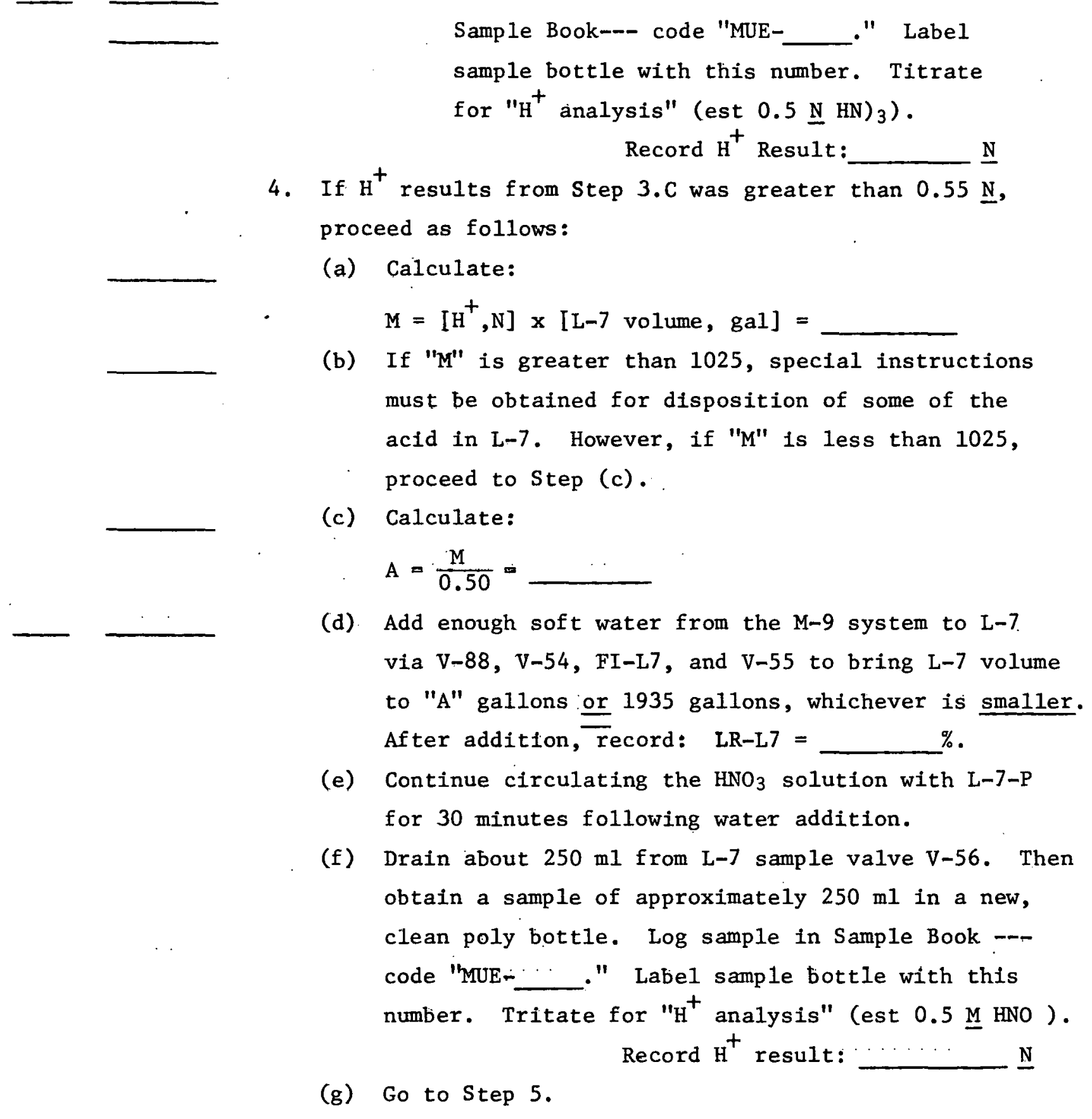

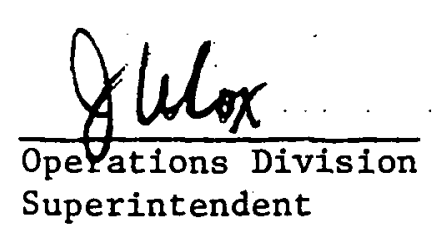

Ejwithe: Labora ofy Pacilities Dept. Superincendent 
Time Initials 5. Confirm $\mathrm{H}^{+}$result in specified range as follows:

(a) Continue to circulate $\mathrm{HNO}_{3}$ solution with L-7-P for at least 15 minutes since last sample was taken.

(b) Drain about $250 \mathrm{ml}$ from L-7 sample valve V-56. Then obtain a sample of approximately $250 \mathrm{ml}$ in a new, clean poly bottle." Log sample in Sample Book --_ code "MUE-_____." Label sample bottle with this number. Submit sample for "H" analysis" (est $0.5 \mathrm{MNNO}_{3}$ ).

$$
\text { Record } \mathrm{H}^{+} \text {result: }
$$
N

(c) If confirming $\mathrm{H}^{+}$result is between 0.45 and $0.55 \mathrm{~N}$, makeup is complete and batch is ready to use. Record LR-L7 Volume: gallons.

(d) Stop $L-7-P$ and turn off seal water. Also close HV $-\mathrm{L} 7 \mathrm{P}-\mathrm{I}$.

(e) Record date completed:

2. Acid Elution of Columi

Date Started

CAUTION: Even with "in-spec $\mathrm{HNO}_{3}$ " ( 0.45 to $\left.0.55 \underline{\mathrm{N}}\right)$, the time of contact with the resin must be minimized to prevent resin degradation. Therefore, as soon as this acid elution procedure is completed, proceed immediately to the water wash step (Section 3). If an extended interruption of the acid elution procedure is necessary, skip to the water wash step and complete that before stopping. Remember: Do not leave $\mathrm{HNO}_{3}$ standing in the column for periods longer than one hour.
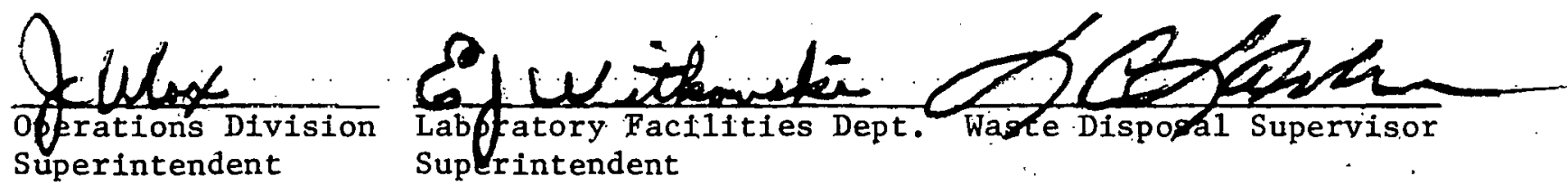


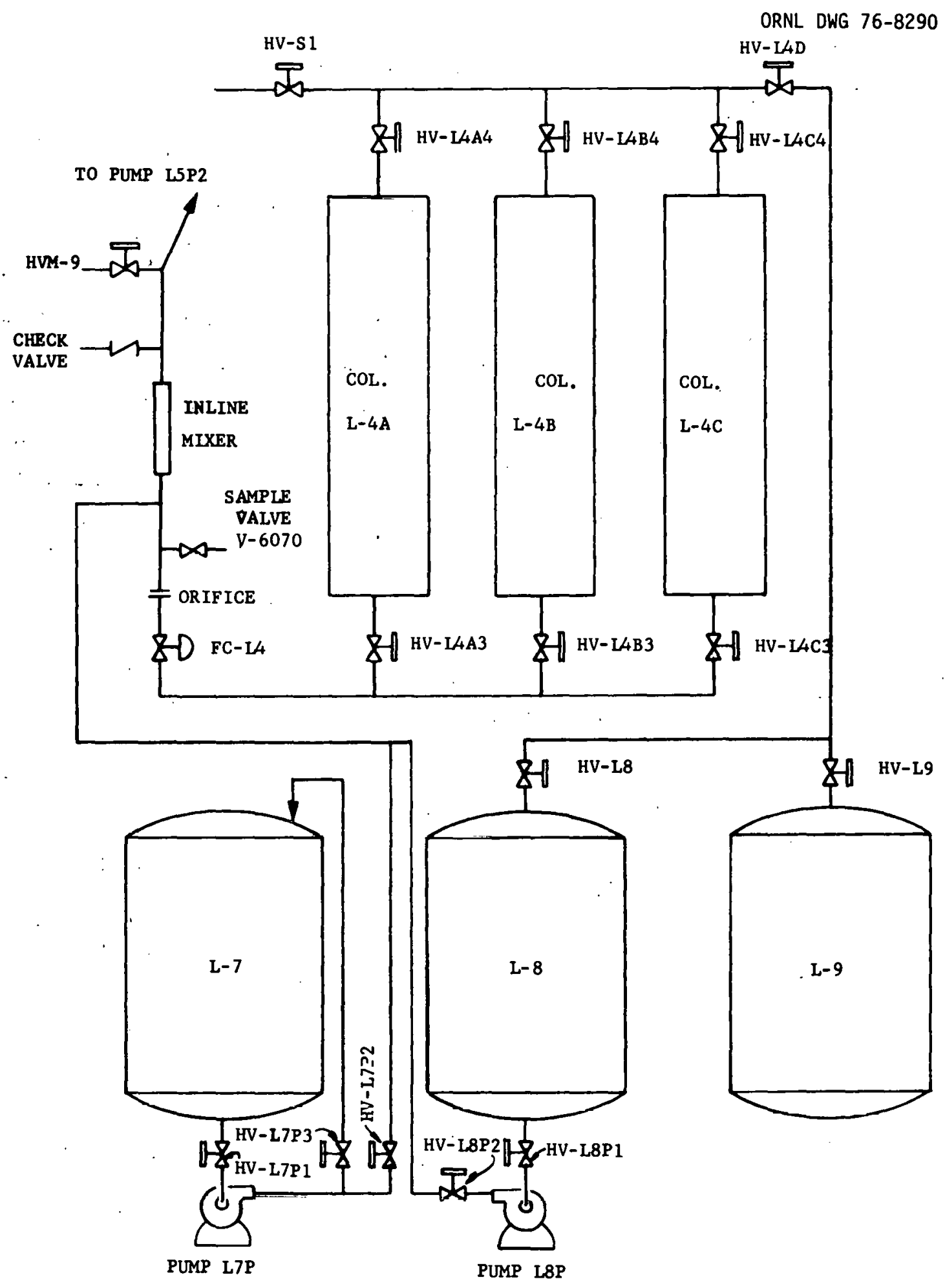

ACID ELUTION OF ION EXCHANGE COLUMNS 
Time Initials

1. Note the following tank contents at the beginning of this elution:

L-7: Will contain approximately 1700 gal of $0.50 \pm$

$0.05 \cdot \underline{N} \cdot \mathrm{HNO}_{3}$ after completion of makeup per Section 1 .

L-8: Will contain approximately $1700 \mathrm{gal}$ of recycle

acid - 2nd acid elution step.

L-9: ' Should be empty.

2. Elute exhausted column with recycle acid from $1-8$ as follows!

(a) Set FC-L4 on zero.

(b) Set valves as follows $(X=$ closed, $0=$ open) to route flow from tank $\mathrm{L}-8$ through column

$A_{2} B_{2}$ or $C$ to sump.

\begin{tabular}{|c|c|c|c|}
\hline X & $V-88$ & HV-L9 & $\mathrm{X}$ \\
\hline $\mathrm{X}$ & HV-M9 & $V-60$ & $\mathrm{X}$ \\
\hline $\mathrm{X}$ & HV-L5P2-1 & HV-L9P-1 & $\mathrm{X}$ \\
\hline $\mathrm{x}$ & HV-L $5 \bar{P} 2-2$ & $\mathrm{H} V-\mathrm{S} 1$ & 0 \\
\hline $\mathrm{X}$ & $H V-L J P-1$ & HV-L4D & $\mathrm{X}$ \\
\hline $\mathrm{X}$ & $H V-L 7 P-2$ & $\begin{array}{l}\mathrm{HV}-\mathrm{L} 4 \Lambda, \mathrm{B} \\
\text { or } \mathrm{C}-1\end{array}$ & $\mathrm{X}$ \\
\hline
\end{tabular}

$\underline{\mathrm{X}}$ HV-L7P-3 HV-L4A,B

or $\mathrm{C}-2$ ?

$\underline{\mathrm{X}} \mathrm{HV}-\mathrm{L} 8, \quad \mathrm{HV}-\mathrm{L} 4 \mathrm{~A}, \mathrm{~B}$

$\begin{array}{ll}\mathrm{O} H V-L 8 P-1 & \mathrm{HV}-\mathrm{L} 4 \mathrm{~A}, \mathrm{~B} \\ & \text { or } \mathrm{C}-4\end{array}$

HO HV $-\mathrm{LP}-2$

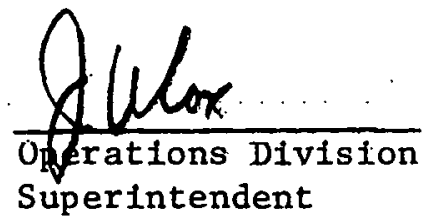
Superintendent

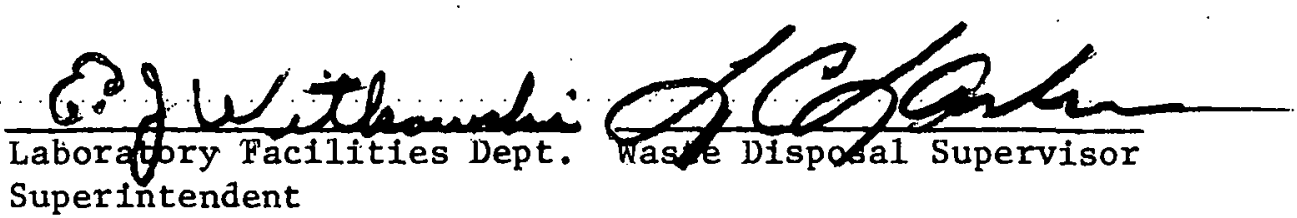


Time Initials

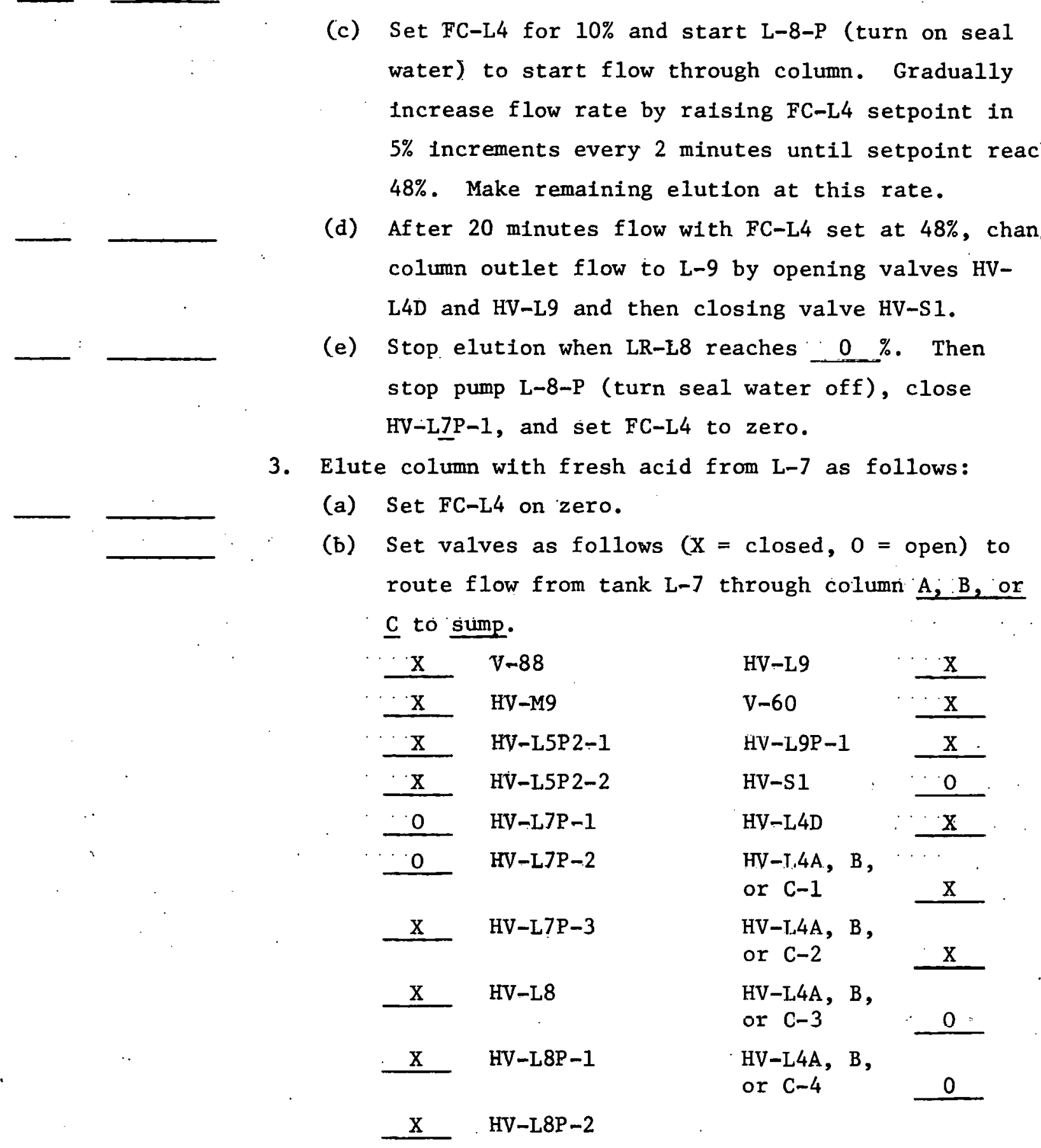
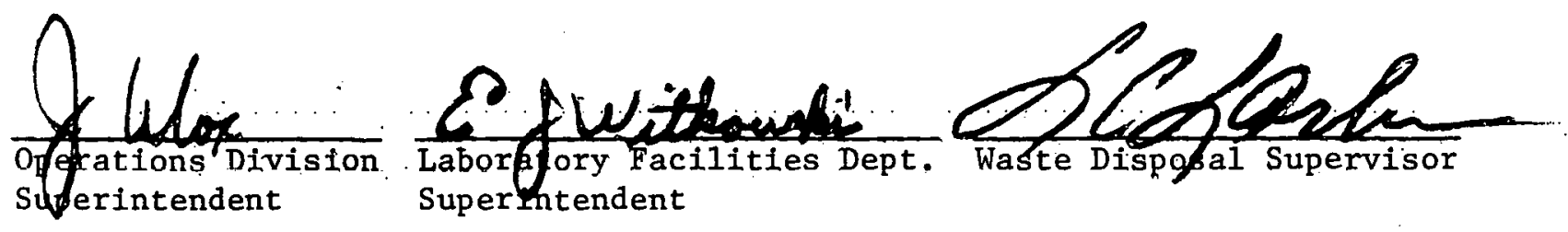
(c) Set FC-L4 to $10 \%$ and start L-7-P (turn on seal water) to start flow through column. Gradually increase flow rate by ralsing FC-L4 setpoint in $5 \%$ increments every 2 minutes unt11 setpoint reaches $48 \%$. Make remaining elution at this rate.

(d) After 20 minutes flow with FC-L4 set at $48 \%$, change column outlet flow to L-8 by opening valves HV-L4D and HV-L8 and then closing valve HV-S1.

(e) Stop elution when LR-L7 reaches $0 \%$. Then stop pump L-7-F (turn seal water off), cluse HV-LIF-1, and set $\mathrm{F} C \mathrm{C}-\mathrm{L} 4$ to zero.

(f) Proceed immediately to water wash and caustic pretreatment (Section 3).

Simultaneously (but at second priority to water wash), proceed to Section 4 (evaporator operation).

3. Water-Wash and Caust1c Pretreatment of Column

Date Startèd

In this step, the column will be washed with water to remove the remaining acid, and then treated with $0.1 \underline{\mathrm{N}} \mathrm{NaOH}$ solution to convert the resin back to the $\mathrm{Na}^{+}$form. Note that the resin swells from 10 to $25 \%$ during the treatment with caustic. Therefore, the resin bed must be kept "fluidized" during the caustic treatment to allow the resin to expand without rupturing the column. In the following procedure, the resin bed will be fluidized during the waterwash step. Then, the water flow will be kept on while adding enough $3 \underline{N} \mathrm{NaOH}$ from M-3A to make the column inlet solution to $0.1 \mathrm{~N} \mathrm{NaOH}$. It is important that the water flow be established before starting caustic flow.

Time Initials

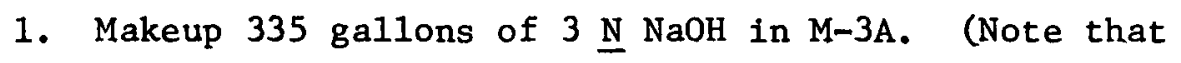
this makeup should be completed whlle acld elution to L-8 (Step 2.5) is in progress).

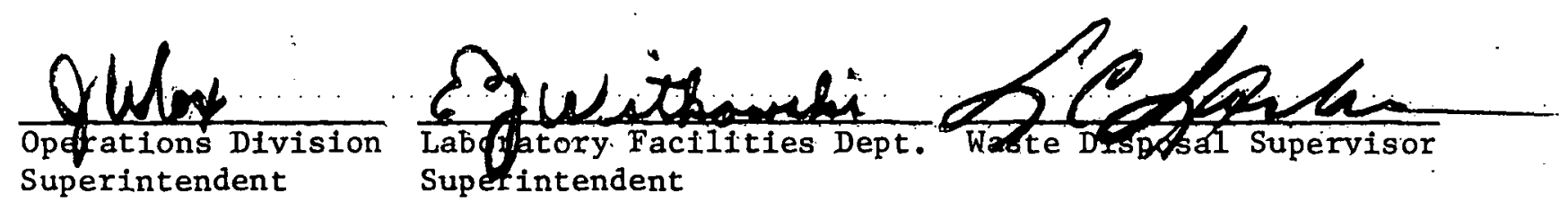




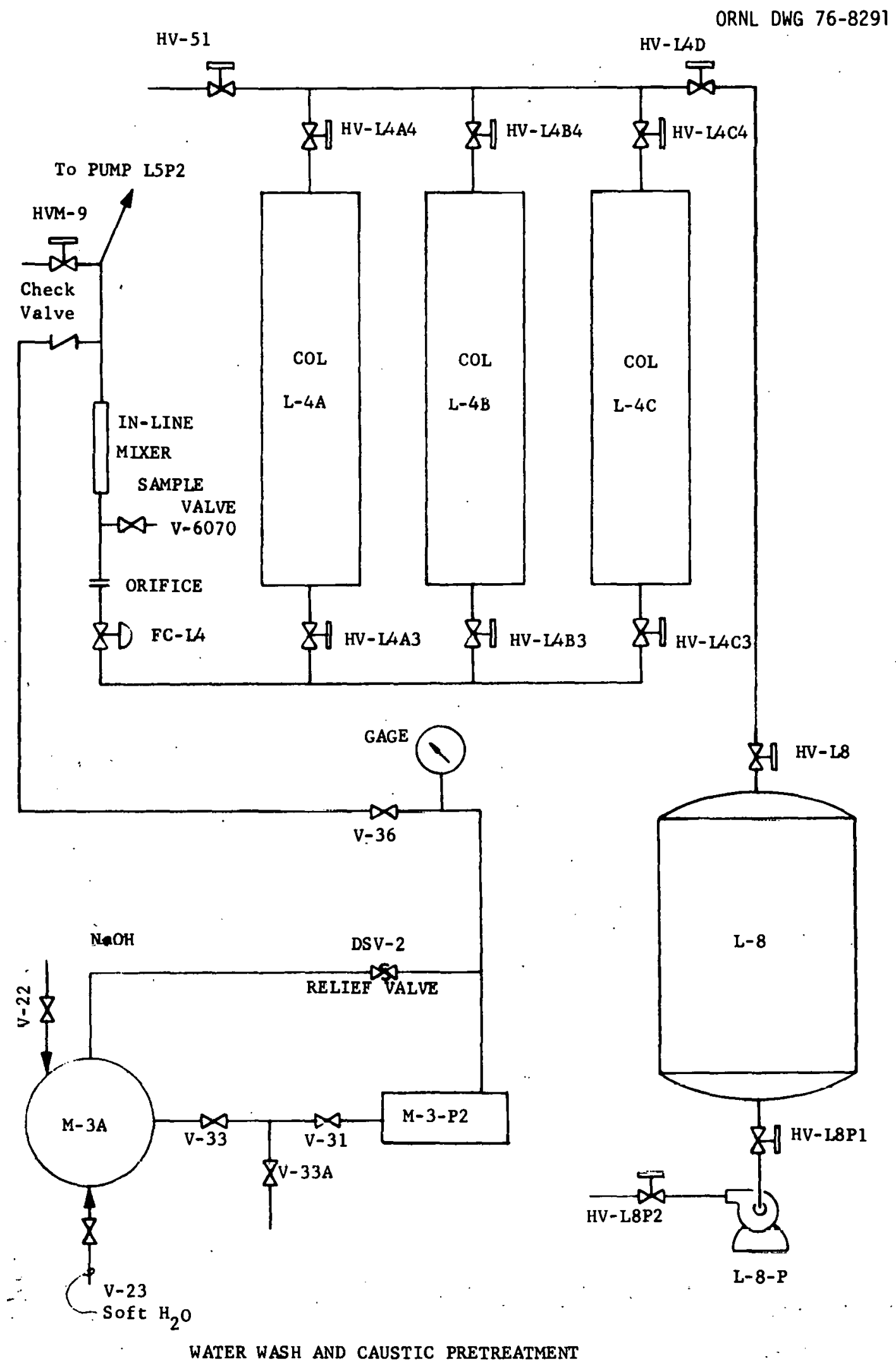




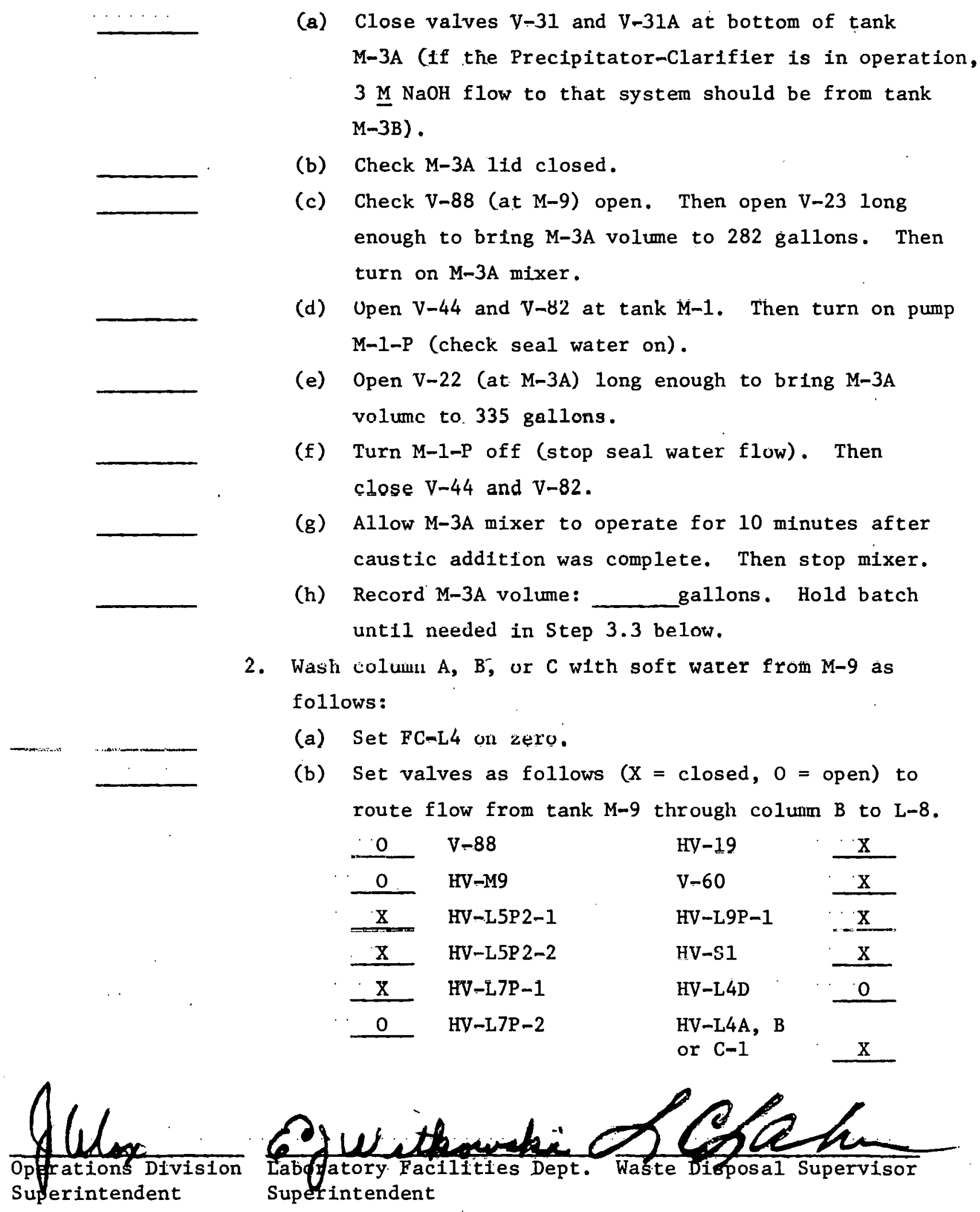


Time Initials

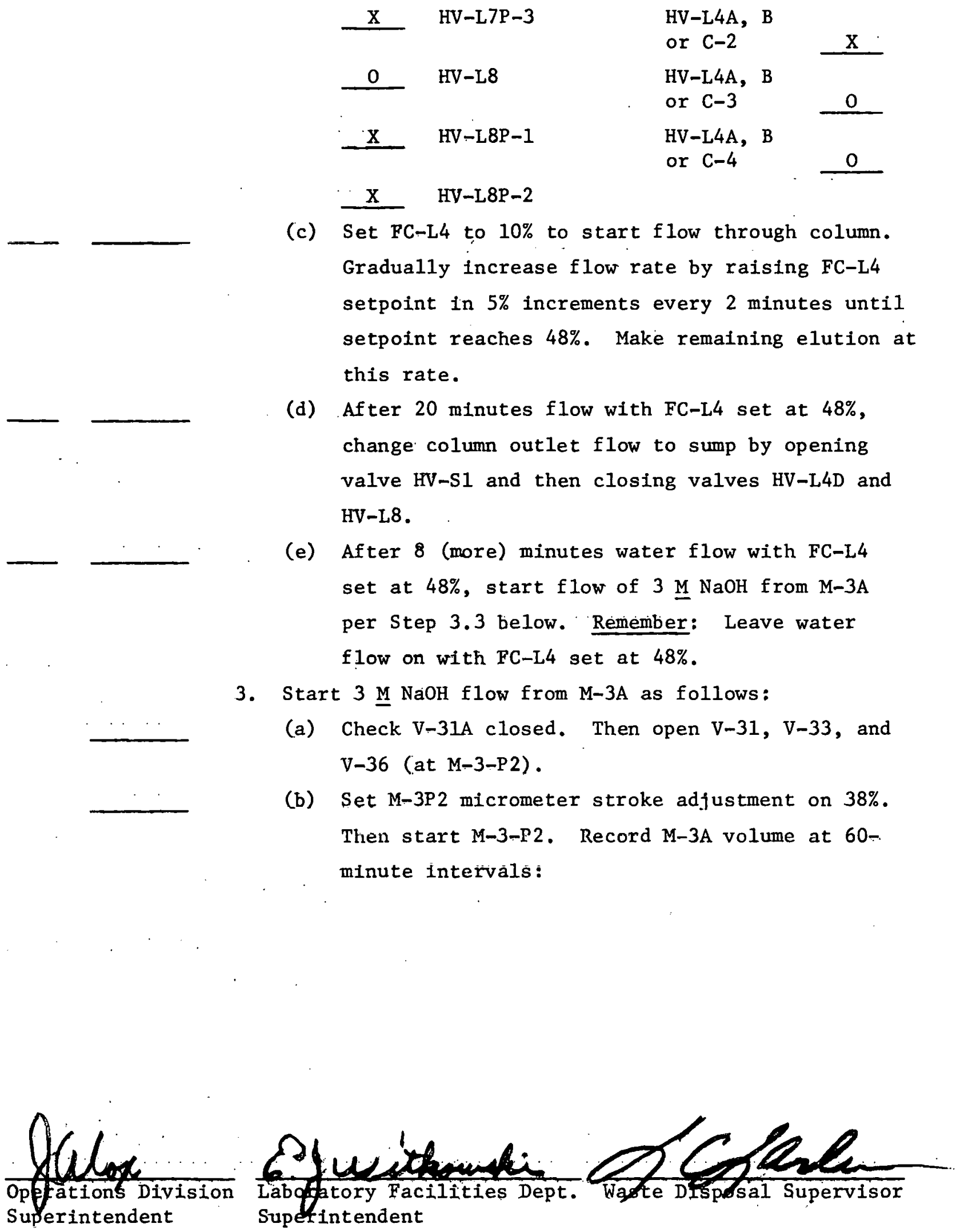




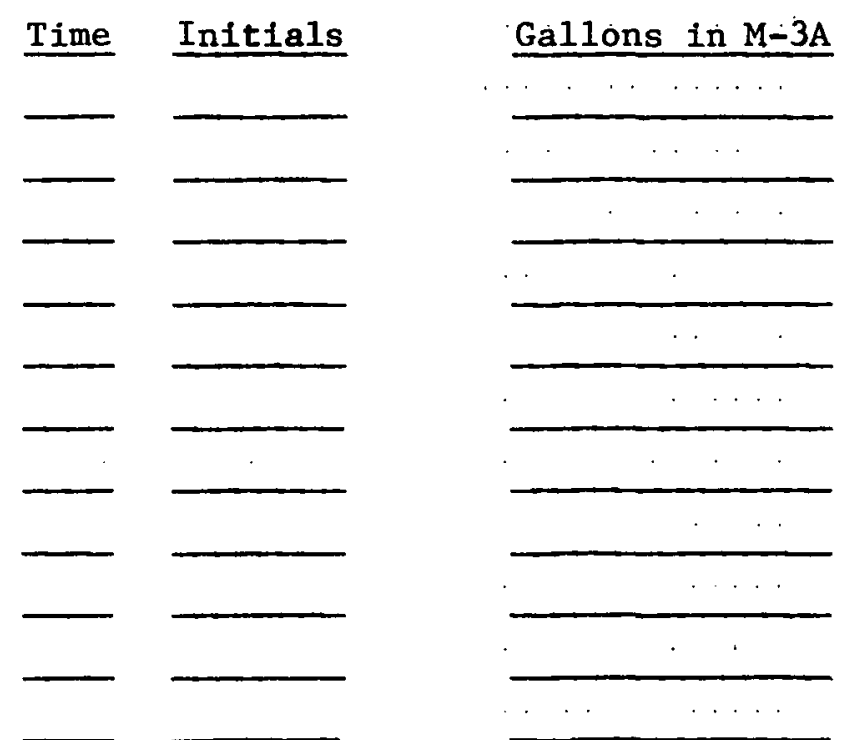

(c) After about 30 minutes of operation of M-3-P2, obtain a sample of the mixed caustic $(0.1 \mathrm{~N})$

from sample tap (on outlet side on in-line mixer L-4B). Code sample C10-

Submit or titrate for $\mathrm{OH}^{-}$(est $0.1 \underline{\mathrm{N}}$ ).

Record result:

$$
\mathrm{OH}^{-}=
$$

If reoult is outside the range of 0.08 to $0.12 \mathrm{~N}$, calculate pump stroke adjustment as follows:

$S=$ (present $M-3-P 2$ etroke, $\%) \times \frac{(0,10)}{\left(\mathrm{OH}^{-}, \mathrm{N}\right)}$

$S=$

Then reset M-3-P2 stroke to "S" \%. If stroke adjustment was required, wait for about $30 \mathrm{~min}$. after adjustment and then repeat this step.

(e) When water flow has continued for 32 minutes (with FC-L4 set at 48\%) after M-3-P2 was stopped, set FC-L4 to zero and then close the following valves:
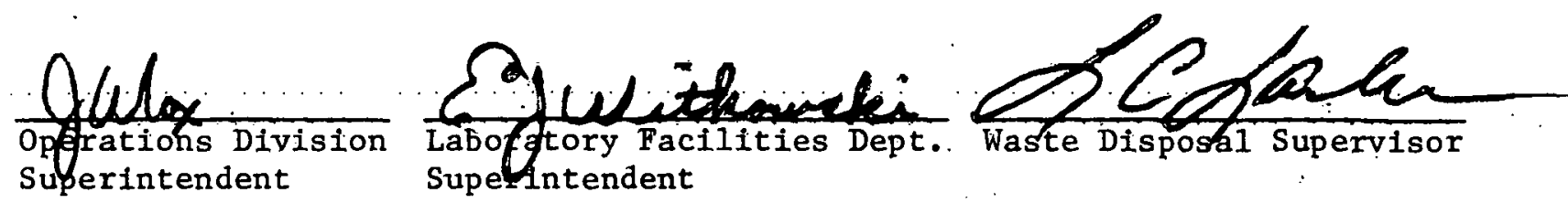


$$
\begin{aligned}
& \text { HV-M9 } \\
& \text { HV-L4B-3 } \\
& \text { HV-L4B-3 }
\end{aligned}
$$

(f) NOTE: The $0.1 \underline{\mathrm{N}} \mathrm{NaOH}$ elution requires 20 bed volumes or approximately 6700 gallons. The operation requires approximately 9 hours for completion.

4. Eluate Concentration and $\mathrm{HNO}_{3}$ Recovery

Date Started:

The equipment to be used for this step is the L-10 Evaporator System. Refer to Dwg: Nos. P21246EE-032 and P21246EE-003 for system set up and operation.

Time Initials

1. Set up the evaporator system as follows:

(a) Note the following tank contents at the beginning of this evaporation:

L-7: Should be empty

L-9: Will contain approximately 1700 gallons of eluate solution.

L-10: Should be empty.
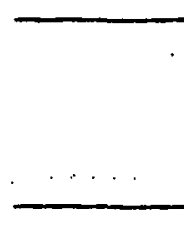

L-11: Should be empty:

(b) Check that fume scrubber ( $\mathrm{L}-12$ system) is in norma1 operation.
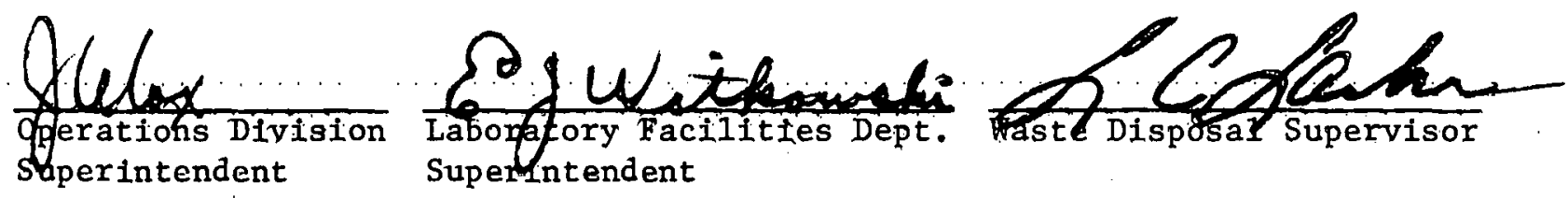
ORNL DWG 76-8292

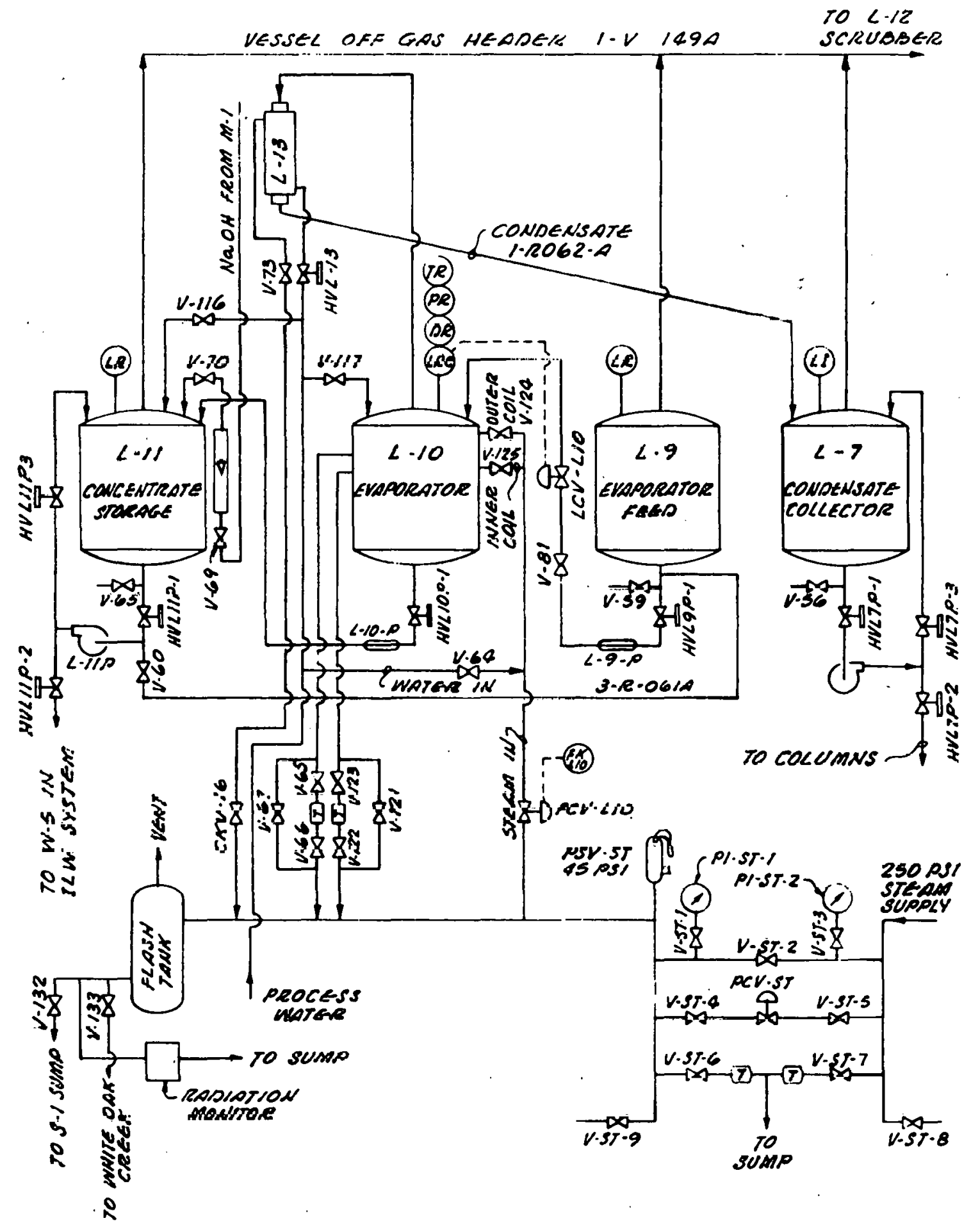




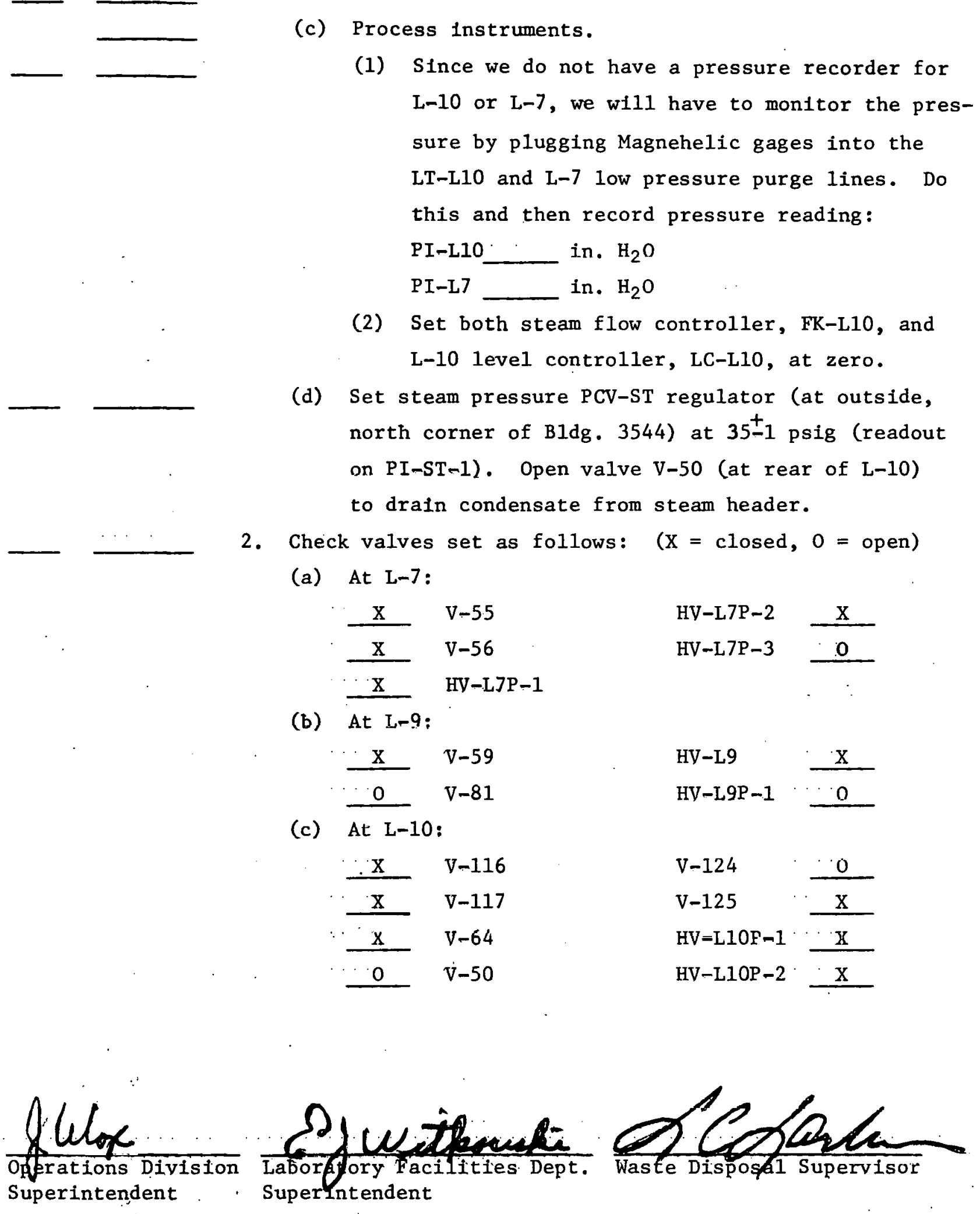


Time Initials

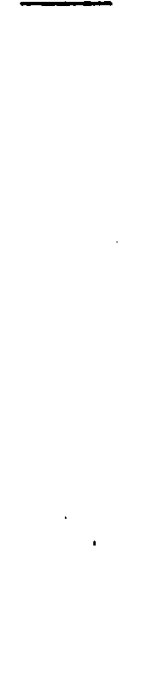

(d) At I-11:

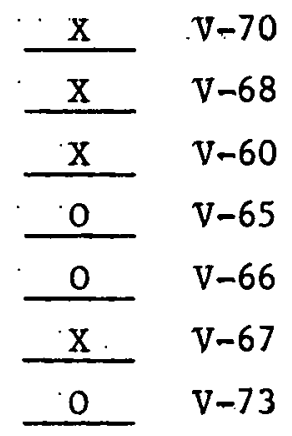

(e) At Flash Tank (outside east corner of Bldg. 3544) X V-132 V-133 U U

(t) At Steam Supply Station (outside north corner of B1dg. 3544)

\begin{tabular}{cccc}
$\frac{\mathrm{O}}{\mathrm{x}}$ & $\mathrm{V}-\mathrm{S} T-1$ & $\mathrm{~V}-\mathrm{ST}-6$ & $\mathrm{O}$ \\
\hline $\mathrm{V}-\mathrm{ST}-2$ & $\mathrm{~V}-\mathrm{ST}-3$ & $\mathrm{~V}-\mathrm{ST}-7$ & $\mathrm{O}$ \\
$\frac{\mathrm{O}}{\mathrm{O}}$ & $\mathrm{V}-\mathrm{ST}-4$ & $\mathrm{~V}-\mathrm{ST}-8$ & $\frac{\mathrm{X}}{\mathrm{O}}$ \\
$\mathrm{O}$ & $\mathrm{V}-\mathrm{ST}-5$ & $\mathrm{~V}-\mathrm{ST}-9$ & $\mathrm{X}$ \\
\hline
\end{tabular}

3. Transfer 250 gal of eluate from L-9 to L-10 as follows:

(a) Put LC-LIO on manual control with set point at $100 \%$.

(b) Start L $9, \mathrm{P}$ and pump until LR-L10 reaches $63 \%$. Then stop L-9-P.

(c) Record LR-L9 reading at end of transfer. LR-L9 \%.

4. Heat solution in $\mathrm{L}-10$ to boiling as follows:
(a) Set FK-L10 at $40 \%$ of s.tart steam flow.
(b) When boiling begins in $\mathrm{L}-10$ (as evidenced by LC-L10 on automatic with setpoint at $60 \%$ and then start pump L-9-P. depletion on LR-LIO and buildup in LR-LT, put
(c) Increase $\mathrm{FK}-\mathrm{L} 1 \mathrm{U}$ setpoint in steps of $5 \%$ at $3-$ minute intervals until FK-L10 setpoint reaches $100 \%$.

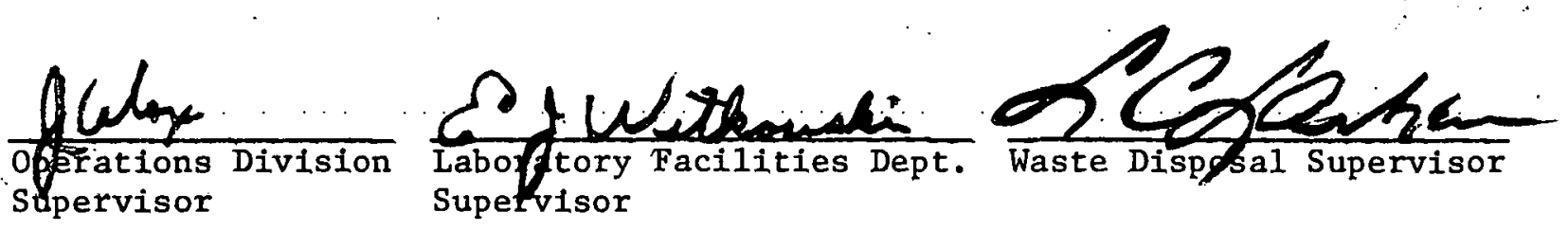


Time Initials

5. When evaporator feed tank $L-9$ is empty, turn off L-9-P and close valves $H V-L 9 P-1$ and V-81. Also, set LC-L10 to zero.

6. Stop bolling in L-10, and cool solution as follows:

(a) Set FK-Lilo to zero.

(b) Open cooling water inlet valve V-64 and outlet valves $\mathrm{V}-6 \mathrm{~J}$ and $\mathrm{V}-121$

(c) When TR-L10 reaches $<100^{\circ} \mathrm{F}\left(<40^{\circ} \mathrm{C}\right)$, stop cooling water by closing $\mathrm{V}-64, \mathrm{~V}-67$, and $\mathrm{V}-121$.

(d) Close condenser water valve HV-L13.

(e) Record the following readings

LR-LIO $\ldots$
DR-LIO $\ldots \%$

7. Sample condensate in $\mathrm{L}-7$ as follows:

(a) Close HV-L7P-2 and open HV-L7P-3. Then open HV-L7P-1 and turn on pump I-7-P (turn seal water on) to circulate solution for mixing.

(b) Circulate solution in $\mathrm{L}-7$ for 15 minutes.

(c) Drain about $250 \mathrm{ml}$ from $\mathrm{L}-7$ sample valve V-56. Then obtain a sample of approximately $250 \mathrm{ml}$ in a new clean poly bottle. Log sample in Sample Book -- code "MUE-_. ". Label sample bottle T1trate for "H" analysis" (est $0.3 \underline{N}$ ).

8. Sample eluate concentrate in L-10 as follows: Drain about $500 \mathrm{~m} 1 \mathrm{f}$ rom $\mathrm{L}-10$ sample valve. Then obtain a sample of approximately $250 \mathrm{ml}$ in a new, clean poly bottle. Log sample in Sample Book ---
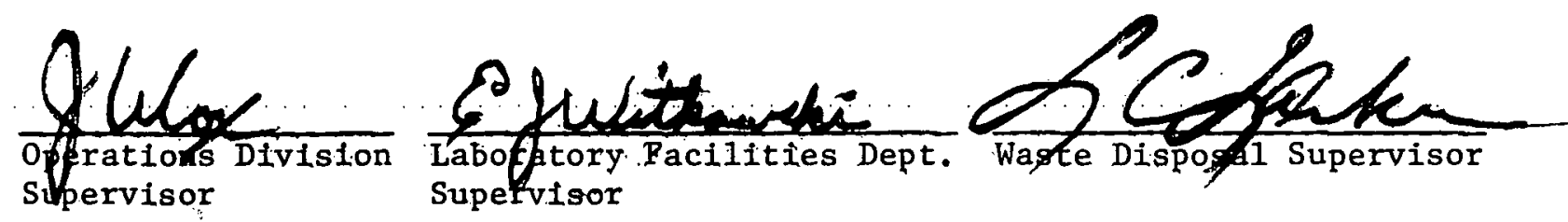
Time Initials

code "ELC." Label sample bottle with this number. Record sample number on attached request sheet and submit sample to Analytical Chemistry. 
Section E. PROCEDURE FOR TRANSFERRING EVAPORATOR CONCENTRATE FROM TANK L-11 TO TANK W-5 IN TANK FARM

When the liquid level in Tank $\mathrm{L}-11$ reaches $50 \%$, the evaporator concentrate should be neutralized with $\mathrm{NaOH}$ solution and then pumped to $\mathrm{W}-5$ in the Intermediate Leve1 Waste Tank Farm.

The detailed procedure is as follows:

1. Recirculate Tank L-11 contents using Pump L-11-P

a. Turn on pump packing gland water

b. Set valves as follows: $(X=$ closed, $0=$ open $)$

$$
\begin{array}{llll}
\frac{0}{\mathrm{X}} & \mathrm{L}-11-\mathrm{P} 1 & \frac{\mathrm{O}}{\mathrm{V}-60} & \text { HVL-11-P3 } \\
& \frac{\mathrm{X}}{\mathrm{X}} & \text { HVL-11-P-2 } \\
& & \mathrm{V}-68
\end{array}
$$

c. Turn switch to ON position on panel board for pump L-11-P and operate for 10 minutes.

d. Switch Pump L-11-P off and turn off packing gland water.

2. Drain approximately $250 \mathrm{~m} 1$ from sampling valve $\mathrm{V}-68$ on tank line from L-11, then obtain a sample of approximately $250 \mathrm{ml}$ in a new clean poly bottle.

3. Titrate sample using 0.1 normal $\mathrm{NaOH}$ and record results in 1 log book.

4. Determine the volume in Tank L-11 from tank calibration curve.

5. Calculate the quantity of $\mathrm{NaOH}(50 \%)$ to add to $\mathrm{L}-11$ to neutralize the acid from

$$
\text { gal } \mathrm{NaOH}=\frac{\text { gal of evaporator concentrate } X \text { normality of concentrate }}{\text { Normality of } \mathrm{NaOH} \text { solution }}
$$

6. Add $\mathrm{NaOH}$ solution to L-11 from $\mathrm{NaOH}$ supply Tank M-1.

a. Check valve positions at $M-1: \quad(X=$ closed, $0=$ open $)$

$$
\begin{array}{llll}
\frac{\mathrm{X}}{\mathrm{X}} & \mathrm{v}-45 & \mathrm{O} & \mathrm{V}-47 \\
\mathrm{X} & \mathrm{V}-46 & \mathrm{O} & \mathrm{v}-44 \\
\hline
\end{array}
$$

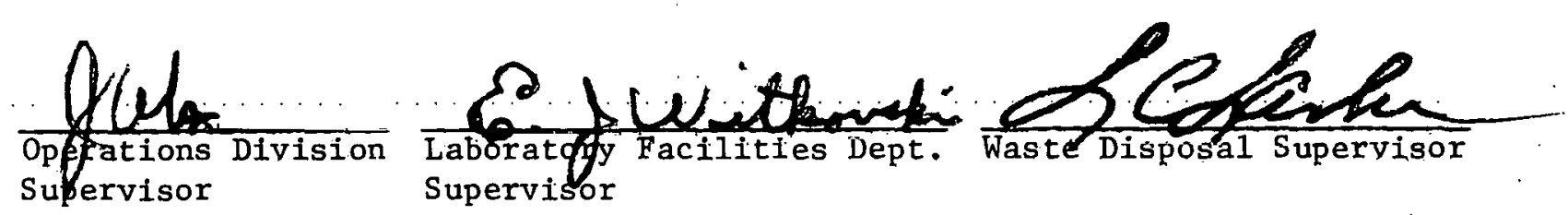




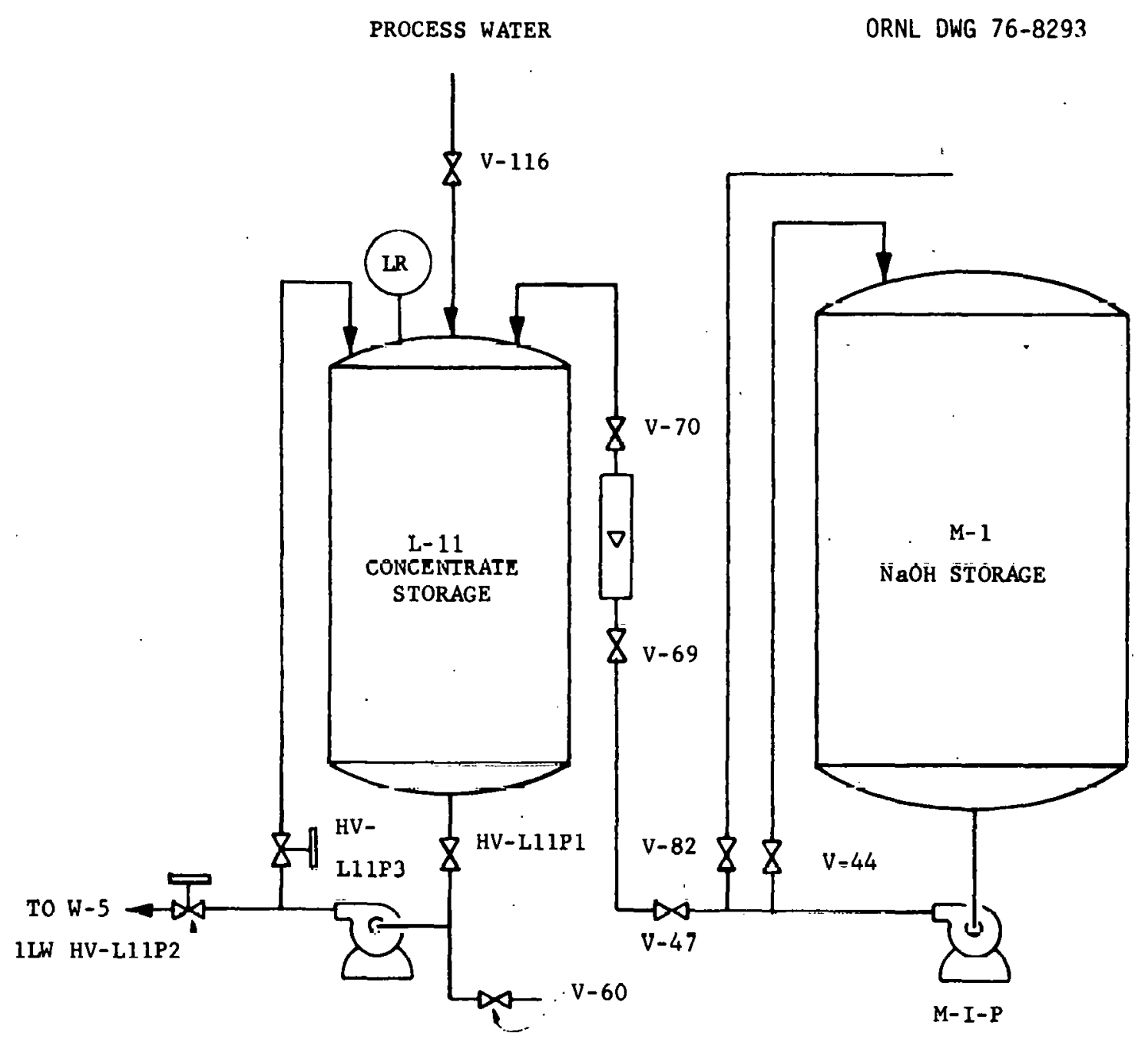

TRANSFER OF EVAPORATOR CONCENTRATE TO W-5 IN ILW SYSTEM 
b. Check valve position at scrubber

$0 \quad \mathrm{~V}-74$

c. At Tank L-11 check valve positions to permit NaOH solution flowthrough flowmeter to L-11: $\quad(X=$ closed, $0=$ open $)$

\begin{tabular}{ll}
0 & $V-70$ \\
\hline & $V-69$
\end{tabular}

d. Turn on packing gland water to Pump M-1-P.

e. Switch Pump M-1-P on manually at the pump and operate for the time period in minutes calculated from the formula

$$
\text { Time }=\frac{\text { gal of } \mathrm{NaOH} \text { solution required }}{\text { flowmeter reading gal/min }}
$$

f. Switch off Pump $M-1-P$ and turn off the packing gland water. Check valve positioning ( $X=$ closed, $0=$ open). At NaOH supply tank this should be:

$\begin{array}{llll}\mathrm{X} & \mathrm{V}-45 & \frac{\mathrm{X}}{\mathrm{X}} & \mathrm{V}-82 \\ \mathrm{y} & \mathrm{V}-44 & \mathrm{X} & \mathrm{V}-47 \\ \mathrm{~V} & \mathrm{~V}-46 & & \end{array}$

At scrubber:

$\mathrm{X} \quad \mathrm{V}-74$

At $\mathrm{L}-11$ tank:

$\begin{array}{llll}\mathrm{X} & \mathrm{V}-70 \quad \mathrm{X} & \mathrm{V}-69\end{array}$

7. Recirculate L-11 contents for 10 minutes.

a. Turn on pump packing gland water.

b. Set valves as follows: $(X=$ closed, $0=$ open $)$

$\begin{array}{llll}\frac{0}{\mathrm{X}} & \mathrm{L}-11-\mathrm{P}-1 & \frac{\mathrm{O}}{\mathrm{V}-6 \mathrm{U}} & \mathrm{HV}-\mathrm{L}-11-\mathrm{P}-3 \\ \mathrm{H} & \frac{\mathrm{X}}{\mathrm{HV}-\mathrm{L}-11-\mathrm{P}-2} & \mathrm{~V}-68\end{array}$
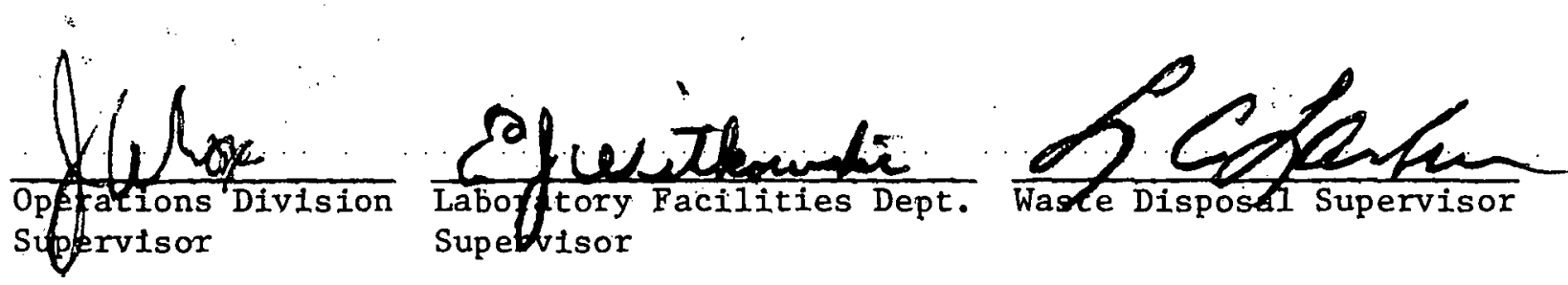
$3-26$

8. a. Set valves at Tank $L-11$ to pump neutralized concentrate to $W-5$ in tank farm ( $X=$ closed, $0=$ open)

$\begin{array}{ll}\mathrm{X} & \mathrm{V}-68 \\ \mathrm{X} & \mathrm{V}-60 \\ \mathrm{X} & \mathrm{HV}-\mathrm{L}-11-\mathrm{P}-3\end{array}$

$$
\begin{array}{ll}
\mathrm{O} & \mathrm{HV}-\mathrm{L}-11-\mathrm{P}-2 \\
\mathrm{O} & \mathrm{L}-11-\mathrm{P}-1
\end{array}
$$

b. Turn on Pump L-11-P gland water.

c. Turn switch on panel board to start Pump L-11-P.

d. When the level indicator in Tank $\mathrm{L}-11$ indicates the tank is empty, switch off Pump L-11-P.

e. Turn off gland water to pump.

f. Reposition valves at Tank $\mathrm{L}-11$ : $(\overline{\mathrm{X}}=$ closed, $0=$ open $)$

$$
\begin{array}{ll}
\frac{X}{X} & V-60 \\
\cline { 1 - 1 } & \mathrm{L}-1.1 .-\mathrm{P}-1 \\
\hline
\end{array}
$$

$$
\begin{array}{ll}
\cdots \mathrm{X} & \mathrm{HV}-\mathrm{L}-11-\mathrm{P}-2 \\
\mathrm{O} & \mathrm{HV}-\mathrm{L}-11-\overline{\mathrm{P}}-3
\end{array}
$$

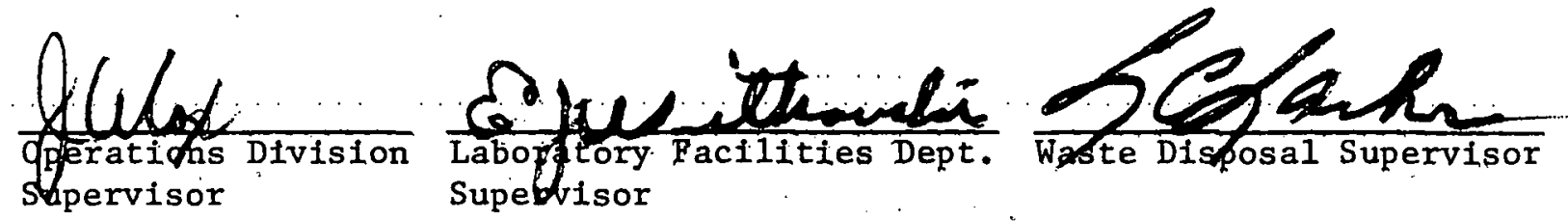

$V$ 


\subsection{L-12 ACID FUME SCRUBBER}

\subsection{References}

Schutte and Koerting Operating Instructions for Type 7025 Package Scrubber Schutte and Koerting Dwg. No. 68-XG-037-A, Sectional Outline for PVC Vent Scrubber

Koertrol Dwg. No. 74-XE-026, 2-30 inch Packaged Vent Scrubber System ORNL Dwg. No. P-21246-EE-003, Process Engineering Flow Sheet No. 2

\subsection{Introduction}

The acid-fume scrubber pulls a vacuum on the off-gas lines from tanks L-7, L-8, L-9, L-1.1, M-2, M-8, and the condenser $\mathrm{L}-13$ (also on each ton-exchange column during regeneration of the resin) and absorbs and neutralizes any acid vapors into a circulating caustic solution. The off-gas from these tanks consists mainly of the instrument air purges but will also include any air in leakage. The scrubber system consists of an Ejector-Venturi (Jet), a circulating pump (L-12-P) and rotameter (FI-L12), and a separator tank ( $L-12)$. This system is shown schematically on Process Engineering Flowsheet No. 2 (Dwg. No. P-21246EE-003-D-Rev. 2). Tank L-12 is vented through an entrainment separator to the roof stack exhaust.

During normal operations, we plan to use approximately $5 \% \mathrm{NaOH}_{3}$ solution as the recirculating fluid. A periodic purge and makeup will be used to prevent excessive buildup of $\mathrm{NaNo}_{3}$ and $\mathrm{Na}_{2} \mathrm{CO}_{3}$.

\subsection{Personne1 Requirements}

1. A waste disposal supervisor, available on a 24 hour call-in basis, who is responsible for the treatment operation.

2. A chemical operator who performs the mechanical, sampling, and analytical functions as required to operate the treatment system.

\subsection{Precautions}

1. The ion exchange room is a goggle area.

2. Wear rubber gloves when handling the scrub solution.

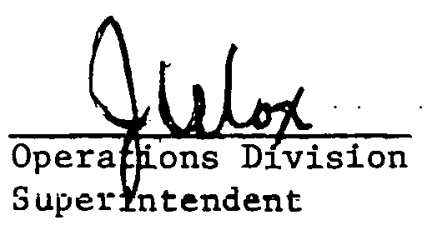

Superintendent

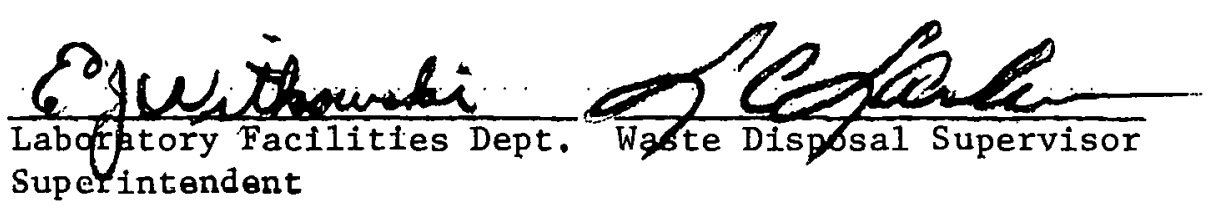




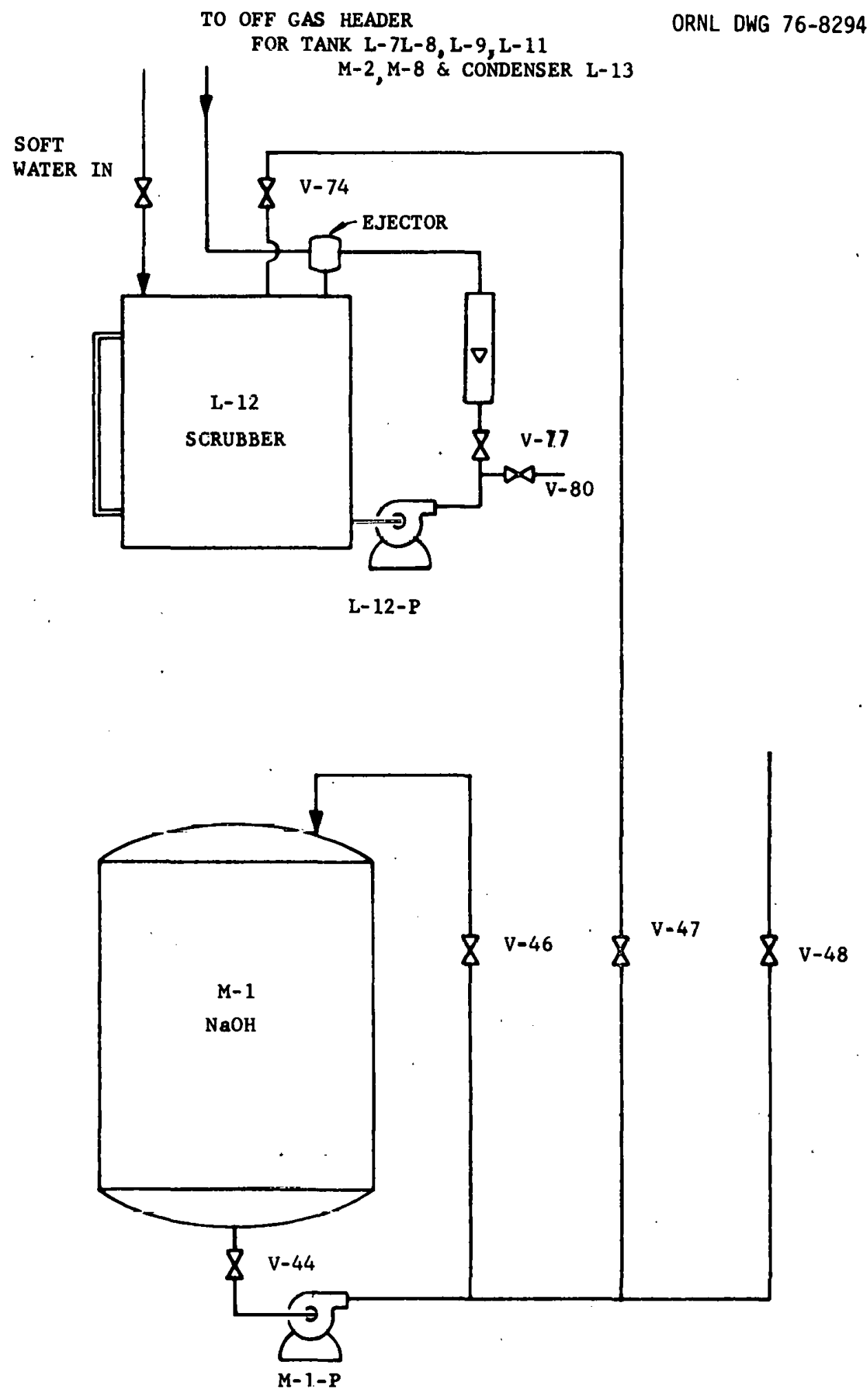

ACID FUME SC̣RUBBER 


\subsection{Procedure}

1. Make up 40 gallons of $5 \% \mathrm{NaOH}$ in the L-12 hold tank.

(a) Close L-12 drain valve, V-76.

(b) Add 36 gallons of soft water into L-12 from M-9 by opening valves $\mathrm{V}-88$ and $\mathrm{V}-75$.

(c) Close valve $\mathrm{V}-80$ and open valve $\mathrm{V}-77$. Start pump L-12P and circulate the water in L-12 through the ejector jet. Record FI-L12 reading in the $10 \mathrm{~g}$ book.

(d) Set up $\mathrm{M}-1$ and transfer 4 gallons of $50 \% \mathrm{NaOH}$ from $\mathrm{M}-1$ into $\mathrm{L}-12$.

(1) Open valves $\mathrm{V}-44$ and $\mathrm{V}-47$ at $\mathrm{M}-1$.

(2) Partially open V-46 to allow some recirculation; adjust the seal water, and then start pump M-1P.

(3) Open $\mathrm{NaOH}$ supply valve $\mathrm{V}-74$ at $\mathrm{L}-12$ and increase the $\mathrm{L}-12$ volume to 40 gallons by $\mathrm{NaOH}$ addition.

(4) Shut down M-1P and close valves $V-44$ and $V-47$.

(e) Circulate the L-12 scrub solution for 10 minutes and then sample:

(1) Drain approximately $250 \mathrm{~m} 1$ from $\mathrm{V}-76$, and then obtain a $250 \mathrm{ml}$ sample in a clean plastic bottle. Label the sample SRL -- and $\log$ it in the sample book. Submit sample for $\mathrm{OH}^{-}(2 \mathrm{~N})$ and $\mathrm{CO}_{3}(0.05 \mathrm{~N})$.

(2) Operate the scrubber circulation system continuously, at $100 \%$ pump capacity.

(3) To replace scrubber solution, open valve $V-80$ and pump contents of L-12 to concentrate tank L-11. Keft11 L-12 per preceding step number 1 . 


\subsection{M9A CATION EXCHANGE WATER SOFTENER}

\subsection{References}

Rock Valley Water Conditioning, Inc., Operating Instruction

Rock Valley Dwg. D2225-1L

ORNL Dwg. P-21246-EE-035, Makeup Area - Process Piping

ORNL Dwg. P-21246-EE-039, Makeup Area - Process Piping

\section{Elevation EE}

ORNL Dwg. P-21246-EE-003, Flow Sheet No. 2

\subsection{Introduction}

The water softener system provides treated water (less than $10 \mathrm{ppm} \mathrm{CaCO}_{3}$ hardness), which is used to prepare chemical feed solutions and to baick flush the clarifier sludge system. The packaged unit consists of an exchange tank, a brine tank, a Badger flow meter, and a timer actuated Solomatic valve which controls the regeneration cycle.

\section{Design Parameters}

Exchange Media

Raw Water Hardness

Soft Water Hardness

Net Gallons Between Regenerations

Eervice Flow Rate

Pressure Drop

Salt per Regeneration

Time to Regenerate

Water to Regenerate
11 cubic feet Duolite C-20. sodium form

$114 \mathrm{ppm}$ (as $\mathrm{CaCO}_{3}$ )

$15 \mathrm{ppm}$ (as $\mathrm{CaCO}_{3}$ )

46,000 gallons

0-100 gpm

15 psi, maximum

66 1bs

66 minutes

627 ga11ons

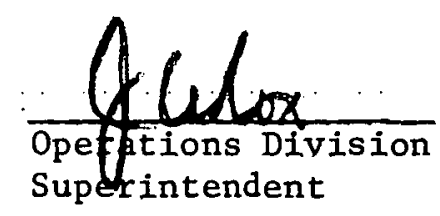

Opeftions Division

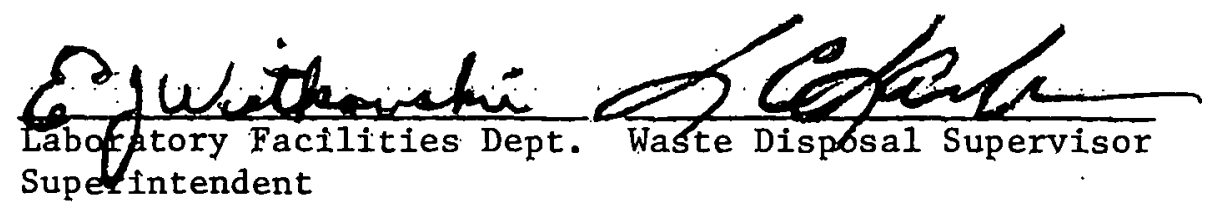




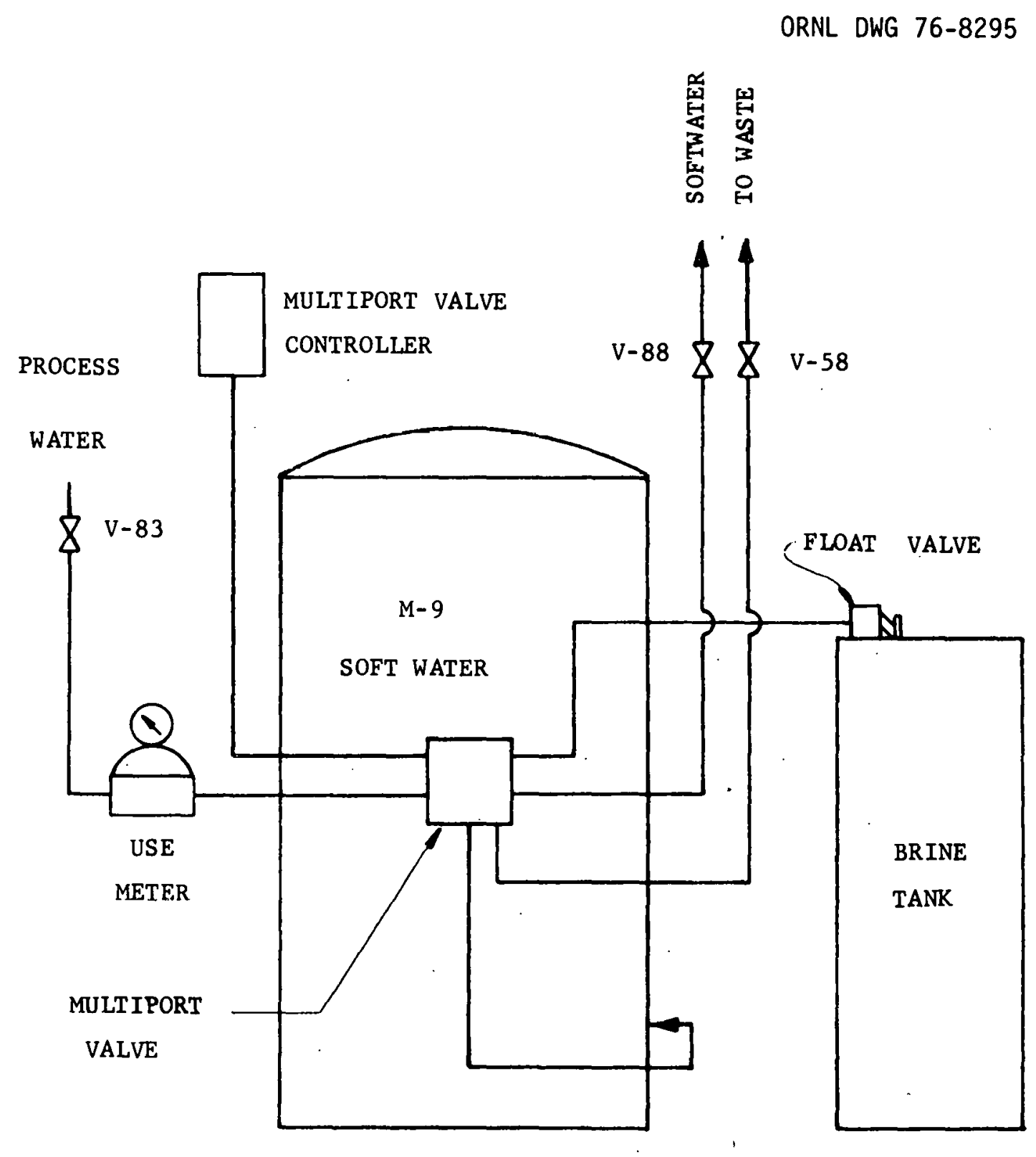

WATER SOFTENING SYSTEM 


\subsection{Precautions}

A. Do not operate the softener if 1 is partially full, or if it is not pressurized. A surge of water or air into a partially empty tank can damage the PVC distribution header.

\subsection{Personnel Requirements}

A. A waste disposal supervisor, available on a 24. hour call-in basis, who is responsible for the treatment operation.

B. A chemical operator who performs the mechanical, sampling, and analytical functions which are required to properly operate the treatment plant.

\subsection{Procedures}

A. Initial Fill

A gate valve $(V-83)$ between the water inlet and the water meter should be used to regulate a slow flow during initial fill, or after a period of shutdown.

1. Loosen the 4" $x$ 6" manhole on the tank to allow air to escape.

2. Open the inlet gate valve and allow the softener tank to fill slowly. Any valve position $(1-4)$ may be used. If the unit is in position 1 (Backwash) care must be taken to fill slowly so resin will not be washed to drain.

3. When the tank is full and pressurized, tighten the manhole.

4. Place pellet salt into the brine tank to within $3^{\prime \prime}$ of the bottom of the float, in its lower position.

5. After the tank is full, open the pet-cock on the solematic valve for 30 seconds, and close for 30 seconds. Do this a total of three (3) times. This will advance the valve to the fast rinse part of its cycle (position 3) and allow the brine to fill with water. The position of the counterweight should be adjusted so that 1 is all the way DOWN whien the float is high, and all the way UP when the float is down. The valve
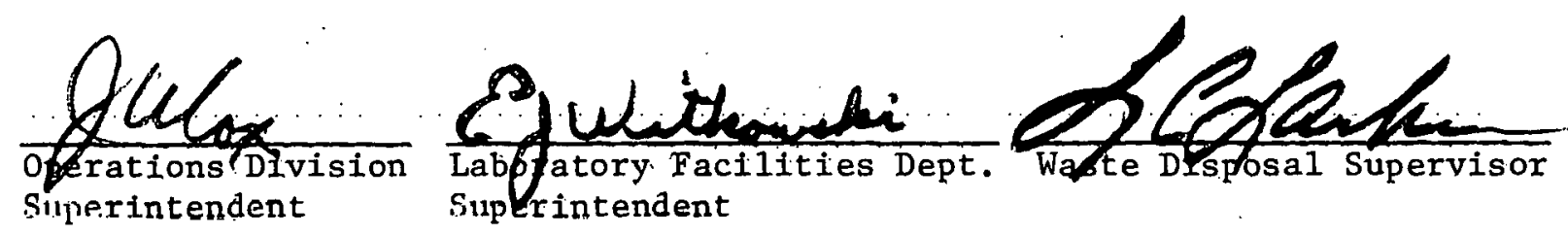
should not move in intermediate positions. After the brine tank is full, advance the valve to the Service Position (1 step with pet cock).

6. To place the unit in service, open valves $\mathrm{V}-83$ and $\mathrm{V}-88$. .

B. Basic Operation Sequence

When a preset number of gallons have passed through the Badger water meter, a contact w111 close initiating an external audible alarm. The meter must then be manually reset (knob on left side of meter). Re-setting will silence the alarm. The unit will stay in service until the red trip switch is tripped. Once initiated, a motor operated adjustable timer sequences the unit through regeneration and return to service.

Control of the regeneration cycle is accomplished by a multiport control valve of the lift-turn type. Manual control of the unit is in the form of a hypass rnrk on the left side of the multiport valve. To manually advance the multiport valve, open the cock until the lift-turn pin is in the topmost position.

Closing the cock will advance the valve to the next regeneration step. Care must be taken to insure that the time and valve are synchronlzed. The valve position is displayed in the sight glass on the top of the valve.

\section{Regeneration}

1. Solomatic valve position:

\#1 Backwash

$\$ 2$ Brine In and Rinse

\#3 Fast Rinse and Brine Tank Fill

\#4 Service and Brine Tank F111

2. Regeneration Steps

When the timer motor is manualiy initiated approximately 4 minutes elapse while the motor advances from "service" to "backwash."
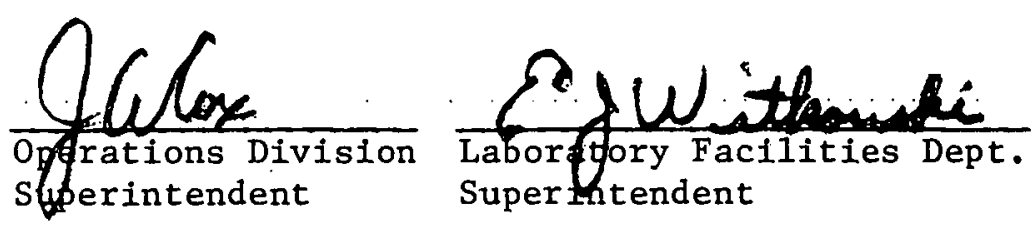

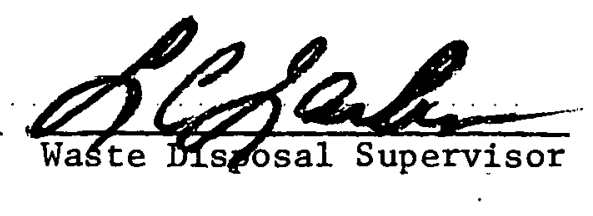


a. Backwash

Adjust the backwash orifice (bottom) for a flow of 15 gallons per minute. Refer to Aque Matic flow chart No. $374 \mathrm{~A}$ for the proper adjustment with respect to the indicated water pressure. Set the S-144-C timer for 10 minutes.

b. Brine Injection and Slow Rinse

(1). Adjust the efector nozzle (right side) for a flow of $2.7 \mathrm{gpm}$ water and $1 \mathrm{gpm}$ brine. Refer to chart No. $374 \mathrm{~A}$ for adjustment for. water pressure.

(2) Adjust the globe valve in the brine draw line so that the float travels $7-5 / 32$ " in 14 minutes. This will result in a salometer reading of 38 . Adjust the timer for 46 minutes, allowing 14 minutes for brine injection and 32 minutes for slow rinse.

(3) When al1 the saturated brine is drawn from the brine tank, the brine float valve will automatically close to prevent air from entering the system.

c. Fast Rinse

(1) No adjustment is required for this step as the proper fixed orifice for the flow rate has been installed. Adjust the timer for 10 minutes duration.

(2) When the softener has advanced to fast rinse, the Clayton brine valve (Item $C$ ) will open. Th1s will allow raw water to automatically refill the brine tank in preparatinn for the next regeneration. When the tank is full, the float will close the valve to prevent overfilling. 


$$
\text { 5-6 }
$$

3. Regeneration of the softener can be accomplished manually by operating the hand valve near the solenoid valve. Open it until the stem plate has risen to the top of its travel as Indicated through the plexiglas window on the Solomatic valve (approximately 30 seconds), then close the valve again. NOTE: When operating the valve in this manner, make sure to leave the cam positioned in coordination with the timer position. 


\subsection{SLUDGE DISPOSAL SYSTEM}

\subsection{References}

ORNL Dwg. P-21246-EE-002, Process Engineering Flowsheet No. 1.

ORNL Dwg. C-21246-EA-008, Sludge Pond Plot Plan and Details. ORNL Dwg. C-21246-EA-010 through 017, 2 in. Sludge Pipe Line Plan and Profile.

ORNL Dwg. C-21246-EA-023, Mechanical Plan, Sections and Detail

\subsection{Introduction}

A 219,000 gallon basin located in Melton Valley has been constructed to dispose of the sludge generated by clarifier L-lA. The basin is equipped with an impermeable liner ( $30 \mathrm{mil} \mathrm{PVC}$ ) which is anchored by a cover of river sand. The solids will be allowed to settle, and periodically, the supernatant liquid will be pumped back to the Equalization Basin for reprocessing.

A $4000 \mathrm{ft}$, schedule 80, PVC transfer line connects the basin to. the holding tank L-6. A centrifugal type pump with a capacity of $40 \mathrm{gpm}$ is provided to transfer the slurry.

\subsection{Personnel Requirement}

1. A waste disposal supervisor, available on a 24 hour call-in basis, who is responsible for the treatment operation.

2. A chemical operator who performs the mechanical functions required to operate the system.

\subsection{Precautions}

1. The clarification area is a goggle area:

2. Valve V-9 must be closed before a sludge transfer is started.

\subsection{Procedures}

A. To pump sludge from holding tank L-6 to the disposal basin:

1. Close valve $\mathrm{V}-9$.

2. Check the level at the sludge basin; open valve $\mathrm{V}-10$.

3. Start a water flow to the seal on pump L-6P.

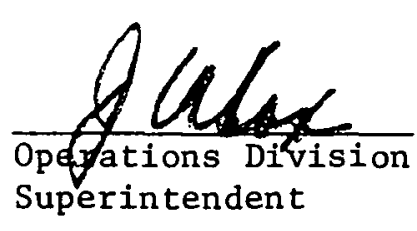

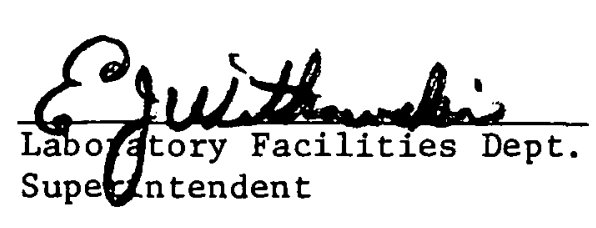


ORNL DWG 76-8296

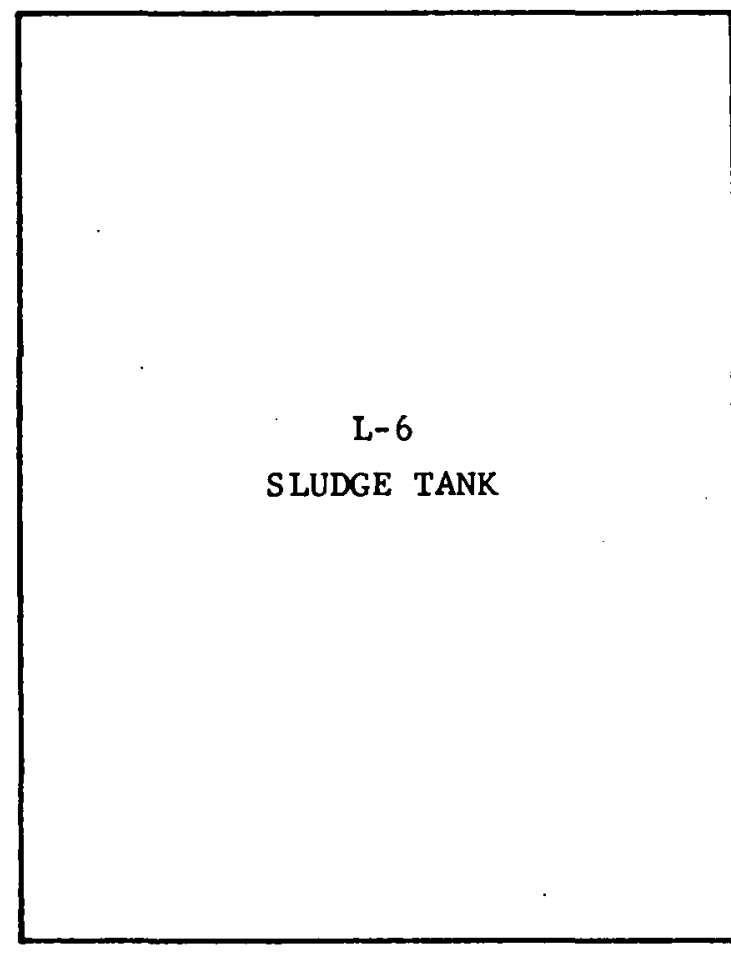

$H V L=6 P 1$

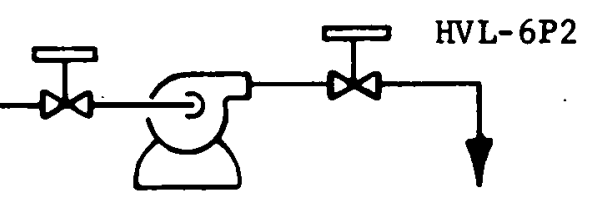

L-6-P

TO HOLDING POND

IN BURIAL GROUND 5 
4. Open valves HVL-6P-1 and HVL-6P-2.

5. Start pump L-6P.

6. When the L-6 level reaches $I$ or $2 \%$, close valve HVL-6P-1, open water supply valve, and flush the line with at least 800 gallons of water.

7. When the line has been flushed, close the water supply valve, HVL-6P-2, and the seal water supply valve.

B. To pump supernatant liquid from the disposal pond to the Equalization Basin:

1. Open valve V-9.

2. Close basin inlet valve $\mathrm{V}-10$.

3. Start pump SD-P. Open the $1 / 2$ inch gate valve on the discharge of SD-P; if the pump is pumping properly, a full stream of water should discharge from the nozzle.

4. Shut down the pump when the supernatant level is one foot above the sludge. Close valve $\mathrm{V}-10$.

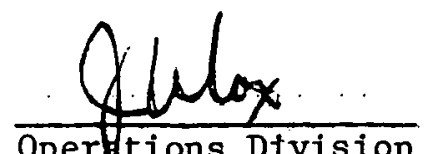

Operftions DIvision Superintendent
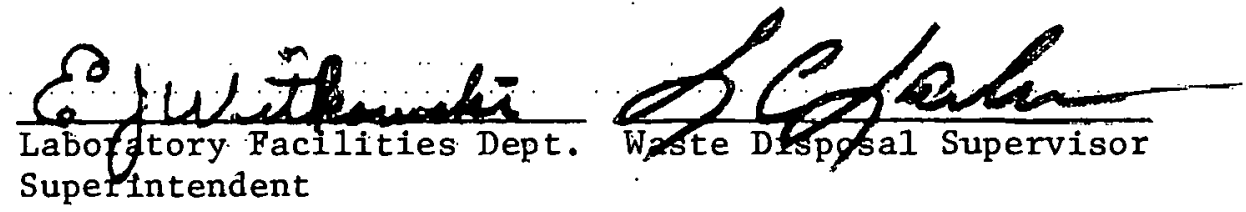


\section{DISTRIBUTION}

1-2. R. G. Affel

3. F. T. Binford

4-9. R. D. Braatz

10. R. E. Brooksbank

11. F. R. Bruce

12. C. D. Cagle

13. R. L. Clark

14-15. J. A. Cox

16. B. F. Crump

17. F. L. Culler

18. J. E. Kahn

19. L. J. King

20-23. L. C. Lasher

24. B. Lieberman

25. H. Postma

26. M. E. Ramsey

27-30. R. A. Robinson

31. R. W. Schaich

32. A. A. Walls

33. W. R. Winsbro

34. E. J. Witkowski

35-36. Central Research Library

37. Document Reference Section

38-45. Laboratory Records Department

46. Laboratory Records, ORNL R.C.

47. ORNL Patent office

48. Research and Technical Support Division, ORO

49-76. Technical Information Center 